UNIVERSIDADE DE SÃO PAULO

FACULDADE DE ECONOMIA, ADMINISTRAÇÃO E CONTABILIDADE DEPARTAMENTO DE ADMINISTRAÇÃO PROGRAMA DE PÓS-GRADUAÇÃO EM ADMINISTRAÇÃo

EFEITOS DO FRAMING DE PROMOÇÕES DE PREÇO NAS ESCOLHAS DOS CONSUMIDORES

Marina Begalli Schreiner

Orientador: Prof. Dr. Claudio Felisoni de Angelo

SÃO PAULO 
Prof. Dr. João Grandino Rodas

Reitor da Universidade de São Paulo

Prof. Dr. Reinaldo Guerreiro

Diretor da Faculdade de Economia, Administração e Contabilidade

Prof. Dr. Adalberto Américo Fischmann

Chefe do Departamento de Administração

Prof. Dr. Lindolfo Galvão de Albuquerque Coordenador do Programa de Pós-Graduação em Administração 


\title{
MARINA BEGALLI SCHREINER
}

\section{EFEITOS DO FRAMING DE PROMOÇÕES DE PREÇO NAS ESCOLHAS DOS CONSUMIDORES}

\author{
Dissertação apresentada ao Programa de \\ Pós-Graduação em Administração da \\ Faculdade de Economia, Administração e \\ Contabilidade da Universidade de São Paulo, \\ para obtenção do título de Mestre \\ em Ciências.
}

Orientador: Prof. Dr. Claudio Felisoni de Angelo

\section{Versão corrigida}

(versão original disponível na Faculdade de Economia, Administração e Contabilidade)

\section{SÃO PAULO}




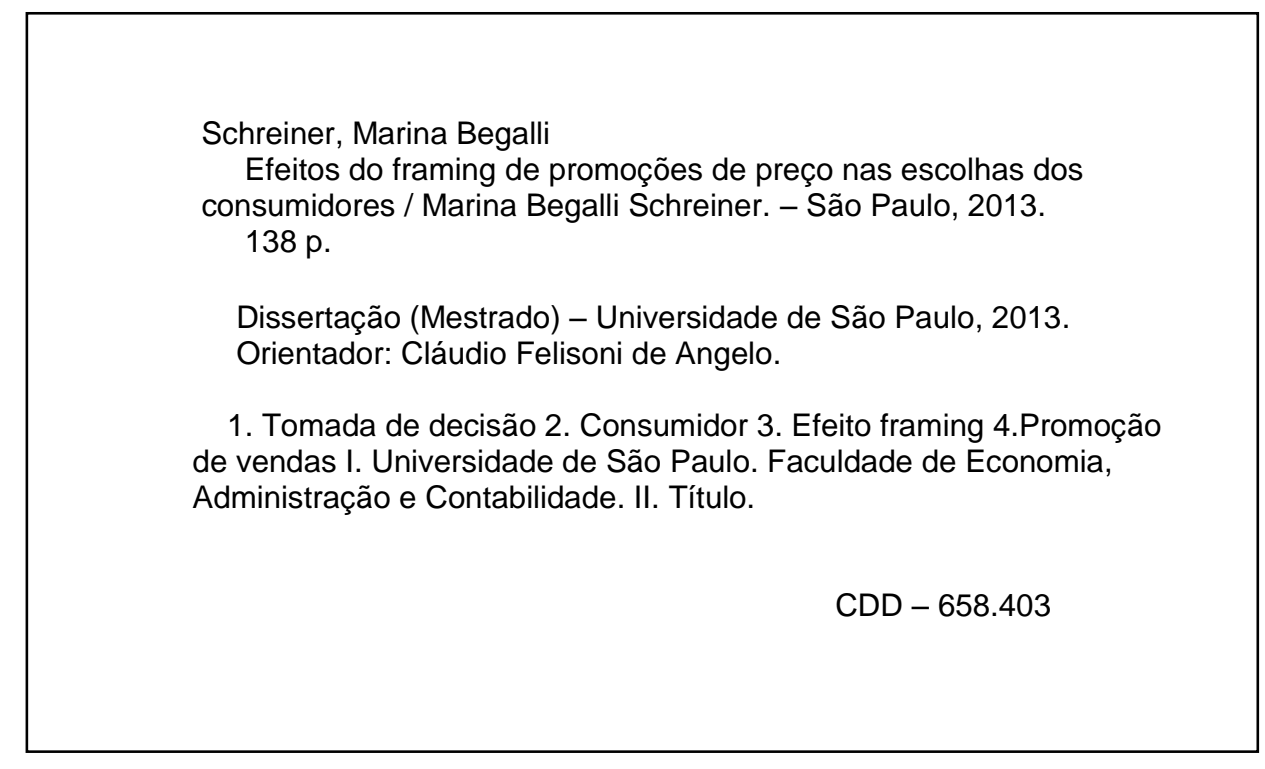


Aos meus pais e ao Fernando, por sempre estarem ao meu lado. 
Este trabalho significa a conclusão de uma importante etapa da minha vida. Muitas pessoas foram importantes e contribuíram para sua realização, a quem devo meus sinceros agradecimentos:

Ao Prof. Dr. Claudio Felisoni de Angelo, pelo conhecimento, orientação e apoio durante todo o mestrado, que foram fundamentais para a conclusão deste trabalho, além de todas as oportunidades de crescimento que me proporcionou;

Ao Prof. Dr. Nuno Fouto, pelo grande suporte dado em todas as etapas do trabalho e por ter contribuído para o desenvolvimento desta pesquisa;

Ao Prof. Dr. Marcos Luppe, pelas conversas e sugestões que foram críticas para a melhoria do trabalho;

Ao Prof. Dr. Denisard Alves, por ter me orientado na decisão de cursar o mestrado; Aos meus pais, Elizabeth e Armando; a minha irmã, Juliana e a minha tia Sílvia, por terem me apoiado sempre em tudo na minha vida;

Ao Fernando, pelos valiosos conselhos, paciência e carinho durante todo o mestrado;

À Susan Ribeiro e Ana Maria Oliveira, pelo suporte e compreensão na minha decisão de cursar o mestrado;

Aos colegas da FEA com quem compartilhei todo o processo do mestrado: Ana Carolina Shinoda, Eduardo Vilas Boas, Luciana Rizzi, Mariana Sutter, Lilian Schreiner, Leandro Pongeluppe, entre outros;

Aos amigos da FIA;

Ao PROVAR, pelo apoio na pesquisa;

E a todos que contribuíram diretamente ou indiretamente no desenvolvimento deste trabalho. 


\section{RESUMO}

O objetivo deste estudo é verificar se os consumidores são suscetíveis aos efeitos do framing de promoções de preço, ou seja, se descontos equivalentes mostrados em porcentagem ou em reais têm atratividades díspares entre os consumidores, em diferentes tipos de produto. $\mathrm{O}$ framing é um conceito discutido por Tversky e Kahneman (1979, 1981, 1986) e Kahneman (2003a) ao demonstrarem que a formulação dos problemas de decisão pode afetar nossos julgamentos cognitivos e, portanto, nossas preferências. Os objetivos específicos deste trabalho são verificar quais tipos de promoções mostram-se mais atrativos para diferentes tipos de produto (alto valor e baixo valor); se variáveis demográficas, como "renda" e "escolaridade", exercem algum efeito nas preferências pelo tipo de promoção; e, se as promoções têm impactos variados em diferentes marcas. O método utilizado consiste em pesquisa descritiva, de abordagem quantitativa, a partir de um experimento com hipóteses, aplicado em 400 consumidores da cidade de São Paulo durante janeiro e fevereiro de 2013. O questionário utilizado teve como base os trabalhos de Chen et al. (1998) e Gendall et al. (2006). Os resultados apontam que para o produto de baixo valor (biscoito recheado), a forma de promoção é indiferente para o consumidor (na forma " $10 \%$ de desconto" ou "De R $\$ 1,71$ por R\$ 1,54”); e que para o produto de alto valor (notebook), o desconto em reais parece ser mais atrativo. Estas conclusões estão de acordo com o trabalho de Gendall et al. (Ibid.). Não foram encontradas diferenças significativas nas preferências dos diversos grupos de renda, escolaridade e outras variáveis demográficas analisadas (sexo, idade, estado civil e região da cidade onde mora). 


\begin{abstract}
The objective of this study is to verify whether consumers are susceptible to price promotions framing effects - more specifically, if showing the same discount as percentage or in monetary terms for different products alters consumer preferences. Framing is a concept described by Tversky and Kahneman (1979, 1981, 1986) and Kahneman (2003a), who demonstrate that the framing of decision problems can affect our cognitive judgment and therefore our preferences. The specific objectives of this study are: to verify which type of price promotions are more attractive to high price and low price products; to access if demographic variables such as "income" and "educational level" present any effects on consumer promotion preferences; and to examine if promotions have different impacts on different brands. The method consists in a quantitative descriptive survey, applied with 400 consumers in São Paulo, Brazil, between January and February 2013. The questionnaire was based on Chen et al. (1998) and Gendall et al. (2006) work. Results show that for the low price product (stuffed cookie), the consumer is indifferent to the promotion type ("10\% off" or "From $R \$ 1,71$ to $R \$ 1,54$ "); and for the high price product (notebook), discount in monetary terms seems to be more attractive. These conclusions are in line with the findings of Gendall et al (Ibid). No significant difference in preference was found between different income groups, educational level and other demographic variables (gender, age, marital status and neighborhood).
\end{abstract}




\section{SUMÁRIO}

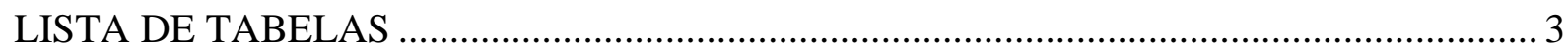

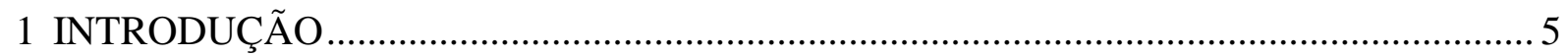

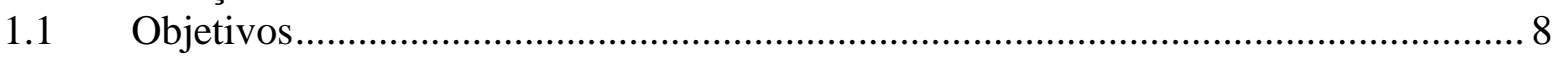

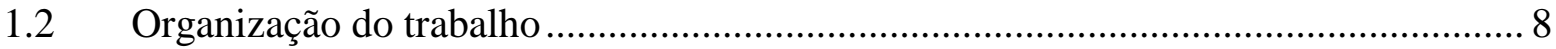

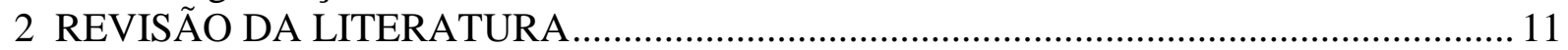

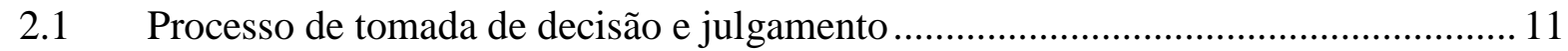

2.1.1 Conceitos normativos para tomada de decisão sob risco .................................. 13

2.1.2 Teoria da Utilidade Esperada: um modelo normativo de escolha racional........ 15

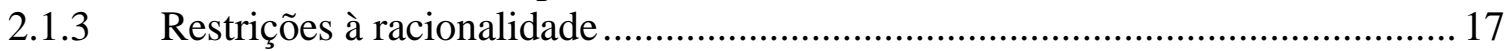

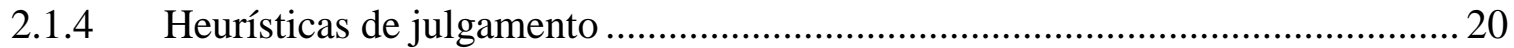

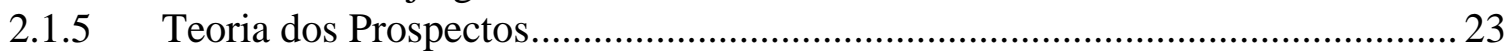

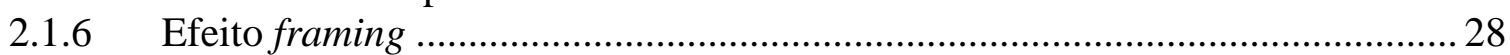

2.1.7 Contabilidade mental e Teoria da Utilidade de Transação ................................ 33

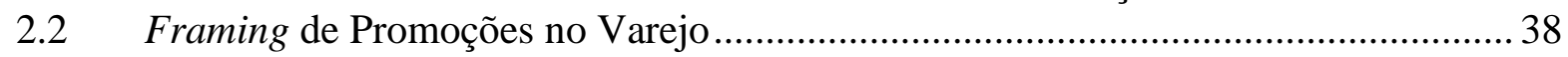

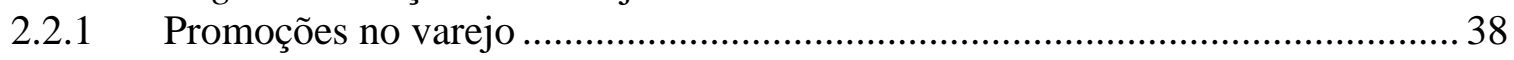

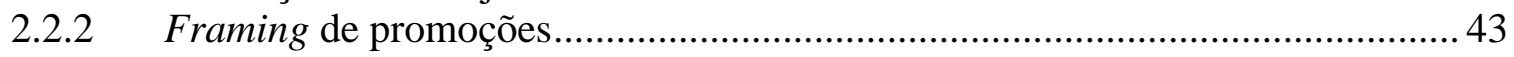

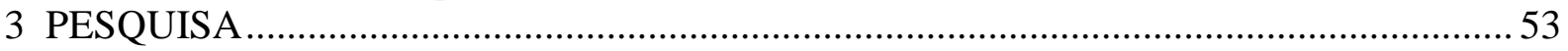

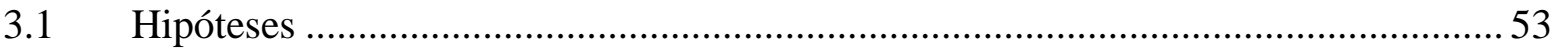

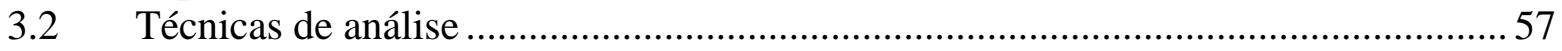

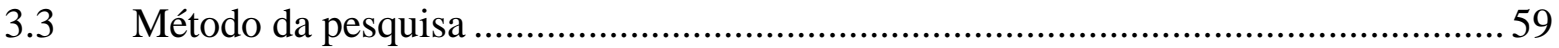

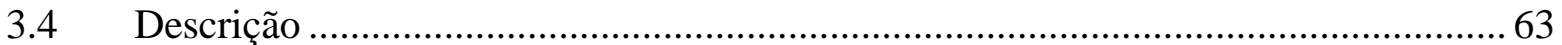

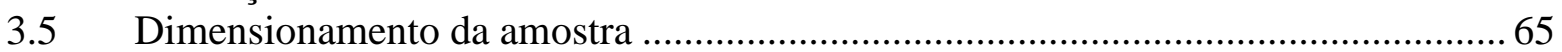

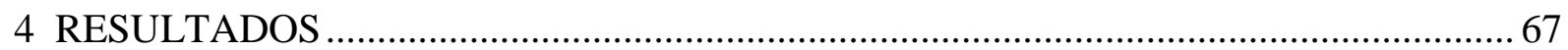

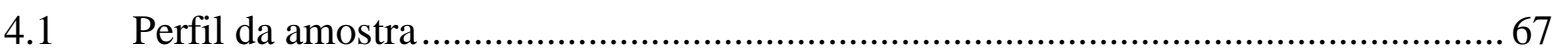

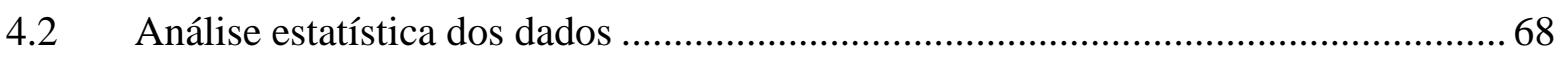

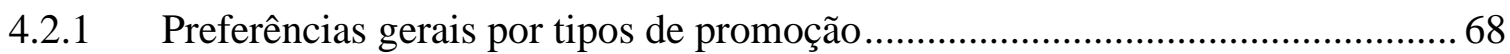

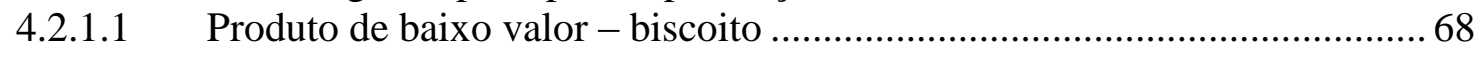

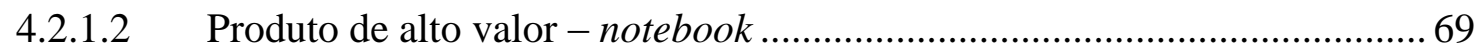

4.2.2 Impacto da promoção na preferência de marca ................................................ 70

4.2.2.1 Produto de baixo valor - biscoito ........................................................... 70

4.2.2.2 Produto de alto valor - notebook .......................................................... 72

4.2.3 Preferências de acordo com a faixa de renda .................................................. 73

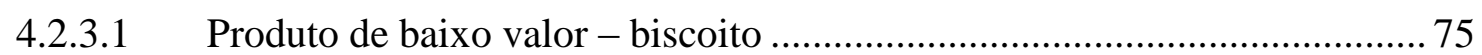

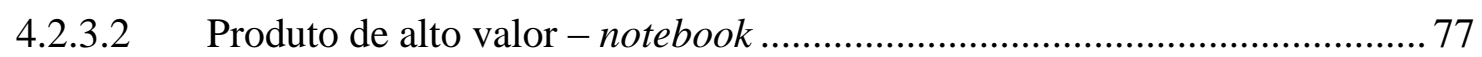

4.2.3.3 Conclusões - produto de baixo valor versus produto de alto valor ............... 82

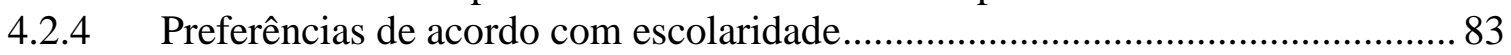

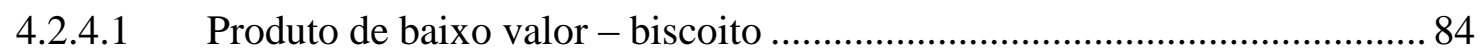

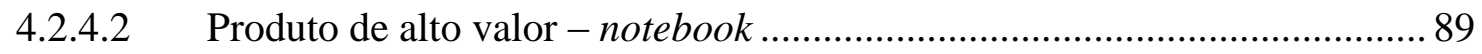

4.2.4.3 Conclusões - produtos de baixo valor $v s$. produtos de alto valor ................ 94

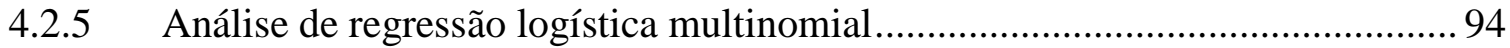

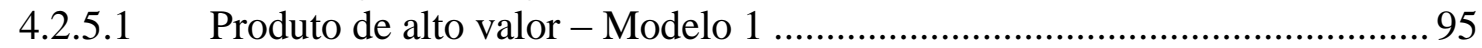

4.2.5.2 Produto de alto valor - Modelo 2 …................................................... 101

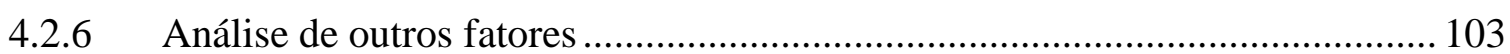

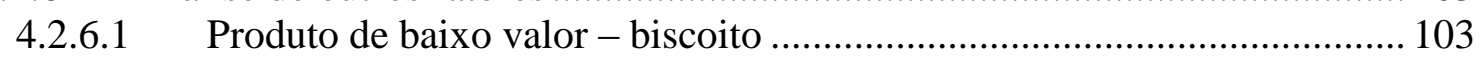

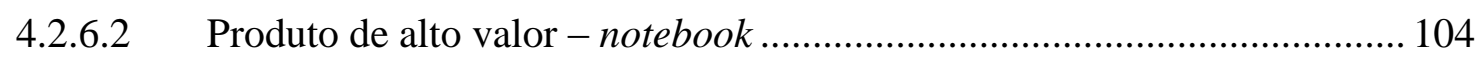

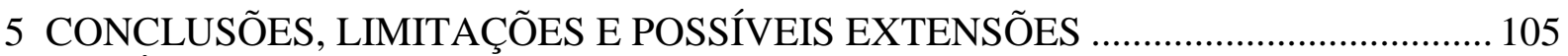

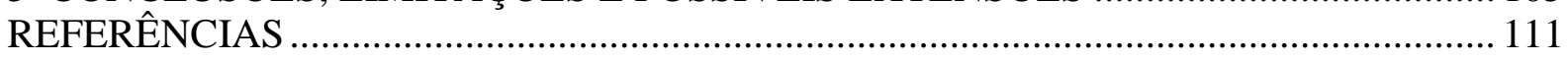


APÊNDICE 1

119

APÊNDICE 2

124 


\section{LISTA DE TABELAS}

Tabela 1 - Preferência dos consumidores por tipos de promoção .......................................... 48

Tabela 2 - Perfil socieconômico e demográfico em função do Fator Principal ........................ 66

Tabela 3 - Perfil demográfico dos consumidores entre vistados ............................................. 67

Tabela 4 - Número de escolhas e intervalo de confiança por tipo de apresentação do produto

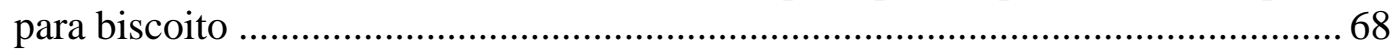

Tabela 5 - Número de escolhas por tipo de apresentação do produto para notebook ...............69

Tabela 6 - Número de respondentes por faixa de renda mensal familiar ............................... 74

Tabela 7 - Contagem do número de escolhas feitas por renda e tipo de desconto para biscoito

75

Tabela 8 - Intervalos de confiança calculados para as diferenças de proporção de escolhas pela forma de apresentação dentro da amostra para biscoito .................................76

Tabela 9 - Contagem do número de escolhas feitas por renda e tipo de desconto para

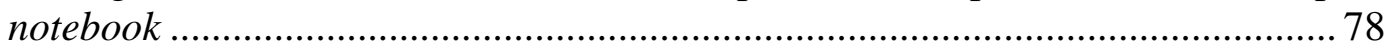

Tabela 10 - Intervalos de confiança calculados para as diferenças de proporção de escolhas pela forma de apresentação dentro da amostra para notebook .............................. 79

Tabela 11 - Teste Qui-quadrado para as variáveis "renda familiar" e "opções de escolha" e sumário da análise de correspondência ............................................................. 80

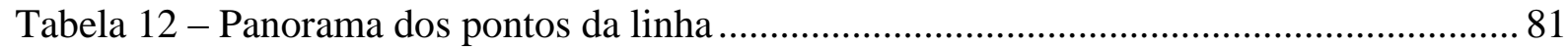

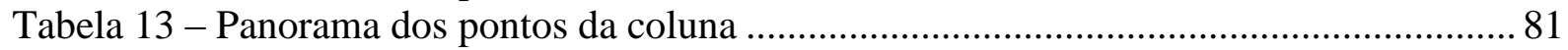

Tabela 14 - Número de respondentes por faixa de renda mensal familiar ............................. 83

Tabela 15 - Contagem do número de escolhas nível de escolaridade e tipo de desconto para

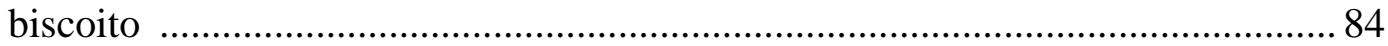

Tabela 16 - Intervalos de confiança calculados para as diferenças de proporção de escolhas pela forma de apresentação dentro da amostra para biscoito ..................................8 85

Tabela 17 - Teste Qui-quadrado para as variáveis "escolaridade" e "opções de escolha" e

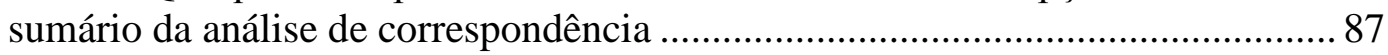

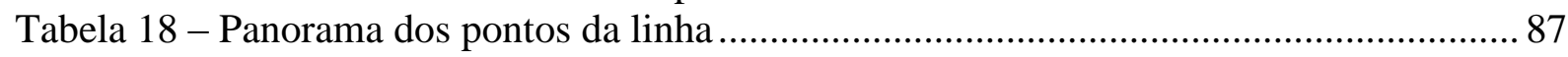

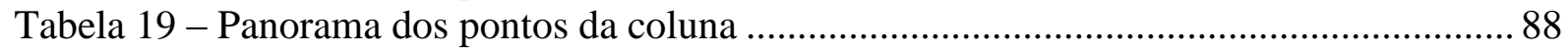

Tabela 20 - Contagem do número de escolhas nível de escolaridade e tipo de desconto para

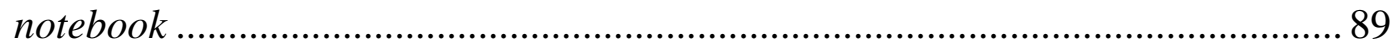

Tabela 21 - Intervalos de confiança calculados para as diferenças de proporção de escolhas pela forma de apresentação dentro da amostra para notebook ............................. 90

Tabela 22 - Teste Qui-quadrado para as variáveis "escolaridade" e "opções de escolha" e sumário da análise de correspondência ............................................................. 92

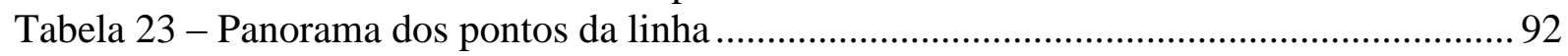

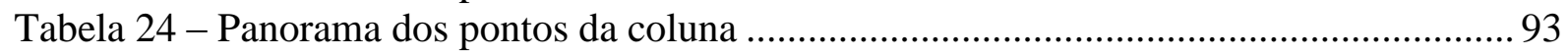

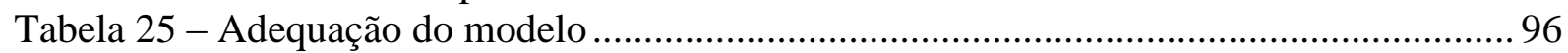

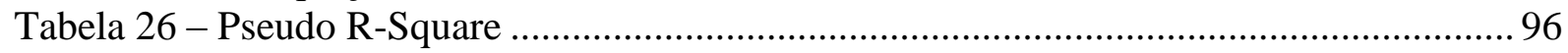

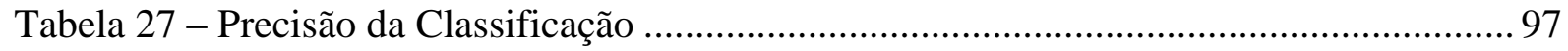

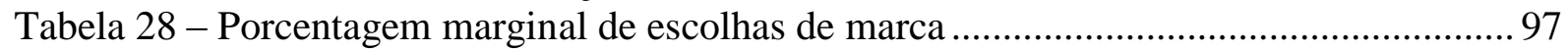

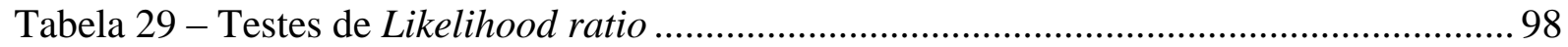

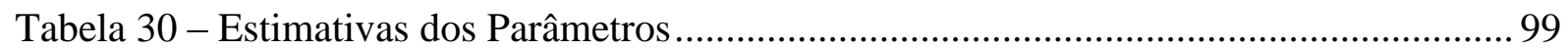

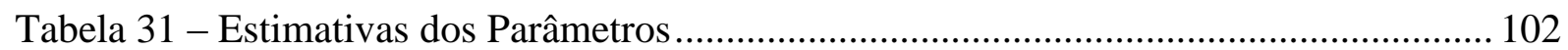

Tabela 32 - Valor-p para o teste qui-quadrado do produto de baixo valor............................ 103

Tabela 33 - Valor-p para o teste qui-quadrado do produto de alto valor.............................. 104 


\section{INTRODUÇÃO}

No varejo é possível encontrar vários tipos de promoções - "Pague dois e leve três", "De R\$ 1.399 por R\$ 999”, “10\% de desconto", dentre outros. Isso permite questionar se os consumidores percebem as distintas opções de promoção de maneira diferenciada. Se o consumidor agir de forma racional, basta que o varejista apresente a economia obtida com a promoção, poupando-o de efetuar cálculos para chegar ao preço final do produto (KRISHNA et al., 2002).

No entanto, diversos estudos apontam a existência de percepções variadas por parte do consumidor quando uma promoção é apresentada de formas diferentes, mesmo que o preço final do produto seja o mesmo. Por exemplo, há evidências que descontos mostrados em reais são mais atrativos do que os apresentados em porcentagem quando o item é de alto valor e o contrário, quando o item é de baixo valor. Um exemplo de item de alto valor seria um carro e itens de baixo valor seriam alimentos (CHEN et al., 1998, p. 353). Promoções mostradas como ganho (compre um molho de \$ 1.89 e ganhe uma sopa que custa \$ 0.49) são mais desejáveis do que aquelas apresentadas como perda reduzida (compre um molho e uma sopa por \$ 1.89 e economize \$ 0.49) (DIAMOND; SANYAL, 1990).

Se as pessoas agissem em concordância com a teoria econômica tradicional e fossem racionais, não exibiriam preferências distintas em promoções equivalentes mas mostradas de modo desigual. A teoria econômica tradicional trata as decisões dos indivíduos como se fossem totalmente racionais, ou seja, assume que o consumidor obtém informações completas sobre as alternativas, faz ponderações que o permite obter uma utilidade para cada alternativa e seleciona aquela que lhe traz maior utilidade (BETTMAN et al., 1991). Esta teoria assume uma série de axiomas que fazem parte de um comportamento racional, por exemplo, a invariância, ao afirmar que somente os resultados e suas probabilidades associadas são necessários para determinar a escolha do indivíduo, e não a maneira como são apresentadas (TVERSKY; KAHNEMAN, 1986, p. 253).

Porém, diversos estudos mostram que os indivíduos podem não ser inteiramente racionais. Em meados da década de 50, Herbert A. Simon introduz o conceito de racionalidade limitada 
e argumenta que os tomadores de decisão têm limitações em suas capacidades de processar informações. Em vez de serem totalmente racionais, esses tomadores de decisão tentam fazer o melhor que podem dadas as limitações a que estão sujeitos (BETTMAN et al., op. cit.). A racionalidade limitada é consistente com o conhecimento do comportamento real de escolha dos indivíduos e assume que o tomador de decisão deve procurar por alternativas, tem notoriamente conhecimento incompleto sobre as consequências das ações, escolhe ações que devem ser satisfatórias, e não necessariamente ótimas (SIMON, 1997).

Na década de 70, dois psicólogos - Daniel Kahneman e Amos Tversky - incorporam o conceito de racionalidade limitada em suas pesquisas. $\mathrm{O}$ trabalho deles busca obter um mapeamento da racionalidade limitada ao explorar vieses sistemáticos que separam as decisões feitas, em geral, pelos indivíduos, das escolhas que deveriam fazer como agentes racionais. Os autores desenvolvem importantes estudos no campo de tomada de decisão: heurísticas de julgamento, Teoria dos Prospectos e efeito framing (KAHNEMAN, 2003b, p. 1449).

Em 1974, alguns estudiosos publicam uma pesquisa indicando que as pessoas utilizam um número limitado de heurísticas para transformar tarefas complexas em processos mais simples de tomada de decisão. As heurísticas permitem que o tomador de decisão utilize um conjunto limitado de informações para chegar a uma decisão. De forma geral, tais heurísticas são bastante úteis, porém podem levar a erros sistemáticos e previsíveis (TVERSKY; KAHNEMAN, 1974, p. 1124).

A Teoria dos Prospectos (1979) identifica desvios no comportamento das pessoas em relação ao modelo normativo e conclui que os indivíduos tendem a fazer escolhas avessas a risco quando a situação envolve ganhos, e escolhas propensas ao risco quando a situação envolve perdas, contrapondo a premissa de que os indivíduos sempre são avessos ao risco em qualquer situação (KAHNEMAN; TVERSKY, 1979, p. 268).

Já o efeito framing demonstra que devido a falhas na percepção humana, a formulação (framing) dos problemas de decisão podem afetar os julgamentos cognitivos e, portanto, as preferências dos indivíduos. Desta forma, a invariância não pode ser totalmente atingida (KAHNEMAN; TVERSKY, 1979; TVERSKY; KAHNEMAN, 1981; 1986; KAHNEMAN, 2003a). 
Com base no trabalho de Kahneman e Tversky, Thaler (1985, p. 199) elabora o conceito de contabilidade mental que consiste na codificação mental de ganhos e perdas utilizando como alicerce a função valor da Teoria dos Prospectos. De acordo com a teoria, existem diferentes maneiras de enquadrar ganhos e perdas, o que implica comportamentos diferentes por parte do consumidor. Ao ter consciência disso, os gestores de empresas podem reduzir o desconforto causado por altos preços modificando a forma como são exibidos. Um exemplo da aplicação deste conceito vem do mercado de cartões de crédito: a indústria prefere anunciar desconto no pagamento em dinheiro, em vez de revelar que há cobrança de sobretaxa pelo uso do cartão.

Estes conceitos podem ser aplicados e testados em consumidores e embasam uma série de pesquisas no campo de promoções. O modo como um preço é apresentado ao indivíduo afeta a avaliação feita sobre a oferta do produto. Assim, muitos estudos concentram-se no framing de preços, ou seja, como a oferta é comunicada ao consumidor. Por exemplo, se o preço é dado junto a um preço de referência; se o preço de referência é plausível; se uma oferta de preço é comunicada em dólares ou em termos percentuais (KRISHNA et al., 2002, p. 101).

O framing de preços pode alterar a relação existente entre o que os consumidores percebem pagar e o que percebem ganhar em troca. Esta linha de pesquisa tem melhorado o entendimento da resposta psicológica do consumidor a preço e valor. Desta forma, a determinação do preço não deve envolver apenas a definição do nível de preço, mas também como ele deve ser mostrado para o consumidor (SMITH; NAGLE, 1995, p. 98).

Portanto, entender os efeitos da apresentação de promoções de preço é importante tanto para varejistas quanto para gestores de marca (KRISHNA et al., op. cit.). A maioria dos estudos nesta área foi feita nos Estados Unidos. No Brasil ainda há poucos trabalhos científicos abordando a questão do framing. Dentre eles, podemos citar Figueiredo (2002) que testa a influência de diversas formas de apresentação de um desconto sobre o comportamento de consumidores de diferentes níveis de escolaridade. Ele conclui que indivíduos com menor nível de escolaridade são mais suscetíveis ao efeito framing. Queiroz (2007), por sua vez, estuda a influência do efeito framing da apresentação das propostas de crédito na decisão de financiamento e conclui que os consumidores preferem efetuar o pagamento em parcelas; o que indica que a forma de apresentação de parcelas afeta a escolha do consumidor. 
Ainda assim, nenhum destes estudos aborda especificamente o efeito do framing de promoções de preço mostradas em porcentagem e reais. Neste contexto, o trabalho ora apresentado espera preencher essa lacuna e procura verificar se o consumidor é suscetível à apresentação de descontos mostrados em reais e em porcentagem, para produtos de alto e de baixo valor. Para tanto, foi realizada uma pesquisa com consumidores no município de São Paulo, visando entender como esse público responde a diferentes tipos de promoção. A seguir, serão mais bem detalhados os objetivos deste estudo.

\section{$1.1 \quad$ Objetivos}

O principal objetivo deste estudo é verificar se os consumidores do município de São Paulo são suscetíveis aos efeitos do framing de promoções de preço, ou seja, se descontos mostrados em porcentagem ou em reais provocam atratividades diferentes nesses consumidores. Se eles apresentarem um comportamento racional na escolha, deveriam preferir a promoção mostrada em reais da mesma forma que selecionariam a promoção apresentada em porcentagem, já que ambas são equivalentes em termos de valor final.

Os objetivos específicos são:

- Verificar qual tipo de promoção (mostrada em termos percentuais ou monetários) é mais atrativo para o consumidor final, para produtos de alto e de baixo valor;

- Determinar se os indivíduos pertencentes a diferentes faixas de renda têm alguma preferência por tipo de promoção;

- Determinar se os indivíduos pertencentes a diferentes faixas de escolaridade têm alguma preferência por tipo de promoção;

- Verificar se o efeito das promoções varia de acordo com a marca oferecida;

- Verificar se existem outras variáveis (região da cidade, sexo, idade, etc.) que podem influenciar na preferência por determinado tipo de promoção.

\subsection{Organização do trabalho}

Este estudo foi estruturado em cinco capítulos, sendo o primeiro composto por uma introdução ao tema, que resume os principais aspectos teóricos analisados e destaca a 
importância deste trabalho. Também é detalhado o objetivo principal do estudo, assim como os objetivos específicos.

O segundo capítulo faz uma revisão da literatura e aborda dois grandes campos de pesquisa. $\mathrm{O}$ primeiro deles é "Processo de tomada de decisão", que discorre sobre o modelo normativo de escolha racional (Teoria da Utilidade Esperada), restrições à racionalidade, heurísticas de julgamento, Teoria dos Prospectos, efeito framing e Contabilidade Mental e Teoria da Utilidade da Transação (TUT). O segundo campo trata do framing de promoções no varejo, abordando os seguintes temas: promoções no varejo e framing de promoções.

O terceiro capítulo descreve as hipóteses para este trabalho, que foram elaboradas com base em estudos que tratam do tema de framing. As hipóteses buscam averiguar quais tipos de promoção são mais atrativas para os consumidores para produtos de alto e de baixo valor, se existe diferença do impacto do desconto em marcas e categorias variadas e se a renda e a escolaridade afetam o padrão de escolhas. Este capítulo também trata do método de pesquisa adotado - pesquisa quantitativa aplicada em consumidores do município de São Paulo -, dimensionamento da amostra e as técnicas estatísticas que serão utilizadas para analisar os dados.

O quarto capítulo apresenta a análise dos dados da pesquisa e descreve os resultados por tipo de produto, por escolaridade e por renda. As análises estatísticas são apresentadas com o objetivo de investigar as hipóteses propostas do terceiro capítulo.

O quinto e último capítulo apresenta as considerações finais em relação ao trabalho realizado, limitações e possíveis extensões deste estudo. Serão sugeridos diferentes aspectos que podem ser analisados dentro do tema de framing de promoções.

O quadro 1 mostra a estrutura deste trabalho, dividido por capítulos e principais temas de cada capítulo: 
Quadro 1 - Estruturação da Dissertação

\begin{tabular}{|c|c|c|c|c|}
\hline \multirow[t]{2}{*}{$\begin{array}{l}\text { Capítulo } 1 \\
\text { Introdução } \\
\text { Objetivo gera } \\
\text { Objetivos Esp } \\
\text { Estrutura do tı }\end{array}$} & $\begin{array}{l} \\
\text { ficos } \\
\text { alho }\end{array}$ & \multicolumn{2}{|c|}{$\begin{array}{l}\text { Capítulo } 2 \\
\text { Revisão da Literatura } \\
\text { Processo de tomada de decisão } \\
\text { e julgamento } \\
\text { Framing de promoções no } \\
\text { varejo }\end{array}$} & $\begin{array}{l}\text { Capítulo } 3 \\
\text { Pesquisa } \\
\text { Hipóteses } \\
\text { Método de Pesq } \\
\text { Universo da Pes } \\
\text { Dimensionamen } \\
\text { e Coleta de dad } \\
\text { Técnicas de aná }\end{array}$ \\
\hline & \multicolumn{2}{|c|}{$\begin{array}{l}\text { Capítulo } 4 \\
\text { Resultados } \\
\text { Descrição da amostra } \\
\text { Análise estatística dos dados }\end{array}$} & \multicolumn{2}{|c|}{$\begin{array}{l}\text { Capítulo } 5 \\
\text { Conclusões e Possíveis } \\
\text { Extensões } \\
\text { Conclusões da pesquisa } \\
\text { Limitações } \\
\text { Possíveis extensões do } \\
\text { trabalho }\end{array}$} \\
\hline
\end{tabular}




\section{REVISÃO DA LITERATURA}

\subsection{Processo de tomada de decisão e julgamento}

O campo de pesquisa em julgamento e tomada de decisão aborda a forma como as pessoas combinam desejos (utilidades, valores pessoais, objetivos, etc.) e crenças (expectativas, conhecimento) para escolher um curso de ação. As decisões podem ser descritas a partir de três componentes: opções alternativas de escolha, consequências e incerteza. O resultado é o que ocorre ao final de cada decisão; as consequências são avaliações subjetivas associadas a cada resultado (como bom/ruim, ganho/perda, etc.). A incerteza, por sua vez, refere-se ao julgamento do tomador de decisão sobre a propensão de determinado evento ocorrer, ou seja, a avaliação que o indivíduo faz sobre as chances de um evento acontecer (HASTIE, 2001, p. $655)$.

Os conceitos de julgamento e de tomada de decisão são diferentes entre si. A tomada de decisão diz respeito ao processo de escolhas entre cursos de ações. Já o julgamento está relacionado com os componentes do processo de decisão que se ocupam da avaliação, estimativa e inferência dos eventos que podem ocorrer e quais as reações do tomador de decisão quanto aos possíveis resultados deste evento (HASTIE, Ibid.).

A pesquisa em julgamento e tomada de decisão compreende um campo vasto e pouco delimitado. De maneira geral, este campo tem se preocupado com escolhas feitas após algum grau de deliberação. Por exemplo, escolher um produto ou um novo emprego exigiria alguma deliberação, ao passo que escolher tirar a mão do fogo, não. A deliberação inclui dois tipos de previsão: as possíveis consequências dos cursos de ação alternativos e a provável reação do indivíduo a estas consequências (CONNOLLY; ORDÓÑEZ, 2003, p. 493).

Neste contexto, uma das principais premissas do comportamento do consumidor indica que as compras são precedidas por um processo de decisão. Praticamente todos os autores que sugeriram modelos para este processo parecem convergir para as seguintes etapas: existência de duas ou mais alternativas de ação onde o indivíduo deve tomar uma decisão; elaboração de critérios de avaliação que facilitam a previsão das consequências de cada alternativa para os objetivos do consumidor; escolha da alternativa, determinada por uma regra de decisão ou 
procedimento de avaliação; e processamento de informação proveniente de fontes externas ou recuperada da memória para aplicação da regra de decisão ou procedimento de avaliação (OLSHAVSKY; GRANBOIS, 1979, p. 93).

Nos últimos anos, elementos mais comportamentais, psicológicos e descritivos têm sido incorporados à teoria do processo de tomada de decisão. Porém, seus limites e outras preocupações teóricas ainda são relacionadas à teoria dominante de utilidade esperada, tornada popular por Von Neumann e Morgenstern em 1947 (HASTIE, op. cit.). Nesta perspectiva de tomada de decisão acredita-se que os consumidores são seres racionais. Este modelo de racionalidade perfeita assume que o consumidor obtém informações completas sobre as alternativas, faz ponderações que o permite obter uma utilidade para cada alternativa e seleciona a alternativa que lhe traz maior utilidade. Quaisquer limitações no processamento dos consumidores são ignoradas neste modelo normativo (BETTMAN et al.,op. cit.). São modelos denominados normativos porque reúnem normas e ajudam a avaliar julgamentos (BARON, 2004).

Uma implicação pouco realista do comportamento racional do agente é que ele faz suas escolhas em um ambiente que incorpora todos os detalhes relevantes da situação, assim como as expectativas sobre todas as oportunidades e riscos futuros (KAHNEMAN, 2003a, p. 706). Muitas vezes os indivíduos precisam decidir em situações de incerteza ou não possuem todas as informações necessárias para a tomada de decisão. Como já assinalado, os indivíduos possuem limitações em sua capacidade de processamento de informação, ou seja, ao fazerem uma escolha não conseguem processar todas as informações disponíveis no ambiente. Assim, levando-se em consideração as limitações a que estão sujeitos, ao invés de tomarem decisões totalmente racionais, tentam fazer o melhor que podem (SIMON, 1955, p. 99).

De acordo com Tversky e Kahneman (1986, p. 251) a teoria moderna de tomada de decisão foi concebida como modelo normativo de um tomador de decisão idealizado e não como uma descrição do comportamento real das pessoas. Desta forma, esse modelo não é suficiente para explicar todas as nuances comportamentais dos indivíduos, porém serve como referência para ilustrar os desvios à racionalidade aos quais as pessoas estão sujeitas quando tomam decisões. 
Segundo Ariely (2008), "somos muito menos racionais do que a teoria econômica clássica presume. Ademais, esses nossos comportamentos irracionais não são aleatórios nem destituídos de sentido. São sistemáticos e, já que os repetimos incessantemente, previsíveis.”

Portanto, pode-se ilustrar o comportamento irracional dos indivíduos por meio da comparação com modelos normativos, e desta forma analisar os padrões de comportamento que permeiam as escolhas do dia-a-dia. A seguir, o modelo normativo (no caso, Teoria da Utilidade Esperada) e seus axiomas serão mais bem detalhados.

\subsubsection{Conceitos normativos para tomada de decisão sob risco}

Para entender melhor os modelos normativos, serão descritos alguns conceitos básicos, como valor médio esperado (VME) e equivalente de certeza (EC). Estes conceitos são importantes para identificar o perfil de risco dos indivíduos na Teoria da Utilidade Esperada.

O valor médio esperado (VME) é a soma final da ponderação das probabilidades pelos resultados possíveis. Kreps (2004, p. 366) dá como exemplo uma loteria com quatro possíveis resultados e suas respectivas probabilidades (Ilustração 1):

\section{Probabilidade Resultado}

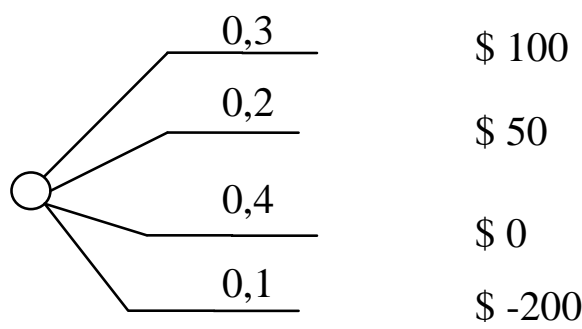

Ilustração 1 - Exemplo de loteria com respectivas probabilidades e resultados FONTE: KREPS, 2004, p. 366

Para calcular o VME, é necessário ponderar a probabilidade pelo resultado. Desta forma, o VME do respectivo jogo é igual a:

$\mathrm{VME}=0,3 * 100+0,2 * 50+0,4 * 0+0,1 *(200)=20$ 
Bazerman (1996) observa que o cálculo do valor esperado pode ser complicado se o tomador de decisão não puder especificar as probabilidades de todos os resultados possíveis. Por exemplo, para determinar um salário que se espera receber daqui a 18 meses, será necessário estimar as probabilidades de estar em diferentes cargos, e o salário esperado em cada posição. Conforme os problemas vão ficando mais complexos, a elaboração deste modelo torna-se cada vez mais difícil e propensa a vieses.

Uma forma simples de tomar decisões é escolher a alternativa de maior valor esperado. A longo prazo, estas decisões no conjunto devem ser ótimas, pois erros e acertos aleatórios irão se compensar ao longo do tempo (BAZERMAN, Ibid.).

No entanto, de acordo com Clemen (1996), basear as decisões no valor médio esperado é conveniente, porém pode levar a decisões que não parecem intuitivamente atraentes. $\mathrm{O}$ autor dá um exemplo que ilustra esta afirmação:

\section{Jogo 1}

Ganhar \$ 30 com probabilidade de 50\%

Perder \$ 1 com probabilidade de 50\%

\section{Jogo 2}

Ganhar \$ 2.000 com probabilidade de 50\%

Perder \$ 1.900 com probabilidade de 50\%

O jogo 1 tem valor esperado de \$ 14.50 enquanto no jogo 2 estima-se \$ 50. Se o indivíduo tomar uma decisão baseada no maior VME, escolherá o jogo 2. No entanto, muitas pessoas considerariam este jogo como muito arriscado, e pode-se suspeitar que a maioria preferiria optar pelo jogo 1. O método de escolher o maior VME não captura o risco da alternativa (CLEMEN, Ibid.).

Para compreender melhor o papel do risco na tomada de decisões, é necessário entender primeiro o conceito de equivalente de certeza (EC). De acordo com Kreps (op. cit.), EC é o valor que torna uma pessoa indiferente entre entrar em um jogo incerto e receber o valor certo. Bazerman (1996) ilustra este conceito com uma questão: que valor o tornaria indiferente entre optar participar de um jogo em que existem $50 \%$ de chances de ganhar $\$$ 
1.000 .000 e $50 \%$ de não ganhar nada? A maioria das pessoas escolheria um valor menor do que o VME (\$500.000), o que denota um perfil de risco mais conservador.

As pessoas têm perfis diferentes em relação a risco. Se o indivíduo tiver um equivalente de certeza menor do que o valor esperado, ele é avesso a risco; se o equivalente de certeza for igual ao valor esperado, este indivíduo é neutro a risco; e se o equivalente de certeza for maior do que o VME, esta pessoa é amante ao risco (KREPS, op. cit.).

De acordo com Bazerman (1996), quando os tomadores de decisão agem como avessos ou amantes a risco, as suas opções frequentemente excluem a maximização do valor esperado. Uma teoria que incorpora a questão do risco e substitui a maximização do VME como critério de escolha pela maximização da utilidade é a Teoria da Utilidade Esperada, que será mais bem detalhada no próximo tópico.

\subsubsection{Teoria da Utilidade Esperada: um modelo normativo de escolha racional}

A Teoria da Utilidade Esperada (TUE), cujas origens são atribuídas a Daniel Bernoulli (1954, p. 22), procura elucidar a tomada de decisão em situações de incerteza, ou seja, trata de decisões baseadas nas probabilidades de ocorrência dos resultados.

A Teoria da Utilidade Esperada dominou a análise de decisão em situações de risco. Tem sido aceita como um modelo normativo de escolha racional, e amplamente aplicado como modelo descritivo de um comportamento econômico (KAHNEMAN; TVERSKY, 1979, p. 263).

Daniel Bernoulli (op. cit.) foi o primeiro a sugerir o uso da utilidade esperada ao invés do valor esperado. A utilidade seria um grau de prazer ou benefício; o mesmo valor pode gerar utilidades diferentes para pessoas distintas. O preço é igual para todas as pessoas; a utilidade, por sua vez, depende de circunstâncias particulares. Por exemplo, uma quantia de dinheiro deve ter maior utilidade para um homem pobre do que para um rico que ganhasse o mesmo valor (BERNOULLI, Ibid.).

A utilidade esperada é a soma ponderada que se obtém ao somar valores da utilidade dos resultados multiplicados por suas respectivas probabilidades. Baron (2004) faz uma analogia com o cálculo do valor esperado de uma aposta. Se você ganhar \$ 12 quando um dado cai 
com a face 1 para cima, e \$ 0 em qualquer outra situação, a média de ganho será $\$ 2$, pois a probabilidade de sair 1 no dado é de 1/6. No entanto, de acordo com Baron (2004, p. 9), "a TUE lida com utilidade, não com dinheiro".

A Teoria da Utilidade Esperada (TUE) afirma que o tomador de decisão escolhe entre alternativas incertas levando em consideração sua utilidade esperada (MONGIN, 1997). Ao eleger a utilidade esperada como critério para tomar uma decisão, o tomador desta decisão deve escolher a opção com maior utilidade, e não necessariamente aquela com maior valor esperado (BAZERMAN, op. cit.).

Além da utilidade esperada, calculada por meio da ponderação da utilidade de cada resultado com a probabilidade de ocorrência, existem outros princípios que regem a TUE, como integração de ativos e aversão a risco. A integração de ativos estabelece que um prospecto é aceitável se a utilidade da integração do prospecto com os ativos de um indivíduo exceder a utilidade individual dos ativos. A aversão a risco determina que a curva de utilidade é côncava, ou seja, que as pessoas avessas a risco preferem uma alternativa certa (x) a quaisquer outras alternativas mais arriscadas e com valor esperado x (KAHNEMAN; TVERSKY, 1979, p. 264).

A TUE assume que todos os indivíduos racionais obedecem a alguns axiomas. Dentre estes axiomas, podemos citar (CLEMEN, op cit.):

- Transitividade: um tomador de decisão pode ordenar (isto é, estabelecer preferência ou indiferença) duas alternativas, e a ordem é transitiva. Por exemplo, se existem 3 alternativas (A,B e C), sendo que A é preferível a $\mathrm{B}$ e $\mathrm{B}$ é preferível a $\mathrm{C}$, logo A é preferível a C;

- Redução de jogos compostos: um tomador de decisão é indiferente entre um jogo composto e um jogo simples, caso o resultado esperado dê o mesmo valor;

- Continuidade: um tomador de decisão é indiferente entre uma consequência A (por exemplo, ganhar 100 em um jogo) e um evento incerto envolvendo apenas duas consequências A1 e A2, onde $A 1>A>A 2$. Ou seja, pode-se construir um jogo de referência com probabilidade $\mathrm{p}, 0<\mathrm{p}<1$, para qual $\mathrm{o}$ tomador de decisão não tem preferência entre o jogo e A.

- Substituição: se a alternativa A é preferível à alternativa B, então uma probabilidade em termos e $\mathrm{A}$ ou $\mathrm{C}$ é melhor do que uma probabilidade em termos de $\mathrm{B}$ ou $\mathrm{C}$; 
- Monotocidade: considerando dois jogos de referência com os mesmos resultados possíveis, um indivíduo opta por aquele com maior probabilidade de ganho do resultado preferido;

- Invariância: somente os payoffs e suas probabilidades associadas são necessários para determinar a escolha do indivíduo, e não a maneira como são apresentadas;

- $\quad$ Finitude: nenhuma consequência é considerada infinitamente boa ou ruim.

Apesar de a maioria das pessoas respeitar estes axiomas, na maior parte do tempo elas violam estes princípios quando fazem escolhas. Há evidências de que os indivíduos têm uma racionalidade limitada, e isso será abordado no tópico seguinte.

\subsubsection{Restrições à racionalidade}

Como já mencionado anteriormente, a linha tradicional de tomada de decisão tem como premissa a racionalidade dos indivíduos, e ignora limitações no processamento dos consumidores (BETTMAN et al., op. cit.).

Para Bazerman (1996), a racionalidade se refere ao processo de tomada de decisão que deve levar a um resultado ótimo, considerando uma avaliação criteriosa dos valores e preferências de risco dos tomadores de decisão. De acordo com TVERSKY e KAHNEMAN (1981, p. 453), a definição do que é ser racional tem sido debatida, mas há um consenso de que as escolhas racionais devem satisfazer alguns requerimentos de consistência e coerência.

A racionalidade global da teoria neoclássica assume que o tomador de decisão tem uma função utilidade consistente e abrangente, conhece todas as alternativas disponíveis para a escolha, consegue computar o valor esperado da utilidade associada a cada alternativa e escolhe a alternativa que maximiza a utilidade esperada (SIMON, 1997). Um processo de decisão racional passa por seis etapas: definição do problema, identificação dos critérios de decisão, ponderação dos pesos dos critérios, geração de alternativas, avaliação de cada alternativa e definição de uma decisão ótima. Adota-se a premissa que todas estas etapas são seguidas de forma racional. No entanto, elas servem mais como um guia para pensar em como seria tomar uma decisão ótima do que ilustrar como uma decisão realmente ocorre (BAZERMAN, 1996). 
Porém, há evidências de que os indivíduos nem sempre tomam as decisões de uma forma considerada racional. A distância entre o comportamento real das pessoas e o teórico aparece em alguns pontos que mostram a incapacidade dos agentes de seguir determinados passos (SIMON, 1947):

- A racionalidade global requer conhecimento de todas as alternativas possíveis, porém apenas algumas delas são consideradas;

- A racionalidade requer total conhecimento e antecipação de todas as consequências futuras resultantes de cada alternativa, porém este conhecimento é incompleto;

- A avaliação das consequências também tem que ser prevista, e tal previsão dependerá dentre outras coisas da imaginação, o que ocorre de maneira imperfeita.

Em meados da década de 50, Simon publicou dois artigos que se tornaram a base do desenvolvimento da Teoria da Tomada de Decisão. O artigo de 1955 examina os limites computacionais e de informação da racionalidade dos indivíduos e explora o conceito de racionalidade limitada (MARCH, 1977). Simon (1955, p. 99) argumenta que os tomadores de decisão têm limitações em suas capacidades de processar informações. Desta forma, as pessoas não podem ser totalmente racionais. Em vez disso, os tomadores de decisão tentam fazer o melhor que podem dadas as limitações a que estão sujeitos. A maior contribuição de Simon é a noção que o processamento de informação tem um papel fundamental na tomada de decisão (BETTMAN et al., op. cit.).

A racionalidade limitada, que é consistente com o conhecimento do comportamento real de escolha dos indivíduos, assume que o tomador de decisão deve procurar por alternativas, tem notoriamente conhecimento incompleto e impreciso sobre as consequências das ações, e escolhe ações que devem ser satisfatórias, ou seja, que atingem metas enquanto satisfazem as restrições (SIMON, 1997).

Em seu artigo de 1956, Simon conclui que a adaptação do comportamento dos indivíduos na aprendizagem e em situações de escolha nem sempre resulta em uma maximização dos resultados. Os indivíduos se adaptam bem para satisfazerem-se, e não necessariamente para melhorar resultados. Esta estratégia de decisão foi denominada satisficing, ou seja, os indivíduos buscam soluções boas o bastante, mas não obrigatoriamente ótimas (SIMON, 1956, p. 129). 
Os dois artigos argumentam, de maneira explicita, que as descrições do comportamento humano de decisão levando em consideração a racionalidade limitada correspondiam mais ao comportamento real do que aquelas baseadas na racionalidade clássica (MARCH, op. cit.). Segundo o princípio da racionalidade limitada, para lidar com situações em um mundo altamente complexo, o indivíduo deve construir um modelo simplificado em cada situação. $\mathrm{O}$ comportamento racional passou a ser concebido como individualizado e resultante de propriedades psicológicas, incluindo percepção, pensamento e aprendizagem. Esse novo comportamento contraria a teoria normativa ao indicar abordagens que buscam uma solução específica ideal para cada problema de decisão (LUPPE, 2006).

Na década de 70, os psicólogos Tversky e Kahneman, com base no conceito de racionalidade limitada, não se contentaram em verificar que muitas vezes tomamos decisões pautadas em estratégias menos do que ótimas. Os autores utilizaram modelos econômicos como uma referência contra as quais contrastaram seus modelos psicológicos (CAMERER; LOEWENSTEIN, 2003).

Para Tversky e Kahneman (1986, p.252),

[...] esses desvios do comportamento real em relação ao modelo normativo são muito difundidos para serem ignorados, muito sistemáticos para serem considerados como erros aleatórios, e muito fundamentais para serem acomodados ao flexibilizar o sistema normativo. ${ }^{1}$

A pesquisa deles buscou obter um mapa sobre a racionalidade limitada, ao explorar vieses sistemáticos que mostram que os indivíduos não se comportam de forma totalmente racional. Os trabalhos desses autores podem ser divididos em três principais vertentes: as heurísticas e vieses que as pessoas utilizam ao tomar decisões sob condições de incerteza; Teoria dos Prospectos, um modelo de escolha sob risco; e efeitos de framing e suas implicações para agentes racionais (KAHNEMAN, 2003b, p. 1449).

Os trabalhos de Kahneman e Tversky atraíram a atenção dos economistas para o ramo de tomada de decisão comportamental (Behavioural Decision Making). Esta vertente emergiu na década de 70 e tem como objetivo identificar um conjunto comum de habilidades cognitivas, seus benefícios e limitações, e explorar como eles ajudam a produzir o comportamento

\footnotetext{
1 "the deviations of actual behavior from the normative model are too widespread to be ignored, too systematic to be dismissed as random error, and too fundamental to be accommodated by relaxing the normative system."
} 
observado. O que distingue a tomada de decisão comportamental de outras teorias de tomada de decisão é que seu ponto de partida são as teorias de decisão racional (ANGNER; LOEWENSTEIN, 2007).

Seguindo a mesma linha de Kahneman e Tversky, o pesquisador Thaler também ajudou a acelerar o conhecimento e a aceitação da economia comportamental entre os economistas da corrente principal (ANGNER; LOEWENSTEIN, Ibid.). Thaler (1980, p. 39) afirma que "a confiança exclusiva na teoria normativa de escolha leva os economistas a cometer erros sistemáticos e previsíveis ao descrever ou prever as escolhas do consumidor." ${ }^{2} \mathrm{O}$ autor utiliza a teoria dos Prospectos de Kahneman e Tversky (1979) para mostrar uma série de problemas onde os consumidores são propensos a se desviarem das previsões do modelo normativo.

Portanto, nos próximos tópicos serão abordados alguns estudos que levam em consideração a racionalidade limitada dos indivíduos e os desvios de comportamento em relação a um modelo normativo. Os tópicos que serão apresentados são as heurísticas de julgamento; Teoria dos Prospectos (KAHNEMAN; TVERSKY, 1979); efeito framing (KAHNEMAN; TVERSKY，1979; TVERSKY; KAHNEMAN，1981; 1986; KAHNEMAN，2003a); e Contabilidade Mental e Teoria da Utilidade de Transação (THALER, 1985).

\subsubsection{Heurísticas de julgamento}

A pesquisa sobre julgamento humano mudou dramaticamente após os trabalhos de Tversky e Kahneman. Os trabalhos realizados no final dos anos 50 e início dos anos 60 consideravam que os indivíduos eram bons estatísticos intuitivos. Porém, um dos estudos iniciais desses autores sugeriu que tanto respondentes leigos quanto cientistas treinados têm intuições fortes, porém incorretas, sobre amostragem aleatória. O programa de heurísticas e vieses começou neste contexto e tem como base os vieses cognitivos e perceptuais que operam independentemente de fatores motivacionais. Ao reconhecer que as previsões intuitivas e os julgamentos de probabilidade não seguem os princípios da estatística, Tversky e Kahneman iniciaram o estudo de vieses como método para investigar as heurísticas de julgamento (SHAFIR, 2004).

2 "exclusive reliance on the normative theory leads economists to make systematic, predictable errors in describing or forecasting consumer choices." 
A distinção entre intuição e razão tem sido tema de interesse nas últimas décadas. Stanovich e West (2000, p. 659) nomearam estes processos cognitivos como Sistema 1 e Sistema 2, respectivamente. As operações do Sistema 1 são tipicamente rápidas, automáticas, sem esforço, associativas e ocasionalmente com alguma carga emocional. Muitas vezes elas são governadas pelo hábito, portanto, difícil de controlar ou modificar. As operações do Sistema 2 são mais lentas, feitas com esforço e mais propensas a serem conscientemente monitoradas ou controladas. A pesquisa de Tversky e Kahneman tem como objetivo entender os erros da intuição, ou seja, do Sistema 1 (KAHNEMAN, 2003a, p. 698).

Em 1974, os autores descrevem três heurísticas - representatividade, disponibilidade e ancoragem e ajuste - que os indivíduos costumam empregar ao estimar probabilidades e prever valores (SHAFIR, op. cit.).

A heurística da representatividade está relacionada ao grau de semelhança que um evento possui em relação a eventos já conhecidos, isto é, sua similaridade com grupos bem conhecidos (BAZERMAN, 2004). De acordo com Tversky e Kahneman (1974, p. 1124), muitas das questões probabilísticas com as quais as pessoas se preocupam são: qual é a probabilidade que o objeto A pertença à classe B? Qual é a probabilidade que o evento A se origine do processo B? Qual é a probabilidade que o processo B irá gerar o evento A? Ao responder estas perguntas, as pessoas confiam na heurística da representatividade, na qual as probabilidades são avaliadas pelo grau em que A é representativo de B, ou seja, pelo grau que A se assemelha a B.

Para ilustrar esta heurística, Tversky e Kahneman (Ibid.) citam o exemplo de uma pessoa descrita por um vizinho: "Steve é muito tímido e solitário, invariavelmente ajuda as pessoas, mas com pouco interesse nas pessoas, ou na realidade. Uma alma mansa e ordenada, ele tem necessidade de ordem e estrutura, e uma paixão por detalhes"3. Como as pessoas estimam que Steve tenha uma determinada profissão e como consideram uma profissão mais provável que a outra? Na heurística da representatividade, a probabilidade de que Steve seja um bibliotecário é estimada pelo grau em que ele é parecido com o estereótipo de um profissional dessa área.

\footnotetext{
3 "Steve is very shy and withdrawn, invariably helpful, but with little interest in people, or in the world of reality. A meek and tidy soul, he has a need for order and structure, and a passion for detail."
} 
Esta forma de julgamento de probabilidade leva a erros sérios, porque a similaridade (ou representatividade) não é influenciada por diversos fatores que deveriam afetar o julgamento de probabilidades, como tamanho da amostra, probabilidades anteriores do mesmo evento, dentre outros. No exemplo mencionado sobre a provável profissão de Steve, o fato de existirem mais agricultores do que bibliotecários na população avaliada deveria fazer parte de qualquer estimativa razoável de probabilidade de que ele seja um bibliotecário em vez de um agricultor, o que não ocorre se utilizamos a heurística da representatividade (TVERSKY; KAHNEMAN, Ibid.).

A heurística da disponibilidade está relacionada com a associação que as pessoas fazem de eventos que estão presentes na memória. Neste caso, eventos mais recorrentes são relembrados mais facilmente do que eventos menos frequentes. Por exemplo, uma pessoa pode estimar o risco de ataque cardíaco em indivíduos de meia-idade ao relembrar ocorrências entre conhecidos. De forma similar, alguém pode avaliar a probabilidade de uma empresa falir ao imaginar as dificuldades que esta encontrará (TVERSKY; KAHNEMAN, Ibid.).

Embora a heurística da disponibilidade seja um atalho útil para a estimativa de frequências ou probabilidades, seu uso inadequado pode levar a erros sistemáticos porque a disponibilidade de informações é afetada por outros fatores que não estão relacionados com a frequência do evento julgado. Estes outros fatores, tais como vividez com o que é revelado, familiaridade e facilidade com que é imaginado podem influenciar de forma inapropriada o julgamento deste evento. Um experimento ajuda a ilustrar um destes vieses. Os participantes ouviram uma lista de personalidades de ambos os sexos e tinham de responder se nela havia maior número de homens ou de mulheres. Listas diferentes foram apresentadas a grupos diferentes. Em algumas destas listas, os homens eram relativamente mais famosos do que as mulheres; em outras, ocorria o contrário. Em cada uma das listas, os participantes julgaram erroneamente que o gênero com mais pessoas famosas era o mais numeroso (TVERSKY; KAHNEMAN, Ibid.).

Segundo a heurística da ancoragem e ajuste, as pessoas fazem avaliações partindo de um valor ou uma situação inicial, chamada de âncora, ajustando-a até obter uma decisão final. O valor inicial, ou ponto de partida, pode ser sugerido pela formulação do problema ou de uma computação parcial. Em ambos os casos, os ajustes são geralmente insuficientes. Isso quer 
dizer que diferentes pontos de partida levam a estimativas distintas, que tem um viés em relação aos valores iniciais (TVERSKY; KAHNEMAN, Ibid.).

Para ilustrar a heurística da ancoragem, Tversky e Kahneman (Ibid.) mencionam um experimento no qual os participantes tinham de estimar vários números (por exemplo, a porcentagem de países africanos nas Nações Unidas). Em cada estimativa, um número entre 0 e 100 era determinado por uma "roda da fortuna" na presença dos participantes. Estes deveriam indicar se o número era maior ou menor do que o algarismo sorteado, além de estimar um valor aumentando ou diminuindo do número sorteado. Os diferentes grupos tiveram diferentes números sorteados, e isso teve efeito nas estimativas. Por exemplo, as medianas das estimativas da porcentagem de países africanos nas Nações Unidas foram 25 e 45 para os grupos que receberam os números sorteados 10 e 65 , respectivamente, como ponto de partida.

Portanto, os trabalhos de Tversky e Kahneman mostram que existem vieses cognitivos que decorrem da confiança nas heurísticas de julgamento. Vários destes erros parecem ser inerentes à forma de julgamento das pessoas, ou seja, ocorrem mesmo que a pessoa seja incentivada a dar a resposta correta.

\subsubsection{Teoria dos Prospectos}

Em 1979, Kahneman e Tversky publicaram um artigo nomeado Prospect Theory: an analysis of decision under risk, com o objetivo de questionar os princípios da Teoria da Utilidade Esperada e desenvolver uma teoria alternativa à tomada de decisão sob condições de risco. $\mathrm{O}$ trabalho descreve problemas nas escolhas dos indivíduos, que violaram os axiomas e propriedades da TUE devido a questões comportamentais e de preferências. A metodologia utilizada para verificar estes desvios foi o experimento com universitários, onde lhes foram apresentadas situações com decisões a serem adotadas.

A Teoria dos Prospectos identificou desvios no comportamento das pessoas em relação ao modelo normativo, dentre os quais podemos destacar o Efeito Certeza, Efeito Reflexão e Efeito Isolação. Além disso, trouxe uma importante contribuição para a análise de comportamento sob risco ao revelar que os indivíduos nem sempre são avessos a risco. 
O Efeito Certeza refere-se ao fato de os indivíduos tenderem a valorizar resultados considerados certos em relação aos incertos ou que envolvam probabilidades (KAHNEMAN; TVERSKY, 1979, p. 265 Ou seja, mesmo que o valor médio esperado (VME) seja maior em uma loteria, caso tenha uma segunda opção com um valor certo a ganhar, o indivíduo tende a escolher a segunda opção. Os primeiros relatos sobre o Efeito Certeza surgiram com o economista francês Maurice Allais em 1953 e foram discutidos por diversos autores sobre as perspectivas normativa e descritiva (KAHNEMAN; TVERSKY, Ibid.). O exemplo a seguir mostra o Efeito Certeza e os valores entre parênteses mostram a porcentagem de respondentes que escolheu cada opção (KAHNEMAN; TVERSKY, Ibid., p. 265-266):

\section{Problema 1}

Escolher entre:

2.500 com probabilidade $33 \%$

2.400 com probabilidade $66 \%$

0 com probabilidade $1 \%$

VME: 2.409

$(\mathbf{1 8 \%})$
B) 2.400 com certeza

VME: 2.400

(82\%)

\section{Problema 2}

2.500 com probabilidade $33 \%$

0 com probabilidade $67 \%$

VME: 825

$(83 \%)$
D) 2.400 com probabilidade $34 \%$

0 com probabilidade $66 \%$

VME: 816

$(17 \%)$

A maioria dos respondentes (82\%) preferiu a opção B no Problema 1, ainda que o valor esperado seja menor do que a opção A; e 83\% preferiram a opção C no Problema 2. Este padrão de escolha viola a Teoria da Utilidade Esperada, pois, de acordo com esta teoria, com $\mathrm{u}(0)=0$, a primeira preferência implica que:

$u(2.400)>0,33 u(2.500)+0,66 u(2.400)$ ou $0,34 u(2.400)>0,33 u(2.500)$

Por outro lado, as preferências no Problema 2 implicam o inverso. Nota-se que o Problema 2 é obtido a partir do Problema 1 ao se subtrair a chance de $66 \%$ de ganhar 2.400 em ambos os jogos. Esta mudança produz uma maior redução na atratividade quando modifica a 
característica do prospecto de um ganho certo para um provável, do que quando se sabe que tanto o jogo original como o reduzido são incertos (KAHNEMAN; TVERSKY, Ibid.).

O Efeito Reflexão implica que a aversão a risco em ganhos positivos é acompanhada por uma busca por risco em situações de perda. Por exemplo, um experimento verificou que a maioria das pessoas prefere aceitar um risco de $80 \%$ de perder 4.000 do que uma perda certa de 3.000 , ainda que o prejuízo certo tenha um valor esperado menor do que o jogo, cuja perda esperada é de 3.200. Uma implicação disso ocorre em situações de ganho, quando o efeito certeza faz com que um retorno certo seja preferível a um rendimento maior incerto, denotando aversão a risco. Já em situações de perda, o mesmo efeito leva a preferência por um prejuízo provável do que outro que seja certo, ainda que este último seja menor se comparado ao valor esperado da perda provável. Portanto, a certeza aumenta a aversão a perdas assim como aumenta a atratividade dos ganhos (KAHNEMAN; TVERSKY, Ibid.).

O Efeito Isolação refere-se ao fato de os indivíduos, com o objetivo de simplificar a escolha entre alternativas, desconsiderarem os componentes compartilhados entre as alternativas orientando-se basicamente por aqueles que as distinguem. Essa questão pode levar a preferências inconsistentes, já que um par de prospectos pode ser descomposto em componentes comuns e diferentes em mais de um jeito, e decomposições desiguais podem levar a preferências diferenciadas (KAHNEMAN; TVERSKY, Ibid.). O exemplo a seguir ilustra o Efeito Isolação, e os valores entre parênteses mostram a porcentagem de respondentes que escolheu cada opção (KAHNEMAN; TVERSKY, Ibid., p. 273):

\section{Problema 3}

Inicialmente, você recebe 1.000 independente do jogo que irá escolher. Agora é preciso escolher uma das loterias abaixo:

A) Ganhar 1.000 com $50 \%$ de probabilidade (16\%)

B) Ganhar 500 com certeza $\mathbf{( 8 4 \% )}$

\section{Problema 4}

Inicialmente, você recebe 2.000 independente do jogo que vai escolher. Agora, deve escolher uma das loterias abaixo:

C) Perder 1.000 com $50 \%$ de probabilidade (69\%)

D) Perder 500 com certeza (31\%) 
A maioria dos respondentes escolheu a alternativa B no Problema 3 e a C no Problema 4. Estas preferências estão de acordo com o Efeito Reflexão, mencionado anteriormente, que identifica aversão a risco em situações de ganho e busca por risco em casos de perda. Nota-se que os dois problemas são idênticos em termos de resultado final, pois $A=(2.000$, com probabilidade 50\%; 1.000, com 50\% de probabilidade $)=\mathrm{C}$, e $\mathrm{B}=(1.500)=\mathrm{D}$. Evidentemente, os indivíduos não integraram os bônus iniciais concedidos com os jogos. $\mathrm{O}$ bônus não entrou na comparação de jogos, pois era comum para ambas as opções em cada problema (KAHNEMAN; TVERSKY, Ibid.).

Pode-se mencionar um exemplo para ilustrar por que os padrões de resposta encontrados não estão de acordo com a TUE. Por exemplo, a utilidade de \$ 100.000 é a mesma independentemente se veio de uma riqueza anterior de $\$ 95.000$ ou de $\$ 105.000$. Logo, a escolha entre os \$ 100.000 certos ou entre um jogo de $\$ 95.000$ e $\$ 105.000$ deveria ser independente do montante (maior ou menor) que a pessoa possuir. Com a nova suposição de aversão a risco, o valor certo de \$100.000 deveria ser sempre preferido a um jogo. Porém, esta escolha ocorre geralmente quando o indivíduo possui o menor montante, e não o maior. A aparente negligência do bônus que era comum a ambas as opções nos problemas 3 e 4 implica que os fatos geradores de valor ou utilidade são as mudanças de riqueza, em vez das posições finais dos ativos. Esta conclusão é essencial para o desenvolvimento de uma nova teoria alternativa de escolha sob risco, a Teoria dos Prospectos (KAHNEMAN; TVERSKY, Ibid.).

De acordo com Bazerman (1996), a Teoria dos Prospectos sugere que ganhos e perdas são avaliados em relação a um ponto de referência neutro; resultados potenciais são expressos como ganhos ou perdas em relação a este ponto; e as escolhas que os indivíduos fazem são formadas com base na mudança resultante na posição dos ativos, como ilustrado por uma função-valor em forma de S (Ilustração 2): 


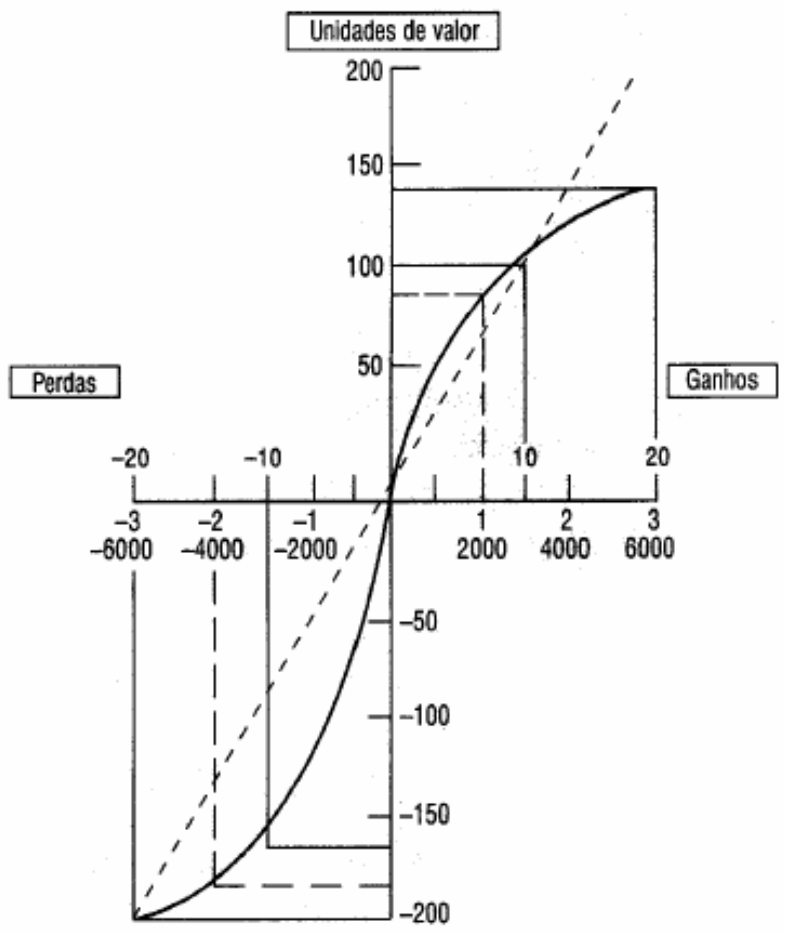

Ilustração 2 - Função Valor

FONTE: BAZERMAN, 2004

Na Ilustração 2, o eixo x representa as unidades nominais ganhas ou perdidas, e o eixo y representa as unidades de utilidade associadas aos diferentes níveis de ganhos e perdas. Por exemplo, a curva em $\mathrm{S}$ implica que a maioria das pessoas escolheria um ganho certo de $\$$ 10.000 ao invés de $50 \%$ de chances de ganhar $\$ 20.000$ já que a utilidade referente à $\$ 20.000$ não é o dobro da de \$10.000. No entanto, em situações de perda o padrão de escolhas muda: as pessoas preferem apostar em um jogo em que tem 50\% de perder $\$ 20.000$ em vez de ter uma perda certa de \$10.000, já que a utilidade negativa de apostar \$ 20.000 não é o dobro da utilidade negativa referente aos \$ 10.000 (BAZERMAN, 1996).

A Teoria dos Prospectos conclui que os indivíduos tendem a fazer escolhas avessas a risco quando a situação envolve ganhos, e escolhas propensas ao risco quando a situação envolve perdas, contrapondo a premissa da teoria da utilidade que afirma que os indivíduos sempre são avessos ao risco em qualquer situação (KAHNEMAN; TVERSKY, 1979, p. 268).

A Teoria da Utilidade Esperada não pode ser considerada a única maneira de analisar as decisões e preferências dos indivíduos como modelo normativo de tomada de decisão em situação de incerteza. Muitos economistas e psicólogos (ALLAIS, 1953; TVERSKY, 1969; SLOVIC; LICHTENSTEIN, 1983) desenvolveram modelos de escolha sob risco que 
explicam as violações encontradas no modelo da TUE. Também se sabe que a Teoria dos Prospectos por si só não responde a todos os questionamentos e se mostra com uma teoria complementar a TUE.

\subsubsection{Efeito framing}

Os autores Tversky e Kahneman $(1979,1981,1986)$ e Kahneman (2003a) demonstraram que a formulação (framing) dos problemas de decisão pode afetar os julgamentos cognitivos e, portanto, as preferências dos indivíduos.

Um dos pressupostos do modelo racional é a invariância, cuja premissa revela que as preferências não são afetadas por variações de características irrelevantes das opções ou dos resultados. Ou seja, se duas caracterizações de problemas fossem vista pelo tomador de decisão como descrições alternativas do mesmo problema, elas deveriam levar a mesma escolha (TVERSKY; KAHNEMAN, 1986, p. 253).

O princípio básico do framing consiste na aceitação passiva da formulação dada. Isto é, as pessoas, de modo natural, não processam exaustivamente todas as opções. Os mecanismos cerebrais que auxiliam a compreensão da linguagem têm uma habilidade substancial de despir os detalhes de superfície para chegar à essência do significado em um enunciado, mas esta habilidade também é limitada (KAHNEMAN, 2003a p. 703).

Como já explicado antes, existem dois sistemas cognitivos: o Sistema 1 (Automático), que é intuitivo; e o Sistema 2 (Reflexivo), que é racional. O Sistema automático é rápido e parece ser instintivo; o Sistema Reflexivo é mais intencional e consciente. O efeito framing ocorre porque as pessoas tendem a tomar decisões de forma distraída. O Sistema Reflexivo não realiza o trabalho necessário para verificar se o reenquadramento das perguntas produziria um resultado diferente (THALER; SUSTEIN; 2009).

Devido a imperfeições na percepção humana e na tomada de decisão, mudanças na perspectiva podem alterar a atratividade relativa das opções, e a invariância pode não ser totalmente atingida (TVERSKY; KAHNEMAN, 1981, p. 453; KAHNEMAN, 2003a, p. 703). Decisões intuitivas são moldadas por fatores que determinam a acessibilidade de características diferentes da situação. Características muito acessíveis - ou seja, facilmente 
lembradas - influenciam decisões, ao passo que características com baixa acessibilidade são ignoradas (KAHNEMAN, 2003a, p. 706). Um exemplo da diferença na acessibilidade de informações é dado na Ilustração 3:

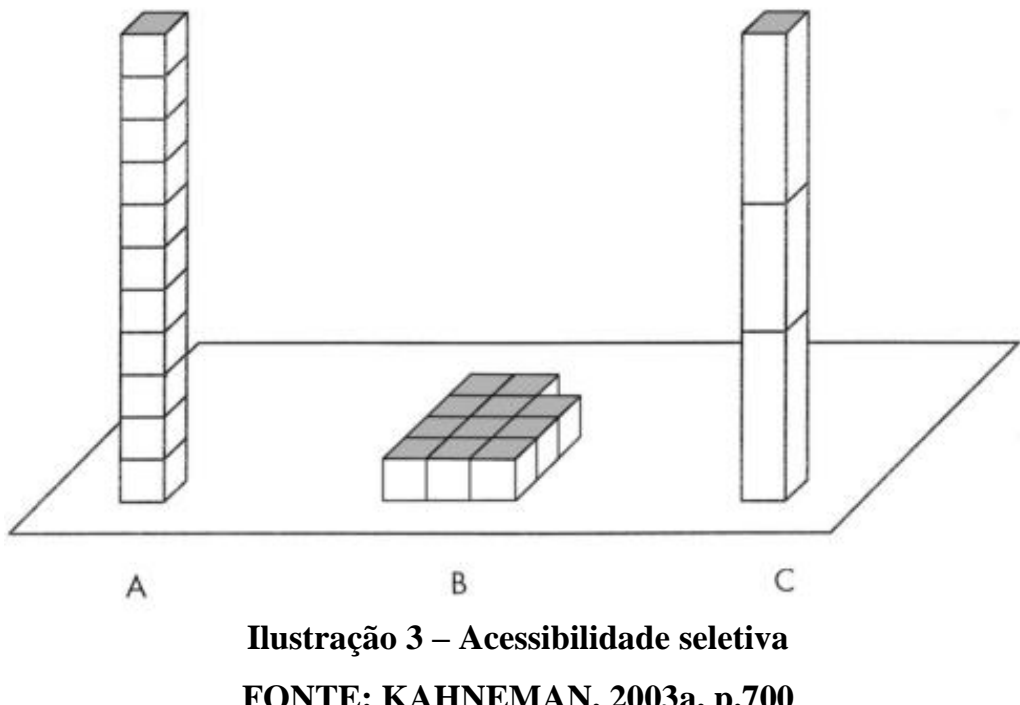

FONTE: KAHNEMAN, 2003a, p.700

Considerando a figura $\mathrm{A}$, o indivíduo tem impressões imediatas sobre a altura da torre, a área da superfície superior e talvez do volume total. Transformar estas impressões em unidades de altura ou volume requer algum esforço mental, mas as impressões em si são bastante acessíveis. Já para outros atributos não existem impressões perceptuais. Por exemplo, a área total que os blocos cobririam se a torre fosse desmontada não é perceptualmente acessível, embora possa ser estimada de outras maneiras. Por outro lado, na figura B os blocos estão no chão, e uma impressão da área é imediatamente acessível, mas da altura dos blocos empilhados não é (KAHNEMAN, Ibid.).

As diferentes representações dos resultados (no caso, do mesmo número de blocos) podem destacar algumas características e mascarar outras. Porém, não há razões para acreditar que as características mais acessíveis são também as mais relevantes para uma boa tomada de decisão (KAHNEMAN, Ibid.). Algumas das heurísticas de julgamento que as pessoas utilizam, como disponibilidade e ancoragem, podem se basear em características mais salientes e gerar julgamentos incorretos. Por exemplo, ao utilizar a heurística da disponibilidade, as pessoas baseiam-se em eventos mais recentes para estimar alguma probabilidade. Mas, nem sempre o evento mais recente pode ser o mais correto para esta 
estimativa; e ao utilizar a ancoragem para avaliar um determinado valor, os indivíduos podem escolher um ponto de partida que não tem relação com este valor e que pode gerar algum viés.

O enquadramento (frame) que um tomador de decisão adota é controlado parcialmente pela formulação do problema, e parcialmente por normas, hábitos e características pessoais. É possível formular o mesmo problema de maneiras diferentes. No entanto, devido a falhas de percepção, as pessoas podem julgar o problema de forma distinta, afetando sua escolha final.

A invariância que ocorre neste tipo de processo é violada em demonstrações sobre os efeitos de enquadramento (framing effects), como, por exemplo, o caso da doença da Ásia (TVERSKY; KAHNEMAN, 1981, p. 453), segundo descreve o problema abaixo:

\section{Problema $5(\mathrm{~N}=152)$}

Imagine que os EUA estão se preparando para o surto de uma doença Asiática exótica. Estima-se que esta doença possa mate 600 pessoas. Dois programas foram propostos para combater a doença. Assuma que as estimativas científicas das consequências dos programas são as seguintes:

- $\quad$ Se o programa A for adotado, 200 pessoas serão salvas (72\%)

- Se o programa B for adotado, há 1/3 de probabilidade que 600 pessoas sejam salvas, e 2/3 de probabilidade que nenhuma pessoa seja salva $(\mathbf{2 8 \%})$

Qual dos dois programas você escolheria?

Nesta versão do problema, a grande maioria escolheria o programa A (72\%), o que indica aversão ao risco. Ou seja, as pessoas preferem salvar com certeza 200 pessoas a correr o risco de que todas morram com probabilidade $2 / 3$.

Outro grupo de respondentes, selecionados de maneira aleatória, recebeu uma questão parecida sobre o mesmo problema, mas com descrição diferente das opções apresentadas no problema anterior:

\section{Problema $6(\mathrm{~N}=155)$}

- Se o programa A for adotado, 400 pessoas morrerão (22\%)

- Se o programa $\mathrm{B}$ for adotado, há $1 / 3$ de probabilidade que ninguém morrerá, e 2/3 de probabilidade que 600 pessoas morrerão (78\%) 
Neste caso, a grande maioria declara preferir o programa B - a opção mais arriscada. Embora não exista diferença substancial entre as versões, elas evocam associações e avaliações diferentes. As opções com maior certeza são supervalorizadas em relação aos resultados de probabilidades altas ou moderadas (KAHNEMAN; TVERSKY, 1979, p. 263). Portanto, a certeza de salvar pessoas é desproporcionalmente atrativa, e a ideia de mortes certas é aversiva.

Outro aspecto existente no conceito de framing refere-se ao framing de resultados (outcomes). Nele os resultados são percebidos como negativos ou positivos em relação a um resultado de referência considerado neutro. Logo, variações do ponto de referência podem definir se um resultado é avaliado como perda ou ganho. A função valor, desenvolvida na Teoria dos Prospectos, é geralmente côncava para ganhos e convexa para perdas. Mudanças na referência podem alterar o valor da diferença entre resultados e, portanto, reverter preferências entre as opções apresentadas. $\mathrm{O}$ caso da doença da Ásia ilustra este padrão: os problemas 5 e 6 mostram uma reversão das preferências induzida pela mudança da referência que transformou ganhos em perdas (Id., 1981, p. 453).

Como a função valor é mais inclinada para perdas do que para ganhos, a diferença entre opções parecerá maior quando esta for enquadrada como uma desvantagem para uma alternativa e como vantagem para outra. Um modelo interessante deste fenômeno foi mencionado por Thaler (1980, p. 45) ao abordar o exemplo da indústria de cartões de crédito. Em meados da década de 70, os cartões não permitiam que as lojas afiliadas cobrassem preços mais altos dos usuários de cartões de crédito. Um projeto de lei para proibir tais acordos foi apresentado ao Congresso dos Estados Unidos. Quando parecia provável que o projeto fosse aprovado, a indústria de cartões voltou sua atenção à forma de apresentação. Isto é, preferiu que quaisquer diferenças entre dinheiro e cartão de crédito fossem apresentadas como desconto no pagamento em dinheiro, em vez de uma sobretaxa do cartão. Os dois rótulos induziam a diferentes pontos de referência, o menor e o maior preço. Como as perdas parecem maiores do que os ganhos, os consumidores estão menos dispostos a aceitar uma sobretaxa no preço do que renunciar a um desconto (TVERSKY; KAHNEMAN, 1981, p. 456).

Muitos pesquisadores afirmam que o framing pode estar relacionado não somente às características contextuais, mas também a atributos pessoais (ROSZKOWSKI; 
SNELBECKER, 1990, p. 237). Um experimento de LeBoeuf e Shafir (2003, p. 77) mostrou que indivíduos que tendem a refletir mais (por serem mais racionais) mostram maior consistência em suas escolhas. Ou seja, notam a relação entre as alternativas apresentadas e tendem a escolher aquelas configuradas de maneira semelhante (perdas ou ganhos). Porém, essa necessidade por cognição não evitou que os indivíduos sofressem a influência do framing.

Outros estudos demonstraram que o conhecimento ou experiência em uma determinada área não evitam o efeito do framing. Em um experimento, os respondentes tinham de escolher entre dois tipos de terapias médias (cirurgia e radioterapia). Os problemas eram descritos em termos de taxa de sobrevivência e taxa de mortalidade. Como $90 \%$ de taxa de sobrevivência parece menos ameaçador do que $10 \%$ de mortalidade, o enquadramento do problema como taxa de sobrevivência levou a uma grande preferência pela cirurgia. Este efeito framing ocorreu tanto entre pacientes quanto entre médicos (MCNEIL et al., 1982 apud KAHNEMAN, 2003a, p.702).

Outro estudo, sobre profissionais que trabalham com planejamento financeiro, verificou que estes indivíduos são tão suscetíveis quanto os leigos em relação ao framing de estratégias de investimento (formuladas como ganhos ou perdas). Os profissionais, apesar da experiência no segmento, não estão imunes ao viés provocado pelo framing. Os anos de experiência destes profissionais também não influenciam a suscetibilidade deles ao framing. $\mathrm{O}$ artigo conclui, portanto, que o viés gerado pelo framing parece ser bastante robusto (ROSZKOWSKI; SNELBECKER, op. cit.).

Como visto, o framing pode alterar a forma como as pessoas enxergam determinado problema e também modificar preferências, independente da experiência ou conhecimento que possuem em algum campo. Este efeito tem aplicações práticas e pode ser usado no mercado consumidor, especialmente na forma como apresenta o preço ou os atributos de um produto. De acordo com Smith e Nagle (1995, p. 100), “como ganhos e perdas são avaliados de forma diferente, os gestores podem influenciar a decisão de compra ao enquadrá-la como ganho ou perda potencial". 4 Thaler (1985, p. 199) utiliza os conceitos da Teoria dos Prospectos e do

\footnotetext{
"'because gains and losses are valued differently, managers can influence purchase decisions by framing as either potential gains or losses."
} 
efeito framing para desenvolver um novo modelo de comportamento do consumidor, que será detalhado a seguir.

\subsubsection{Contabilidade mental e Teoria da Utilidade de Transação}

Ainda sob a premissa de que os indivíduos apresentam limitações cognitivas, Thaler (Ibid.) desenvolve um novo modelo de comportamento do consumidor, que utiliza conceitos da psicologia e da microeconomia. Deste modelo, extraiu-se o conceito de contabilidade mental, que é a codificação mental de ganhos e perdas tendo como base a função valor da Teoria dos Prospectos. No mesmo artigo, a avaliação das compras é modelada usando o novo conceito de utilidade de transação.

Esta nova teoria difere da normativa em três aspectos. Primeiro, a função utilidade é substituída pela função valor da Teoria dos Prospectos. Segundo, o preço é introduzido diretamente na função valor, adotando o conceito de preço de referência (parâmetro interno de comparação para os preços que os consumidores consideram razoável pagar). Como resultado, um novo conceito de utilidade de transação se desenvolve. O terceiro aspecto mostra que o princípio normativo de fungibilidade é atenuado. Este princípio estabelece que bens móveis podem ser substituídos por outros da mesma espécie, como dinheiro por exemplo. Thaler (1985, p.199) exemplifica como as pessoas podem violar este princípio:

O Sr. e Sra. L e o Sr. E Sra. H fizeram uma viagem de pesca e pescaram alguns salmões. Eles embalaram o peixe e enviaram para casa por avião, porém o peixe foi perdido pela companhia aérea. Como compensação, receberam \$ 300 da empresa aérea. Os casais pegam o dinheiro, saem para jantar e gastam $\$ 225$. Eles nunca gastaram esse tanto em um restaurante antes. ${ }^{5}$

De acordo com Thaler (Ibid.), o dinheiro não deveria ser ligado a rótulos. No entanto, os casais se comportaram como se ele tivesse, já que os \$ 300 parecem ter sido classificados como "ganhos extraordinários" e "alimentação". O jantar extravagante não teria ocorrido se cada casal tivesse recebido um aumento de \$ 150 no salário, embora o valor seja o mesmo da compensação. Portanto, na nova teoria, este princípio de fungibilidade é atenuado.

\footnotetext{
5 "Mr. and Mrs. L and Mr. and Mrs. H went on a fishing trip in the northwest and caught some salmon. They packed the fish and sent it home on an airline, but the fish were lost in transit. They received $\$ 300$ from the airline. The couples take the money, go out to dinner and spend \$225. They had never spent that much at a restaurant before."
} 
Tomando como base o efeito framing e a Teoria dos Prospectos, Thaler (Ibid.) propõe alguns princípios que maximizam o valor na tomada de decisão. Estes princípios fazem parte do que se denomina de "edição hedônica" (hedonic editing), ou seja, supõe que os indivíduos configurem situações de decisão ("apostas") de uma forma que pareçam mais prazerosas (THALER; JOHNSON, 1990, p. 647).

De acordo com a Teoria dos Prospectos, perdas e ganhos tem um efeito reduzido conforme ficam maiores em relação ao ponto de referência. Isto quer dizer que cada montante adicional de ganho ou perda tem um efeito marginal decrescente na utilidade. Como consequência, ganhar \$ 100 não é dez vezes melhor do que ganhar \$ 10, e perder \$ 100 não é dez vezes pior do que perder \$ 10 (SMITH; NAGLE, op. cit.). Esse efeito ajuda a explicar os princípios propostos por Thaler (1985):

- Separar ganhos múltiplos: é melhor mostrar os ganhos de forma separada do que agregada. Os compradores percebem maior valor em vários pequenos ganhos separados do que em um único ganho maior. Ao desvincular um ganho do outro, o indivíduo volta ao ponto de referência na função valor, fazendo com que o próximo rendimento seja percebido como se fosse iniciado do ponto zero, e não como um ganho marginal. Por exemplo, uma pessoa tende a ficar mais satisfeita ao adquirir dois bilhetes de loteria que lhe dê prêmios de $\$ 50$ e $\$ 25$, do que apenas um que lhe proporcione um total de $\$ 75$. Agrupar perdas múltiplas: as pessoas acreditam que a utilidade é menos afetada de forma negativa se perdas múltiplas forem agregadas, já que várias perdas separadas são percebidas como mais prejudiciais do que uma perda única maior. Smith e Nagle (op. cit.) citam como exemplo a compra de um rádio para o carro. É mais fácil induzir alguém a adquirir um rádio de $\$ 250$ no momento da aquisição de um carro de $\$ 20.000$ do que comprar somente este rádio algum tempo depois.

- Integrar perdas menores com ganhos maiores: pessoas que enxergam o preço de um produto como simples redução de um ganho tem insatisfação menor do que se vissem o preço como uma perda individual. Smith e Nagle (op. cit.) mencionam como exemplo o fato de as pessoas serem mais propensas a adquirir seguros que são descontados da folha de pagamento do que comprados individualmente.

- Segregar ganhos pequenos de grandes perdas: os consumidores tendem a ficar mais satisfeitos se conseguem obter um pequeno ganho separado de uma grande perda. Por exemplo, a indústria automobilística americana nos anos 80 dava um cupom para 
reembolso posterior do cliente (rebate), em vez de um desconto no preço do carro (SMITH; NAGLE, op. cit.).

Portanto, existem diferentes maneiras de enquadrar ganhos e perdas, o que implica comportamentos diferentes por parte do consumidor. Ao ter consciência disso, os gestores de empresas podem reduzir o desconforto causado por altos preços modificando a forma como são exibidos. Já foram conduzidos diversos experimentos nos quais mostrou-se o mesmo problema, mas com uma forma de apresentação diferente. Ao modificar a estruturação de ganhos e perdas, os pesquisadores também mudaram as escolhas dos indivíduos (THALER, 1985).

A hipótese de edição hedônica sugere que as pessoas aplicam estes quatro princípios sempre que possível. No entanto, esta suposição parece ser bastante radical e pode ser questionada. Primeiro, sugere que os tomadores de decisão são bastante ativos na configuração de potenciais resultados, e isso pode exigir mais esforço cognitivo do que as pessoas estão dispostas. Segundo, esta hipótese prevê que a mesma codificação será utilizada independente do formato da apresentação, e há evidências de que a forma de apresentação importa, como já detalhado anteriormente. Por fim, a edição hedônica é um processo de maximização, embora talvez não seja um processo racional (THALER; JOHNSON, 1990).

Existem alguns limites à hipótese de edição hedônica. Um deles se refere ao espaço de tempo entre dois eventos. Alguns experimentos revelam que as pessoas preferem espaçar eventos prazerosos (ganhar em um sorteio, por exemplo), fato que está de acordo com o princípio de segregar ganhos. No entanto, esses indivíduos também preferem sofrer perdas em situações diferentes - seja para perdas grandes ou pequenas, monetárias ou não monetárias, para eventos relacionados ou independentes. Isso contraria o princípio de integração de perdas (THALER; JOHNSON,Ibid.).

Outros experimentos apresentam evidências mistas sobre a hipótese de edição hedônica. Enquanto as pessoas parecem segregar ganhos de forma ativa, e cancelam perdas versus grandes ganhos, elas aparentemente não agregam perdas. Os indivíduos também não reconfiguram ativamente as situações para torná-las equivalentes, sugerindo que a forma de apresentação tem um papel importante. Com isso, uma nova regra de edição é proposta: a hipótese de edição quase-hedônica (THALER; JOHNSON,Ibid.). 
A hipótese de edição quase-hedônica segue a hipótese de edição hedônica na maior parte do tempo. No entanto, esta última assume que os indivíduos não alteram a configuração do problema ativamente; e quando as escolhas são apresentadas em uma única etapa (por exemplo, escolher entre um ganho certo de \$30 e chances $50 \%$ de ganhar \$39 ou \$21) eles não segregam ativamente o ganho certo. Os experimentos também revelam dificuldade de integrar perdas. Portanto, na hipótese quase-hedônica, quando existe uma situação de dois estágios envolvendo uma perda anterior, as pessoas não irão integrar a perda subsequente com a perda inicial (porém no caso de ganhos, as pessoas irão integrar a perda subsequente ao ganho anterior) (THALER; JOHNSON,Ibid.).

Thaler (1985) também descreve a Teoria da Utilidade da Transação (Transaction Utility Theory), que serve para analisar a estrutura das transações tendo como base o comportamento frente a perdas e ganhos descritos anteriormente na Contabilidade Mental. É proposto um processo de dois estágios: primeiro, os indivíduos avaliam as transações potenciais; depois, aprovam ou desaprovam cada transação em potencial. O primeiro estágio é um processo de julgamento; e o segundo, um processo de decisão.

O exemplo a seguir ajuda a ilustrar os principais conceitos da Teoria da Utilidade da Transação (Thaler, 1985, p. 205):

\footnotetext{
Minha irmã descobriu que, pela sublocação de \$ 235 que ela divide com outra mulher, ela paga $\$$ 185 e a mulher paga $\$ 50$ por mês. A mulher justifica seu valor pago de duas maneiras: primeiro, está fazendo um favor à minha irmã ao deixá-la morar lá, dadas as condições de moradia em Nova York; segundo, qualquer pessoa com um quarto que pode ser sublocado em Nova York irá trapaceá-la e cobrar pelo menos esse valor. Suas razões são verdadeiras, e isso as torna quatro vezes mais repugnantes. ${ }^{6}$
}

De acordo com Thaler (Ibid.), nota-se que a irmã provavelmente está recebendo um bom valor por seu dinheiro (o quarto vale os \$ 185 mensais), mas ainda está insatisfeita com a situação. Para incorporar este aspecto psicológico no modelo, são elaborados dois tipos de utilidade: de aquisição e de transação. O primeiro depende do valor do bem recebido comparado com o desembolso, e o último resulta somente do mérito percebido do negócio.

\footnotetext{
6 "My sister just found out that for a $\$ 235$ per month sub- let she shares with another woman, she pays $\$ 185$ per month. The other woman justifies her $\$ 50$ per month rent two ways: one, she is doing my sister a favor letting her live there given the housing situation in New York City, and, two, everyone with a room to sublet in NYC will cheat her at least as badly. Her reasons are undeniably true, and that makes them quadruply disgusting."
} 
Existem três conceitos de preço importantes para o modelo. O preço atual cobrado por algum bem $(z)$ é chamado de $p$. Para um determinado indivíduo, $\bar{p}$ é o valor equivalente a $z$, isto é, o montante de dinheiro que torna o indivíduo indiferente entre receber $\bar{p}$ ou $z$ como presente. Enquanto $p^{*}$ refere-se ao preço de referência por $z$ (Thaler, Ibid.). O preço de referência é um valor esperado para $z$, ou seja, é um parâmetro interno de comparação para os preços atuais dos produtos e que os consumidores acham razoável pagar.

Um dos fatores para determinar o preço de referência ( $p^{*}$ ) é o senso de 'justiça' do negócio, ou seja, se o consumidor considera a compra como justa ou não. Esse senso de justiça depende em grande parte do custo do vendedor. Foi elaborado um experimento para ilustrar este conceito. Assim sendo, apresentou-se aos participantes uma situação - ele e um amigo estão na praia e querem beber uma cerveja. $\mathrm{O}$ amigo se oferece para comprar a bebida. Depois são mostrados dois cenários para dois grupos diferentes: no primeiro cenário, o amigo vai comprar a cerveja em um resort de luxo; e no segundo cenário, em uma pequena loja de alimentos. Os participantes têm que citar um valor máximo pelo qual pagariam a cerveja. No caso do resort, o preço médio dado pelos respondentes foi de $\$ 2.65$;na loja, $\$ 1.50$. Um consumidor racional deveria estar disposto a pagar a mesma quantia pelas bebidas.

Apesar de o produto ser o mesmo e o indivíduo não ir ao local de compra, houve diferença considerável entre os preços. A explicação para estas escolhas é pautada no conceito de utilidade de transação, já que essa variante aparece nos dois casos. Enquanto pagar \$ $2.50 \mathrm{em}$ um resort é um aborrecimento esperado, desembolsar o mesmo valor em um pequeno comércio varejista seria um péssimo negócio. Portanto, os consumidores consideram mais ‘justo' pagar um preço maior em um estabelecimento mais refinado do que o mesmo valor em um local mais simples, embora o produto seja o mesmo (THALER,Ibid.).

Isto posto, podemos definir a utilidade de aquisição como o valor do seguinte resultado $(z,-p)$ $=(\bar{p},-p)$, ou seja, $\mathrm{v}(\bar{p},-p)$. A utilidade de aquisição consiste na utilidade líquida obtida de comercializar $p$ para obter $z$ (que tem o valor de $\bar{p}$ ). A medida da utilidade de transação, por sua vez, depende do preço que o indivíduo paga comparado com um preço de referência, $p^{*}$. Formalmente, é definido como v(- $p$ : $\left.-p^{*}\right)$, ou seja, o valor de pagar $p$ quando o preço esperado ou de referência é $p^{*}$. Assim, a utilidade total de efetuar uma compra é a soma da utilidade de 
aquisição e da utilidade de transação, sendo definida como $\mathrm{v}\left(z, p, p^{*}\right)=\mathrm{v}(\bar{p},-p)+\mathrm{v}\left(-p:-p^{*}\right)$ (THALER,Ibid.).

Os princípios descritos neste capítulo podem ser aplicados no mercado consumidor e, mais especificamente, nas promoções mostradas no varejo. Entre os princípios que serão usados para tratar do tema de framing de promoções temos a Teoria da Utilidade da Transação (THALER,Ibid.), que explica por que os descontos podem aumentar tanto a utilidade de aquisição ao reduzir o montante pago por um bem quanto a utilidade de transação, que é o mérito do negócio; os princípios da Contabilidade Mental, que podem alterar a forma como os consumidores percebem as promoções ao estruturá-las como ganhos ou perdas; o efeito framing, que mostra que promoções equivalentes porém mostradas de formas diferentes geram reações distintas nos consumidores, dentre outros conceitos que serão mais bem explorados no próximo capítulo.

\subsection{Framing de Promoções no Varejo}

\subsubsection{Promoções no varejo}

As promoções de vendas são um componente importante do marketing mix de uma empresa. Pode ser definido como "um evento de marketing orientado cujo objetivo é ter impacto direto no comportamento do consumidor" (BLATTBERG; NESLIN, 1990 apud NESLIN, 2002, p. 310). Essas promoções incluem descontos no preço, displays especiais, cupons, programas de recompensa, sorteios, dentre outros benefícios (NESLIN,Ibid.).

De acordo com COBRA (2005, p. 362), a promoção busca "incrementar as vendas no curto prazo, encorajando o consumidor a comprar em quantidades e a continuar a comprar". Entre os seus principais objetivos estão: estimular a demanda de curto prazo, encorajar o consumidor a comprar determinada marca, induzir à experimentação, promover orientação para o preço, obter imediata e frequente medida de resultados. Além disso, a técnica de preço promocional - redução temporária do preço de um produto - pode ser vista como uma estratégia promocional para inibir o crescimento da concorrência (COBRA,Ibid.). 
As promoções podem ser classificadas como monetárias ou não monetárias. As monetárias são aquelas que envolvem diretamente descontos em dinheiro (por exemplo, "10\% de desconto", "economize \$100”, etc.). Já as não monetárias reúnem outros tipos de benefícios, como prêmios, sorteios, brindes, produto extra. Existem também as mistas, que são uma combinação de ambos os tipos de promoção, caso, por exemplo, dos cupons de desconto com um brinde (DIAMOND; CAMPBELL, 1989; LECLERC, 1997).

Diamond e Johnson (1990) elaboraram uma classificação dos tipos de promoções reunidos em dois grandes grupos - as mostradas como ganhos ou como uma redução na perda (no caso, a perda seria o preço pago pelo produto). Uma das premissas desta classificação ocorre quando a promoção está na mesma unidade do preço, esta é mais facilmente integrada com o preço final, sendo vista como uma perda reduzida. As promoções não monetárias (brindes ou produto extra, por exemplo) são apresentadas em uma unidade diferente do preço, tornando sua integração ao preço final mais difícil. O consumidor pode não fazer esforço para integrar estas promoções incomensuráveis no preço pago, e, portanto, este tipo de promoção é considerado como um ganho separado. A lógica desta hipótese deriva do trabalho de Thaler (1985, p. 199), que aborda a Contabilidade Mental.

As promoções monetárias são as mais comuns no varejo, inclusive no mercado brasileiro onde não é tão frequente encontrar promoções de volume ou baseadas em brindes. Por ser bastante utilizado, este formato de promoção e seus efeitos têm sido amplamente estudados. Vários autores apontam que as promoções monetárias podem trazer consequências indesejáveis à marca, tais como: influência no preço de referência, redução da escolha da marca e impacto na lealdade, impacto na percepção de qualidade do produto.

A influência no preço de referência ocorre conforme os consumidores frequentam uma loja. Eles desenvolvem um preço de referência, tomado como parâmetro de comparação para os preços atuais dos produtos. Preços acima desta referência parecem ser altos; preços abaixo desta referência são percebidos como baixos. A busca por preços baixos fornece um estímulo para o varejista definir preços promocionais como forma de aumentar suas vendas no curto prazo. No entanto, estes preços promocionais diminuem a expectativa de preços do consumidor, assim como sua propensão a adquirir produtos a preços mais altos no futuro (POPESCU; WU, 2007, p. 414). 
Diamond e Campbell (op. cit.) testaram este tipo de efeito em um experimento no qual participantes foram expostos a informações de preço e promoção de uma marca fíctícia de sabão de roupa. A conclusão do estudo revela que descontos realmente reduzem o preço de referência do produto. Outro ponto observado mostra que lançar um produto novo com valor promocional mais baixo pode estabelecer um preço de referência baixo, podendo afetar o julgamento de valor de compras futuras (SMITH; NAGLE, op . cit.).

Outra consequência da utilização de promoções monetárias seria a redução da escolha da marca depois da promoção. Isso ocorreria por diversos motivos: as promoções de preço promocional podem reduzir a percepção de qualidade da marca e, portanto, reduzir a probabilidade de recompra (DODSON et al., 1978, p. 72) ou condicionar os consumidores a esperar por boas promoções (MELA et al., 1998, p. 250).

As promoções de preço podem ter um impacto na lealdade à marca. De acordo com Gedenk e Neslin (1999, p. 450), esse tipo de promoção tem um efeito positivo imediato mais forte na compra da marca do que promoções não monetárias. Porém, as promoções de preço têm um efeito negativo na futura preferência da marca em comparação a produtos sem promoção. Promoções não monetárias tiveram efeito nulo ou positivo nesta preferência de marca. De acordo com Delvecchio et al. (2006, p. 203), em média as promoções não afetam as preferências de marca pós-promoção. No entanto, promoções agressivas (maiores que $20 \%$ do valor do produto) podem gerar um efeito negativo na preferência de marca. Assim, os gestores devem equilibrar um aumento imediato nas vendas causado por promoções com o risco de afetar a marca no longo prazo.

O uso de promoções também pode gerar inferências negativas sobre a qualidade do produto. Segundo Darke e Chung (2005, p. 35), os consumidores fazem inferências negativas sobre a qualidade dos produtos quando estes são oferecidos com desconto, principalmente se houver dúvida quanto à qualidade (por exemplo, se for de uma marca desconhecida). Quando havia garantia de qualidade, os descontos tiveram um efeito positivo sobre a percepção do consumidor de ter feito um bom negócio. Já quando o produto era oferecido juntamente com um brinde gratuito, a percepção de qualidade se manteve em relação a um produto sem oferta, e, neste caso, a sensação do consumidor de ter feito um bom negócio aumentou. 
Como resultado destes estudos, muitos especialistas da indústria estão recomendando o uso de promoções mais efetivas e eficientes que utilizam menos a redução de preço (PROMOTION MARKETING ASSOCIATION OF AMERICA INC.1994 apud CHANDON et al., 2000, p. 65). Outros autores, como Lal e Rao (1997, p. 60), sugerem eliminar a maior parte das promoções e adotar a política de preço baixo todo dia.

No entanto, como o uso de cupons e redução temporária de preço são as formas mais comuns de promoção de vendas, a maioria das pesquisas da área assume que a economia de dinheiro é o único benefício para o consumidor. Como consequência desta premissa, muitos estudos examinaram os inconvenientes de utilizar promoções, mas poucos investigaram os benefícios para o consumidor (CHANDON et al.,op. cit.).

Há autores que demonstram que descontos podem gerar impacto positivo na percepção do consumidor em termos do valor associado à oferta, e não apenas em relação à economia financeira gerada pelo desconto. Há evidências de que o desconto aumenta a satisfação de compra devido às recompensas não financeiras que estão associadas ao senso de justiça do negócio efetuado (DARKE; DAHL, 2003, p. 328); e que adicionar um preço de referência a uma oferta de produto aumenta a estimativa do preço normal desse produto e o valor percebido da oferta (URBANY et al., 1988, p. 95).

Como já descrito, a Teoria da Utilidade da Transação (THALER, 1985) sugere que dois tipos de valor são encontrados em situações de compra. Os descontos não somente oferecem utilidade de aquisição ao reduzir o montante pago para receber os mesmos benefícios do produto, mas também fornecem utilidade de transação, que é o mérito percebido no negócio realizado e vai além dos resultados econômicos. O cálculo mental para avaliar a utilidade de transação envolve a comparação do preço corrente do produto $(p)$ com o preço de referência $\left(p^{*}\right)$, onde a utilidade de transação aumenta se o preço ofertado for igual ou menor que o preço de referência. $\mathrm{O}$ desconto aumenta a utilidade de transação ao ampliar a expectativa de preço do consumidor - por exemplo, os consumidores podem utilizar o preço inicial sugerido em um desconto para determinar $p^{*}$ (DARKE; CHUNG, op. cit.).

O desconto, ao aumentar a diferença entre o preço inicial e final, gera aumento na percepção de justiça e no valor do negócio na mente do consumidor. De forma geral, há evidências de que os consumidores veem o preço como mais satisfatório quando este é mostrado como 
desconto (por exemplo, “De \$49,90 por \$39,90” em vez de apenas “\$ 39,90”). Provavelmente, há um aumento da utilidade de transação associado à percepção que o preço com desconto é justo (DARKE; DAHL,op. cit.). De acordo com Darke e Chung (op. cit.), manipular um desconto desta maneira afeta a utilidade de transação associada ao negócio, enquanto a utilidade de aquisição é constante (o preço pago em ambas as ocasiões é o mesmo). Smith e Nagle (op. cit.) ainda afirmam que, mesmo que o preço de referência anunciado seja exagerado, há evidências de que oferecer um produto com um preço de referência aumenta a percepção de valor e economia. Embora os compradores possam questionar a credibilidade deste preço sugerido, suas percepções e comportamentos são influenciados positivamente.

Os benefícios das promoções monetárias podem ser analisados sob outra óptica além da Teoria da Utilidade da Transação. Chandon et al. (op. cit.) acreditam que as promoções de vendas proveem uma série de benefícios hedônicos (experienciais e afetivos) e utilitários (instrumentais e funcionais) além da economia de dinheiro. Portanto, a política de preço baixo todo dia pode não substituir totalmente as promoções de venda sem o risco de excluir os consumidores que valorizam os benefícios não monetários das promoções. $\mathrm{O}$ estudo chegou às seguintes conclusões:

- As promoções de venda fornecem uma série de benefícios para o consumidor além da economia financeira. Os benefícios hedônicos incluem a reafirmação de seus valores pessoais (value expression), entretenimento e busca por variedade (exploration). Os benefícios utilitários incluem economia de dinheiro, possibilidade de comprar um produto com qualidade maior e conveniência (redução dos custos de procura e decisão);

- Promoções não monetárias fornecem mais benefícios hedônicos e menos benefícios utilitários do que promoções monetárias;

- $\quad$ Para marcas com alto valor (high equity brand), promoções de vendas são mais efetivas quando fornecem benefícios congruentes com o produto em questão. Isto é, promoções monetárias são mais efetivas para produtos utilitários do que para produtos hedônicos. Já as promoções não monetárias são relativamente mais efetivas para produtos hedônicos do que para produtos utilitários.

Portanto, os gestores de marketing podem aumentar a efetividade da promoção ao combinar o tipo de promoção com o tipo de produto. As monetárias podem ser mais efetivas para aumentar a experimentação, enquanto as não monetárias podem ser mais efetivas para reter o 
consumidor; uma decisão hedônica, já que compradores frequentes muitas vezes esperam um reconhecimento simbólico do seu 'bom' comportamento (CHANDON et al.,Ibid.).

\subsubsection{Framing de promoções}

Os trabalhos de Tversky e Kahneman $(1979,1981,1986)$ e Kahneman (2003a) demonstraram que a formulação (framing) dos problemas de decisão podem afetar os julgamentos cognitivos e, portanto, as preferências. Isso ocorre também no mercado consumidor, seja na forma de apresentação de preços ou promoções, ou então por meio da apresentação de características do produto.

Nas últimas décadas, muitas pesquisas procuraram entender a questão do framing, um fator de mudança na relação entre o que os consumidores percebem como preço pago com o que recebem em troca. Estas pesquisas aprimoraram o entendimento da resposta psicológica do consumidor ao preço e ao valor. Assim, o gerenciamento de preços não deve levar em conta somente o nível de preço, mas também como preço e benefícios são exibidos ao consumidor (SMITH; NAGLE, op. cit.).

Thaler (1985) e Monroe e Chapman (1987, p. 193) foram alguns dos primeiros pesquisadores a sugerirem que a percepção do comprador sobre a promoção (na forma de anúncios, cupons, rebates e descontos) afeta a avaliação que fazem do produto e a propensão deles para comprar. Levin e Gaeth (1988, p. 374) descobriram que as pessoas avaliam mais positivamente uma carne com a etiqueta " $75 \%$ magro" do que " $25 \%$ de gordura". Isso revela que a forma de apresentar uma promoção pode alterar a percepção do consumidor.

As pesquisas mencionadas fazem parte de uma ampla corrente de trabalhos denominada como "semântica da transação" (deal semantic) ou "enquadramento da transação" (deal framing). Estes estudos abordam os mecanismos pelos quais os consumidores processam e internalizam o estímulo de preço em situações de compra, examinando questões como preço de referência, deal framing, precisão na recuperação de preços na memória, codificação e armazenamento (SINHA; SMITH, 2000; GENDALL et al., 2006). Uma generalização essencial para esta literatura é que os consumidores frequentemente exibem um comportamento não racional contraditório às suposições da economia neoclássica - e são altamente sensíveis a dicas 
contextuais oferecidas nas ofertas de preço. Ou seja, a forma como as ofertas de preço são mostradas afeta a resposta dos consumidores (SINHA; SMITH,op. cit.).

Uma promoção, monetária ou não monetária, pode ser apresentada de diversas maneiras. Uma promoção não monetária de volume pode ser comunicada "compre dois e leve um de graça", "três pelo preço de dois", "leve $500 \mathrm{ml}$ e pague $400 \mathrm{ml}$ ", dentre outras formas. Existem também formas híbridas de promoção, que mesclam tanto elementos monetários quanto não monetários, como, por exemplo, "compre dois e ganhe 50\% de desconto" (SINHA; SMITH, 2000; GENDALL et al., 2006).

Para comunicar uma promoção monetária, um varejista pode elaborar uma promoção como redução de preço em moeda ou porcentagem, ou usando uma combinação de ambos. Comunicar uma promoção monetária de maneiras diferentes pode ser similar ao framing das decisões de compra (MONROE, 1990 apud CHEN et al., 1998, p. 354).

Os descontos podem ser mostrados de forma absoluta ou relativa, criando um efeito de enquadramento específico no preço. A maneira como os consumidores processam informações de preço, em termos absolutos ou relativos, afeta as percepções de um desconto de preço (GREWAL e MARMORSTEIN, 1994 apud CHEN et al., 1998, p. 355). Por exemplo, os consumidores perceberão uma redução de \$20 tanto em uma jaqueta de \$100 quanto em uma televisão de $\$ 400$ similarmente se eles processarem a redução de preço de uma forma absoluta - isto é, uma economia de \$20. Por outro lado, se os consumidores processarem o desconto de forma relativa, a economia da jaqueta $(20 \%)$ será percebida como mais favorável do que da televisão (5\%) (CHEN et al.,Ibid.).

De acordo com a "heurística psicofísica de preço" proposta por Grewal e Marmorstein em 1994, a utilidade gerada pelos consumidores ao economizar uma quantia fixa de dinheiro é inversamente relacionada ao preço do produto. Esta heurística implica dizer que uma economia de $\$ 20$ na jaqueta de $\$ 100$ (equivalente a $20 \%$ do preço) irá levar a um prazer psicológico maior do que uma economia de \$20 em uma televisão de \$ 400 (equivalente a $5 \%$ do preço) (CHEN et al.,Ibid.).

Os pesquisadores Tversky e Kahneman (1981) contrastam estes dois cenários com os questionamentos apresentados a seguir: 
- Imagine que você irá comprar uma jaqueta por \$125. O vendedor informa que o produto que você deseja está em promoção por \$ 120 em outra filial da loja a 20 minutos de carro. Você iria até a outra loja para comprar a jaqueta?

- Imagine que você vá comprar uma calculadora por \$15. O vendedor informa que o produto está em promoção por \$ 10 em outra filial da loja a 20 minutos de carro. Você iria até a outra loja para comprar a calculadora?

Este experimento mostrou que $68 \%$ dos respondentes $(\mathrm{N}=88)$ estavam dispostos a se dirigir a outra filial para economizar \$ 5 em uma calculadora de $\$ 15$, mas apenas $28 \%$ deles fariam a mesma viagem motivados pela economia de \$5 em uma jaqueta. Estes resultados são consistentes com a proposição que os consumidores tendem a avaliar as reduções de preço relativamente do que em termos absolutos (GREWAL e MARMORSTEIN, 1994 apud CHEN et al., 1998, p. 355).

A tendência de os consumidores olharem a diferença de preço em termos relativos é conhecida como a Lei Weber-Fechner. Trata-se de uma lei que sugere que os compradores percebem os preços em termos proporcionais, e não de forma absoluta. No cenário da jaqueta, o comprador economizará somente $4 \%$ do valor, enquanto no caso da calculadora a economia fica em 33\%, embora o valor absoluto seja o mesmo (\$5). Uma implicação importante da Lei Weber-Fechner é que existe um limiar acima e abaixo do preço de um produto nos quais as mudanças de preço são ignoradas ou notadas. Uma série de pequenos aumentos abaixo do limiar mais alto obtém mais sucesso do que um grande aumento. Contrariamente, os compradores respondem mais a um grande corte de preço abaixo do limite inferior do que uma série de descontos menores sucessivos (SMITH; NAGLE,op. cit.).

Portanto, em uma promoção monetária, o varejista pode mostrar a redução de preço tanto em termos relativos quanto absolutos. A percentagem aplicada ao preço é um indicador relativo da profundidade da redução, variando de $0 \%$ a 100\%. A existência destes dois extremos permite que os consumidores comparem a atratividades das reduções de preço entre produtos. Quanto maior a porcentagem, mais atrativa será a promoção de preço. Desta forma, os consumidores podem utilizar a percentagem para comparar a atratividade relativa de promoções de preço de produtos vendidos a preços diferentes. Porém, uma promoção de x\% de desconto não fornece informação sobre quanto dinheiro realmente o consumidor vai economizar, a não ser que o preço esteja listado (CHEN et al.,op. cit.). 
Por outro lado, a quantia de dinheiro advinda de uma redução de preço é na realidade a economia que os consumidores farão naquela promoção. Quanto maior a quantia de dinheiro da redução de preço, mais atrativa se mostra a promoção. No entanto, a atratividade relativa de uma promoção de preço depende não somente do valor absoluto de economia, mas também do nível de preço do produto em promoção. Dado que a economia de uma promoção de preço é constante, quanto maior o nível de preço do produto em promoção, mais os consumidores terão de se sacrificar para aproveitar a economia e, portanto, menos atrativa é a promoção (CHEN et al.,Ibid.).

Dependendo do nível de preço do produto em promoção, os varejistas podem escolher entre dinheiro ou porcentagem. Por exemplo, um desconto de \$1.000 em um carro de $\$ 20.000$ parece significativo em termos de economia em dinheiro, mas os equivalentes $5 \%$ de desconto parecem pouco atrativos. Em contrapartida, um desconto de $50 \%$ parece ser mais significativo em uma lata de refrigerante de $\$ 0.50$ do que seu equivalente $\$ 0.25$ de economia. Desta forma, os varejistas podem acreditar que é mais efetivo apresentar uma redução de preço em reais para produtos de mais alto valor, mas em porcentagem para produtos de baixo valor (HEATH et al., 1995 apud CHEN et al., 1998, p. 356).

Estudo realizado por Chen et al. (op. cit.) comprova a hipótese que para produtos de mais alto valor, os consumidores perceberam uma redução de preço apresentada em dólares como mais significativa do que a mesma redução de preço em porcentagem. Para produtos de menor valor, os indivíduos perceberam uma redução de preço mostrada em porcentagem como mais significativa.

Os autores realizaram um experimento no qual os participantes avaliavam a percepção de redução de preço nas seguintes condições: produto de alto valor (computador) ou baixo valor (disquete); promoção apresentada em porcentagem ou dólares (equivalente a $10 \%$ de desconto); promoção apresentada em cupons ou desconto. No caso do computador, os participantes perceberam uma redução de preço apresentada em dólares de forma mais significativa ( $X=5,97$, escala crescente de 1 a 7 em importância percebida da economia) do que a mesma redução de preço apresentada em porcentagem $(X=5,45)$. Por outro lado, a redução dos preços no disquete mostrada em porcentagem foi considerada mais significativa $(X=5,47)$ do que em dólares $(X=4,97)$. Estes resultados dão suporte à hipótese. 
Gendall et al. (op. cit.), baseados no estudo de Chen et al. (op. cit.), procuram testar a hipótese que uma redução de preço apresentada em dólares é mais efetiva para itens de alto valor, ao passo que a redução mostrada em porcentagem é mais significativa para bens de baixo valor. Batatas chips e refrigerante cola foram escolhidos como itens de baixo valor, com desconto de $10 \%$, e computadores e rádios exemplificaram itens de alto valor, com desconto de $15 \%$. Diferentemente do estudo de Chen et al. (op. cit.), o grupo de participantes selecionado foi composto por compradores, em um shopping center; e não estudantes. Os autores concluíram que para dois itens de baixo valor (refrigerante e batata chips), o framing do desconto tem pouco ou nenhum efeito. Nos itens de alto valor (rádio e computador) mostrar o preço com desconto em dólares foi significativamente mais efetivo do que mostrar o desconto em porcentagem.

Enquanto Chen et al. (op. cit.) e Gendall et al. (op. cit.) trabalham com níveis parecidos de desconto (10\% e 15\%), Hardesty e Bearden (2003, p. 19) variam os níveis de desconto em moderado $(28,6 \%)$ e alto (50\%). Para níveis moderados, os consumidores valorizam de forma parecida as promoções apresentadas em dólares e em porcentagem. Para descontos altos, eles valorizam mais as promoções mostradas em porcentagem do que aquelas anunciadas em dólares. O estudo avaliou apenas produtos de baixo valor, como pasta de dentes e sabão de roupas. Uma possível explicação para isso é que para altos níveis de promoção, os consumidores não estariam tão dispostos a processar informação, mas sim propensos a realizar um processamento mínimo usando heurísticas simples de decisão. Neste caso, a heurística seria a forma de confirmar que uma alta porcentagem de desconto indicaria um bom negócio.

Há, portanto, evidências de que quando o produto é de alto valor, o consumidor valoriza mais o desconto apresentado em dinheiro; e que quando o produto é de baixo valor, o consumidor valoriza mais o desconto em porcentagem; isso se aplica aos casos em que o desconto é considerado baixo.

Diversos autores também trabalham com comparações entre promoções monetárias e não monetárias. Diamond e Sanyal (op. cit.) conduzem um estudo comparando promoções formuladas como ganho e perda. A conclusão revela que as promoções mostradas como ganho (compre um molho de \$ 1.89 e ganhe uma sopa que custa \$ 0.49) são mais desejáveis do que aquelas que oferecem perda reduzida (compre um molho e uma sopa por $\$ 1.89$ e 
economize \$ 0.49). A comparação foi feita com uma oferta monetária (economize $\$ 0.25$ ao comprar este molho de \$1.89). No caso da promoção mostrada como ganho, $55 \%$ dos consumidores preferiram a promoção que dava a sopa de brinde e $45 \%$ o desconto de $\$ 0.25$; já na outra situação, apenas $27 \%$ dos consumidores preferiram a promoção mostrada como perda reduzida, e $73 \%$ preferiram o desconto de $\$ 0.25$. É interessante notar que a atratividade do desconto é determinada por outros fatores além da maneira como é formulado. A oferta de comparação (desconto de $\$ 0.25$ ) foi bastante escolhida pelos consumidores, embora seja mostrada como perda reduzida e resulte em uma economia muito menor do que as ofertas testadas $(\$ 0,25$ vs. $\$ 0,49)$.

Sinha e Smith (op. cit.) testam três diferentes formas de promoção: de preço ("50\% de desconto"); extra ("compre um e ganhe outro"); mista ("compre dois, ganhe 50\% de desconto"). Embora todas elas tenham o mesmo custo unitário de produto, as duas últimas são iguais matematicamente tanto no custo total quanto no custo unitário. Os resultados do estudo sugerem que os consumidores atribuem maior valor de transação para a promoção de preço ("50\% de desconto"), seguida por "compre um e ganhe outro" e, finalmente, "compre 2, ganhe $50 \%$ de desconto. A Tabela 1 mostra a ordem de preferência de promoções:

Tabela 1 - Preferência dos consumidores por tipos de promoção

\begin{tabular}{|l|l|}
\hline Promoção & Porcentagem de preferência \\
\hline $\mathbf{5 0 \%}$ de desconto & $49 \%$ \\
\hline Compre um e ganhe outro & $21 \%$ \\
\hline $\begin{array}{l}\text { Compre dois, ganhe } \mathbf{5 0 \%} \text { de } \\
\text { desconto }\end{array}$ & $4 \%$ \\
\hline As promoções são iguais & $18 \%$ \\
\hline Outras combinações & $8 \%$ \\
\hline
\end{tabular}

FONTE: SINHA; SMITH, 2000, p. 271.

No entanto, a atratividade da promoção varia com o tipo do produto: para produtos não estocáveis (perecíveis), a promoção de preço mostrou-se mais atrativa; já para produtos estocáveis, a promoção de produto extra é quase equivalente ao desconto, e a mista é menos atrativa do que as primeiras. Aparentemente, os indivíduos preferiram "leve um e ganhe outro" devido à clara indicação de que ganhariam um item extra (SINHA; SMITH,Ibid.).

Hardesty e Bearden (op. cit.) testam o efeito das promoções diferenciando níveis de promoção em baixo (16,7\%), moderado $(28,6 \%)$ e alto $(50 \%)$ e tipo da promoção (desconto em centavos ou volume extra, por exemplo "10\% MORE FREE $5.7 \mathrm{oz}$. at the $5.2 \mathrm{oz}$. price"). Os produtos 
utilizados são bens de consumo de baixo valor (por exemplo, pasta de dente, sabão para roupas, creme para as mãos, etc.). Os autores concluem que os descontos de preço e volume extra foram avaliados de forma similar para níveis baixos e moderados de promoção; já o desconto foi preferido quando o nível promocional era alto (50\%). Os autores recomendam que promoções em porcentagem devam ser apresentadas quando o desconto é alto; já quando o desconto é baixo ou moderado, pode-se usar a promoção de volume, o que poderia trazer menos efeitos negativos à imagem da marca.

Gendall et al. (op. cit.) comparam a atratividade de promoções de volume ("compre 2, leve 1 de graça" e "3 pelo preço de 2") com promoções monetárias (“33\% de desconto" e “economize x centavos"). As três promoções são equivalentes. Os autores também diferenciam os produtos em estocáveis (macarrão) e não estocáveis (água engarrafada e manteiga). Para o produto estocável, a promoção em volume mostrou-se mais atrativa que o desconto monetário; já para os produtos não estocáveis, os descontos monetários (especialmente o formato "economize x centavos") foram mais atraentes.

Por fim, Palazon e Delgado-Ballester (2009, p. 1108) chegam a conclusões semelhantes as de Hardesty e Bearden (op. cit.): em um nível alto de promoção, o desconto do preço mostrou-se mais efetivo do que o oferecimento de um brinde ao comprador; já em níveis baixos de desconto, a preferência por brindes prevalece.

O Quadro 2 resume as principais conclusões dos estudos mencionados acima. Uma das colunas traz os tipos de promoções avaliados, na sequência aparecem as conclusões e, por último estão descritos os autores que embasam a respectiva análise. 
Quadro 2 - Principais conclusões de estudos sobre promoções no varejo

\begin{tabular}{|c|c|c|}
\hline $\begin{array}{l}\text { Tipos de } \\
\text { promoções } \\
\text { estudados }\end{array}$ & Conclusões & Autores \\
\hline \multirow[t]{3}{*}{$\begin{array}{lr}\text { Monetárias } & - \\
\text { desconto } & \text { em } \\
\text { dólares } & \text { e } \\
\text { porcentagem } & \end{array}$} & $\begin{array}{l}\text { Para produtos de alto valor, os consumidores perceberam uma } \\
\text { redução de preço apresentada em dólares como mais } \\
\text { significativa do que a mesma redução em porcentagem. Para } \\
\text { produtos de baixo valor, os consumidores avaliaram uma } \\
\text { redução de preço mostrada em porcentagem como mais } \\
\text { significativa do que em dólares. O desconto utilizado foi de } \\
10 \% \text {. }\end{array}$ & $\begin{array}{l}\text { Chen et al. } \\
(1998)\end{array}$ \\
\hline & $\begin{array}{l}\text { Para níveis moderados de desconto }(28,6 \%) \text {, os consumidores } \\
\text { valorizam as promoções apresentadas em dólares e } \\
\text { porcentagem de forma parecida. Para descontos altos, os } \\
\text { consumidores preferem mais as promoções mostradas em } \\
\text { porcentagem mais do que em dólares. }\end{array}$ & $\begin{array}{l}\text { Hardesty e } \\
\text { Bearden (2003) }\end{array}$ \\
\hline & $\begin{array}{l}\text { Os autores concluem que para dois itens de baixo valor, o } \\
\text { framing do desconto }(10 \%) \text { tem pouco ou nenhum efeito; já } \\
\text { para os itens de alto valor, mostrar o preço como desconto em } \\
\text { dólares foi significativamente mais efetivo do que em } \\
\text { porcentagem (desconto de } 15 \%) \text {. }\end{array}$ & $\begin{array}{l}\text { Gendall et al. } \\
(2006)\end{array}$ \\
\hline $\begin{array}{l}\text { Monetárias e não } \\
\text { monetárias } \\
\text { promoções } \\
\text { formuladas como } \\
\text { ganho e perda }\end{array}$ & $\begin{array}{l}\text { Promoções mostradas como ganho (compre um molho de } \$ \\
1.89 \text { e ganhe uma sopa que custa } \$ 0.49 \text { ) são mais desejáveis } \\
\text { do que as apresentadas como perda reduzida (compre um } \\
\text { molho e uma sopa por } \$ 1.89 \text { e economize } \$ 0.49 \text { ). }\end{array}$ & $\begin{array}{l}\text { Diamond e } \\
\text { Sanyal (1990) }\end{array}$ \\
\hline $\begin{array}{l}\text { Monetárias e não } \\
\text { monetárias } r \\
\text { promoção } \\
\text { preço, de } \\
\text { extra e misto } \\
\text { ("compre dois, } \\
\text { ganhe } 50 \% \text { de } \\
\text { desconto") }\end{array}$ & $\begin{array}{l}\text { Os consumidores atribuem maior valor de transação para a } \\
\text { promoção de preço (" } 50 \% \text { de desconto"), seguida por "compre } \\
\text { um e ganhe outro" e "compre } 2 \text {, ganhe } 50 \% \text { de desconto". A } \\
\text { atratividade da promoção varia com o tipo do produto. Para } \\
\text { produtos não estocáveis, a promoção de preço mostrou-se } \\
\text { mais atrativa. Já nos produtos estocáveis, a promoção de } \\
\text { produto extra é quase equivalente ao desconto. A mista é } \\
\text { menos atrativa do que as duas primeiras. }\end{array}$ & $\begin{array}{l}\text { Sinha e Smith } \\
(2000)\end{array}$ \\
\hline $\begin{array}{lr}\text { Monetárias e não } \\
\text { monetárias } & - \\
\text { promoção } & \text { de } \\
\text { preço e brinde }\end{array}$ & $\begin{array}{l}\text { Em um nível alto de promoção, o desconto do preço mostrou- } \\
\text { se mais efetivo do que um brinde; em níveis baixos de } \\
\text { desconto, a preferência por brindes prevalece. }\end{array}$ & $\begin{array}{l}\text { Palazon } \quad \text { e } \\
\text { Delgado- } \\
\text { Ballester (2009) }\end{array}$ \\
\hline \multirow{2}{*}{$\begin{array}{l}\text { Monetárias e não } \\
\text { monetárias } \\
\text { promoção } \\
\text { preço e volume } \\
\text { extra }\end{array}$} & $\begin{array}{l}\text { O desconto no preço e o volume extra foram avaliados de } \\
\text { maneiras similares para níveis baixos e moderados de } \\
\text { promoção; enquanto o desconto no preço foi preferido quando } \\
\text { o nível promocional era alto }(50 \%) \text {. }\end{array}$ & $\begin{array}{l}\text { Hardesty e } \\
\text { Bearden (2003) }\end{array}$ \\
\hline & $\begin{array}{l}\text { Para o produto estocável, a promoção em volume mostrou-se } \\
\text { mais atrativa que o desconto monetário. No caso dos produtos } \\
\text { não estocáveis, os descontos monetários (especialmente o } \\
\text { formato "economize x centavos") foram mais atrativos. }\end{array}$ & $\begin{array}{l}\text { Gendall et al. } \\
(2006)\end{array}$ \\
\hline
\end{tabular}

De acordo os estudos anteriormente mencionados, a atratividade da promoção depende de vários fatores: amplitude do desconto (baixo, moderado, alto); tipo de produto (estocável vs. não estocável); forma de apresentação da promoção. Como são muitas variáveis, torna-se difícil generalizar uma conclusão destes estudos em relação à atratividade das promoções frente aos consumidores. No entanto, há evidências que promoções em volume podem ser 
mais atrativas para produtos estocáveis e promoções em porcentagem mais atrativas para produtos não estocáveis. Em níveis altos de promoção, o desconto monetário pode ser mais atrativo do que uma promoção não monetária. 


\subsection{Hipóteses}

Para atingir os propósitos deste trabalho, a pesquisa ocorreu em duas etapas: a primeira, com caráter qualitativo, que teve por objetivo identificar as hipóteses de pesquisa; e a segunda, com caráter quantitativo. Nesta fase, realizou-se o levantamento de dados numéricos para entendimento do problema de pesquisa.

A definição das hipóteses ocorreu com base na revisão da literatura. Foram levantadas cinco hipóteses principais. As duas primeiras foram baseadas nos trabalhos de Chen et al. (op. cit.) e de Gendall et al. (op. cit.). Os dois trabalham com a hipótese de que é melhor mostrar um desconto em porcentagem para itens de baixo valor e desconto em dólares para itens de alto valor. O trabalho de Chen et al. (op. cit.) comprova totalmente esta hipótese; enquanto no estudo de Gendall et al. (op. cit.) a comprovação é parcial, uma vez que não é certo afirmar que é melhor mostrar o desconto em porcentagem para itens de baixo valor.

Portanto, com base nesses estudos, as duas primeiras hipóteses são:

Hipótese 1 (H1): Para produtos de baixo valor, os consumidores percebem as promoções de preço apresentadas como desconto em porcentagem como mais vantajosas do que as mostradas em reais.

Hipótese 2 (H2): Para produtos de alto valor, os consumidores percebem as promoções de preço apresentadas em reais como mais vantajosas se comparadas aquelas mostradas em formato de porcentagem.

A terceira hipótese tem como base o trabalho de Gendall et al. (Ibid.). Os autores modificam o método utilizado por Chen et al. (op. cit.) ao incluir comparações entre marcas no estudo do framing de descontos. Este estudo tem por base um experimento de modelagem de escolha feito com consumidores e por isso, apresenta um cenário mais realista do que o experimento feito com estudantes (que utilizou produtos sem marca). Ao incluir marcas como atalhos para escolha, o levantamento de Gendall et al. (op. cit.) supera críticas de que quando apenas o 
preço é a única informação disponível, os indivíduos naturalmente sobrevalorizam sua importância. Portanto, a terceira hipótese da pesquisa é:

Hipótese 3 (H3): A efetividade do desconto em reais e do desconto em porcentagem será diferente para marcas diferenciadas, encontradas em categorias diferentes.

As hipóteses 4 e 5 tratam dos efeitos do framing em pessoas de renda e escolaridade diferentes. Os estudos utilizados para derivar H1 e H2 não diferenciam renda ou escolaridade, assim como no geral os artigos analisados sobre framing de promoções não tratam destas variações, visto que utilizam experimentos feitos com estudantes. Portanto, foram selecionados estudos similares sobre framing para elaborar as hipóteses 5 e 6.

Queiroz (2007) revela que as variáveis socioeconômicas e demográficas não explicam a preferência dos consumidores pelo parcelamento de compras, ou seja, há evidências que o efeito de apresentação do parcelamento (efeito framing) sobre a apresentação do valor à vista ocorre em quase todos os grupos da amostra. Existe um efeito da apresentação da forma de pagamento na preferência dos consumidores, independente do perfil socioeconômico que este se enquadre.

LeBoeuf e Shafir (2003) demonstram que indivíduos que tendem a refletir mais (ou seja, são mais racionais) mostram maior consistência em suas escolhas. São pessoas que notam a relação entre as alternativas apresentadas e se inclinam a escolher aquelas configuradas de maneira semelhante. Porém, essa necessidade por cognição não evitou que os indivíduos sofressem a influência do framing.

Outros estudos demonstraram que o conhecimento ou a experiência em uma determinada área não necessariamente evitam o efeito do framing. Em um destes estudos, os participantes tinham de escolher entre dois tipos de terapias médias (cirurgia e radioterapia). Os problemas eram descritos em termos de taxas de sobrevivência e taxa de mortalidade. A formulação do problema como taxa de sobrevivência levou a uma grande preferência pela cirurgia. Este efeito framing ocorreu tanto entre pacientes quanto entre médicos (MCNEIL et al., 1982 apud KAHNEMAN, 2003a, p. 702). Em outra pesquisa, verificou-se que profissionais experientes que trabalham com planejamento financeiro são tão suscetíveis quanto leigos em relação ao framing de estratégias de investimento (formuladas como ganhos ou perdas). Portanto, a 
maioria dos indivíduos parece ser sujeita ao efeito do framing; e isso independe de sua experiência profissional ou formação acadêmica.

Com base nos estudos mencionados, percebe-se que o perfil socioeconômico e a necessidade por cognição ou experiência/formação em algum ramo (que poderia ser uma proxy para escolaridade) não evitam o efeito framing nas preferências dos indivíduos durante o processo de aquisição de algum bem.

Hipótese 4 (H4): A renda não deve afetar o padrão de escolhas de promoção, ou seja, pessoas de alta renda e baixa renda devem ser igualmente suscetíveis ao efeito do framing de promoções.

Hipótese 5 (H5): A escolaridade não deve afetar o padrão de escolhas de promoção, ou seja, pessoas com alta escolaridade e baixa escolaridade devem ser igualmente suscetíveis ao efeito do framing de promoções.

O Quadro 3 mostra os objetivos específicos e hipóteses que foram testadas. Além disso, são apresentados, de maneira sintética, os métodos para verificação das suposições formuladas. Na próxima seção, estão detalhados os procedimentos estatísticos utilizados para verificar as hipóteses deste trabalho. 
Quadro 3 - Objetivos específicos do trabalho, hipóteses e os métodos utilizados

\begin{tabular}{|c|c|c|}
\hline $\begin{array}{l}\text { Objetivos específicos do } \\
\text { Trabalho }\end{array}$ & $\begin{array}{l}\text { Hipóteses } \\
\text { relacionadas }\end{array}$ & Métodos utilizados \\
\hline $\begin{array}{l}\text { Verificar qual tipo de } \\
\text { promoção (mostrada em } \\
\text { termos percentuais ou } \\
\text { monetários) é mais } \\
\text { atrativo para } \\
\text { consumidor final, para } \\
\text { produtos de baixo valor e } \\
\text { alto valor. }\end{array}$ & $\begin{array}{l}\text { H1: Para produtos de baixo valor, os } \\
\text { consumidores percebem as promoções } \\
\text { de preço apresentadas como desconto } \\
\text { em porcentagem como mais vantajosas } \\
\text { do que as mostradas em reais. } \\
\text { H2: Para produtos de alto valor, os } \\
\text { consumidores percebem as promoções } \\
\text { de preço apresentadas em reais como } \\
\text { mais vantajosas se comparadas aquelas } \\
\text { mostradas em formato de } \\
\text { porcentagem. }\end{array}$ & $\begin{array}{l}\text { - Cálculo do intervalo de } \\
\text { confiança da diferença entre } \\
\text { proporções dentro da mesma } \\
\text { amostra }\end{array}$ \\
\hline $\begin{array}{l}\text { Determinar se as } \\
\text { diferentes faixas de renda } \\
\text { têm alguma preferência } \\
\text { por tipo de promoção. }\end{array}$ & $\begin{array}{l}\text { H4: A renda não deve afetar o padrão } \\
\text { de escolhas de promoção, ou seja, } \\
\text { pessoas de alta renda e de baixa renda } \\
\text { devem ser igualmente suscetíveis ao } \\
\text { efeito do framing de promoções. }\end{array}$ & $\begin{array}{l}\text { - Teste qui-quadrado } \\
\text { - Cálculo do intervalo de } \\
\text { confiança da diferença entre } \\
\text { proporções dentro da mesma } \\
\text { amostra } \\
\text { - Teste de proporções entre } \\
\text { amostras diferentes (alta renda } \\
\text { e baixa renda) } \\
\text { - Análise de correspondência }\end{array}$ \\
\hline \begin{tabular}{ll} 
Determinar & \multicolumn{1}{c}{ se } \\
diferentes faixas de \\
escolaridade têm alguma \\
preferência por tipo de \\
promoção.
\end{tabular} & $\begin{array}{l}\text { H5: A escolaridade não deve afetar o } \\
\text { padrão de escolhas de promoção, ou } \\
\text { seja, pessoas com alta escolaridade e } \\
\text { baixa escolaridade devem ser } \\
\text { igualmente suscetíveis ao efeito do } \\
\text { framing de promoções. }\end{array}$ & $\begin{array}{l}\text { - Teste qui-quadrado } \\
\text { - Cálculo do intervalo de } \\
\text { confiança da diferença entre } \\
\text { proporções dentro da mesma } \\
\text { amostra } \\
\text { - Teste de proporções entre } \\
\text { amostras diferentes (sem } \\
\text { faculdade completa e com } \\
\text { faculdade completa) } \\
\text { - Análise de correspondência }\end{array}$ \\
\hline $\begin{array}{l}\text { Verificar se o efeito das } \\
\text { promoções varia de } \\
\text { acordo com a marca }\end{array}$ & $\begin{array}{l}\text { H3: A efetividade do desconto em } \\
\text { reais e do desconto em porcentagem } \\
\text { será diferente para marcas } \\
\text { diferenciadas, encontradas em } \\
\text { categorias diferentes. }\end{array}$ & $\begin{array}{l}\text { - Comparação do número de } \\
\text { escolhas por produtos sem } \\
\text { promoção, com promoção em } \\
\text { reais e promoção em } \\
\text { porcentagem } \\
\text { - Análise de regressão logística } \\
\text { multinomial }\end{array}$ \\
\hline $\begin{array}{lr}\text { Verificar se } & \text { existem } \\
\text { outras variáveis } & \text { (região } \\
\text { da cidade, sexo, idade, } \\
\text { etc.) que r podem } \\
\text { influenciar r na } \\
\text { preferência por algum } \\
\text { tipo de promoção. }\end{array}$ & & - Teste qui-quadrado \\
\hline
\end{tabular}




\subsection{Técnicas de análise}

As técnicas estatísticas utilizadas para a análise dos dados serão detalhadas neste tópico. Utilizou-se cálculo do intervalo de confiança da diferença entre proporções dentro da mesma amostra, teste de proporções entre amostras diferentes, teste qui-quadrado, análise de correspondência, e análise de regressão logística multinomial.

Para saber se existem diferenças entre as proporções da amostra, foram calculados os intervalos de confiança da diferença de proporções. Utilizou-se a fórmula de diferença entre proporções amostrais (RAO, 2000), para calcular o intervalo de confiança da diferença entre proporções dentro da mesma amostra. Se o zero estiver contido neste intervalo, então não podemos afirmar que exista diferença entre as proporções.

Para o cálculo da diferença de proporções entre amostras diferentes, optou-se pelo uso da estatística de teste para testes de hipóteses sobre p1-p2 (Ilustração 4):

$$
\mathrm{Z}=\frac{\left(\bar{p}_{1}-\bar{p}_{2}\right)}{\sqrt{\bar{p}(1-\bar{p})\left(\frac{1}{n_{1}}+\frac{1}{n_{2}}\right)}}
$$

onde,

$\bar{p}_{1}$ é a proporção amostral de pelo tipo de apresentação feita na alta renda;

$\bar{p}_{2}$ é a proporção amostral de escolhas pelo tipo de apresentação feita na baixa renda;

$n_{1}$ é o tamanho da amostra de alta renda;

$n_{2}$ é o tamanho da amostra de baixa renda;

$\bar{p}$ é a estimativa agrupada da proporção populacional, calculada da seguinte maneira:

$\bar{p}=\frac{n_{1} \bar{p}_{1}+n_{2} \bar{p}_{2}}{n_{1}+n_{2}}$

Podemos aplicar esta estatística em situações de grandes amostras, em que $n_{1} \bar{p}_{1}, n_{1}\left(1-\bar{p}_{1}\right)$, $n_{2} \bar{p}_{2}, n_{2}\left(1-\bar{p}_{2}\right)$ são maiores do que 5. Para o caso das amostras analisadas, foram efetuados estes cálculos e todos foram maiores do que 5, o que permite utilizar esta técnica. A hipótese nula diz que a proporção do grupo $\mathrm{A}$ é menor ou igual à proporção do grupo $\mathrm{B}$, e a hipótese alternativa estabelece que a proporção do grupo A é maior do que proporção do grupo $\mathrm{B}$. Se o 
$\mathrm{z}$ calculado pela fórmula acima for menor do que o z crítico, não podemos rejeitar a hipótese nula (ANDERSON et al., 2007).

O teste qui-quadrado também foi uma técnica de análise escolhida. De acordo com Anderson (Ibid., p. 411), "uma aplicação importante da distribuição qui-quadrado envolve usar dados amostrais para testar a independência de duas variáveis”. A hipótese nula diz que as variáveis são independentes e a hipótese alternativa diz que as variáveis são dependentes. Se o valor do qui-quadrado (valor-p) for menor do que a significância estabelecida, podemos rejeitar a hipótese A.

A análise de correspondência é uma representação multivariada da interdependência de dados não métricos, ou seja, a técnica permite a representação visual de opiniões, atitudes e perfis em duas ou mais dimensões. Cada ponto tem uma posição espacial no mapa perceptual, refletindo a relação entre características de variáveis, segundo as dimensões do mapa perceptual (HAIR et al., 2010).

A regressão logística permite analisar variáveis qualitativas, ao contrário de outras técnicas como a análise discriminante, que trabalha com variáveis quantitativas para discriminar entre grupos previamente conhecidos, ou seja, utiliza uma variável categórica como dependentes e variáveis métricas como independentes (HAIR et al.,Ibid.). Esta técnica permite elaborar modelos que são utilizados para computar a probabilidade de um indivíduo pertencer a um determinado grupo.

A regressão logística multinomial compara grupos múltiplos por meio da combinação de regressões logísticas binárias. Ou seja, para cada variável independente, haverá duas comparações. A regressão logística multinomial fornece uma série de coeficientes em cada uma das duas comparações. Os coeficientes para o grupo de referência são todos iguais a zero. Portanto, há um total de três equações, uma para cada um dos grupos definidos pela variável dependente. Estas equações irão computar a probabilidade de um indivíduo pertencer a cada um dos grupos. O indivíduo deve pertencer ao grupo associado com a maior probabilidade (UNIVERSITY OF TEXAS, 2012a).

Finalmente, a regressão logística multinomial não faz nenhuma suposição de normalidade, linearidade e homogeneidade da variância para as variáveis independentes. Por ter menos 
restrições, é preferível à análise discriminante quando os dados não correspondem a essas condições (UNIVERSITY OF TEXAS,Ibid.).

\subsection{Método da pesquisa}

Para a realização deste trabalho, foi aplicada uma pesquisa descritiva, de abordagem quantitativa, a partir de um experimento baseado em hipóteses, e que teve como público-alvo consumidores da cidade de São Paulo abordados no período entre janeiro e fevereiro de 2013.

A pesquisa descritiva tem como objetivo a exposição das características de determinada população ou o estabelecimento de relações entre variáveis. Um de seus atributos mais importantes refere-se a utilização de técnicas padronizadas de coletas de dados. Como o trabalho ora proposto trata de variáveis já conhecidas e testadas em outros estudos, optou-se por este tipo de pesquisa (GIL, 1999).

Já a pesquisa quantitativa permite que o pesquisador mensure opiniões, hábitos e atitudes por meio de uma amostra estatisticamente representativa. Este tipo de estudo geralmente obedece a um plano pré-estabelecido, ou seja, o pesquisador precisa ter sua pergunta-problema bem definida. Ele parte da teoria para embasar as hipóteses e variáveis e assim chegar ao problema. Este tipo de pesquisa geralmente emprega técnicas estatísticas para a análise dos dados. Os dados representam uma população específica (amostra), a partir do qual os resultados podem ser generalizados. Geralmente trabalha-se com uma pequena margem de erro. Para obtenção dos dados primários, os instrumentos utilizados incluem questionários estruturados (TERENCE; ESCRIVÃO FILHO, 2006).

O instrumento de coleta deste estudo foi composto por um questionário com perguntas fechadas, dividido em duas partes: preferências dos respondentes e perguntas sobre quesitos socioeconômicos. O questionário - que pode ser visualizado nos Apêndices 1 e 2 - teve como base o estudo de Gendall et al. (op. cit.). Para a primeira parte, foram selecionados dois produtos: um de baixo valor (biscoito recheado sabor chocolate) e outro de alto valor (notebook). Estes produtos foram escolhidos em linha com o estudo de Gendall et al. (Ibid.), que trabalhou com batata chips e computadores. A segunda parte do questionário inclui perguntas de cunho socioeconômico, como faixa de renda, região da cidade, sexo, faixa etária, 
estado civil, classe social (de acordo com o Critério de Classificação Econômica Brasil, CCEB) e faixa de escolaridade.

Por se tratar do mercado brasileiro, para o produto de baixo valor optou-se por um item popular e que conta com grande diversidade de marcas, de forma a evitar uma preferência desmedida por uma das marcas, o que poderia anular o efeito do framing de promoções. $\mathrm{O}$ mercado de biscoitos é bastante fragmentado e, de acordo com o jornal Folha de S.Paulo (2011), as três marcas líderes de lembrança de marca detinham apenas 7\% (Trakinas), 6\% (Nestlé) e 6\% (Mabel) das respostas, respectivamente. Quanto à seleção das marcas, optou-se por trabalhar com as três mais preferidas no Brasil (SUPERMERCADO MODERNO, 2010): Passatempo, Trakinas e Bono. O pré-teste do questionário revelou que a grande maioria dos respondentes conhecia as três marcas selecionadas.

A escolha do produto de alto valor utilizou o mesmo critério adotado para a seleção do item de baixo valor. O mercado de notebooks é bastante fragmentado no Brasil e, de acordo com o jornal Folha de S.Paulo (op. cit.), as marcas com maior lembrança por parte dos consumidores são LG, com 7\% das respostas, Samsung, com 5\%, e Positivo, com 4\%. No entanto, no primeiro pré-teste a marca Positivo praticamente não foi escolhida pelos respondentes. Por conta deste detalhe, optou-se por trabalhar com a marca Dell que teve melhor aceitação.

Nas páginas de escolha que compõe o questionário contém imagens das três marcas dos produtos selecionados, sendo que em cada uma delas aparece uma destas três situações: preço cheio; preço cheio riscado com uma promoção ao lado dizendo "oferta especial" e " $10 \%$ de desconto" (para biscoitos) ou "15\% de desconto" (para notebooks); preço cheio riscado com uma promoção ao lado dizendo "oferta especial" e "De R \$ x por R \$ y".

As formas de desconto escolhidas foram aquelas encontradas mais frequentemente no varejo brasileiro. No estudo de Gendall et al. (op. cit.), os autores utilizam a frase "economize 10\%" e "Economize \$ x". No entanto, no Brasil é mais comum encontrar " $10 \%$ de desconto" e "De $\mathrm{R}$ \$ x por R \$ y", ao invés de "Economize \$ x". Portanto, também foi efetuada esta adaptação em relação ao questionário de Gendall et al. (Ibid.).

No caso dos biscoitos, procurou-se manter o mesmo tamanho das figuras, para que estas não influenciassem na escolha; e, no caso do notebook, utilizou-se o logotipo da marca e a mesma 
figura. O preço cheio foi o mesmo em todas as situações do biscoito, e o mesmo para todas as situações do notebook. Os valores do biscoito e do notebook são uma média dos preços das marcas, pesquisados em sites de e-commerce. As figuras abaixo mostram as folhas do questionário para biscoitos e notebooks:

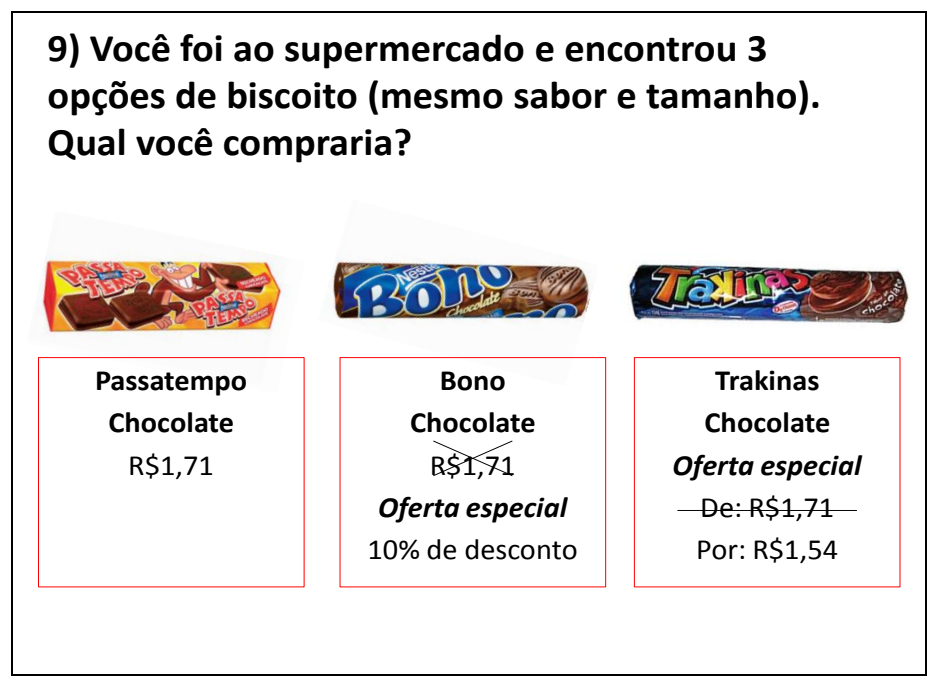

Ilustração 5 - Modelo de pergunta do questionário para produto de baixo valor

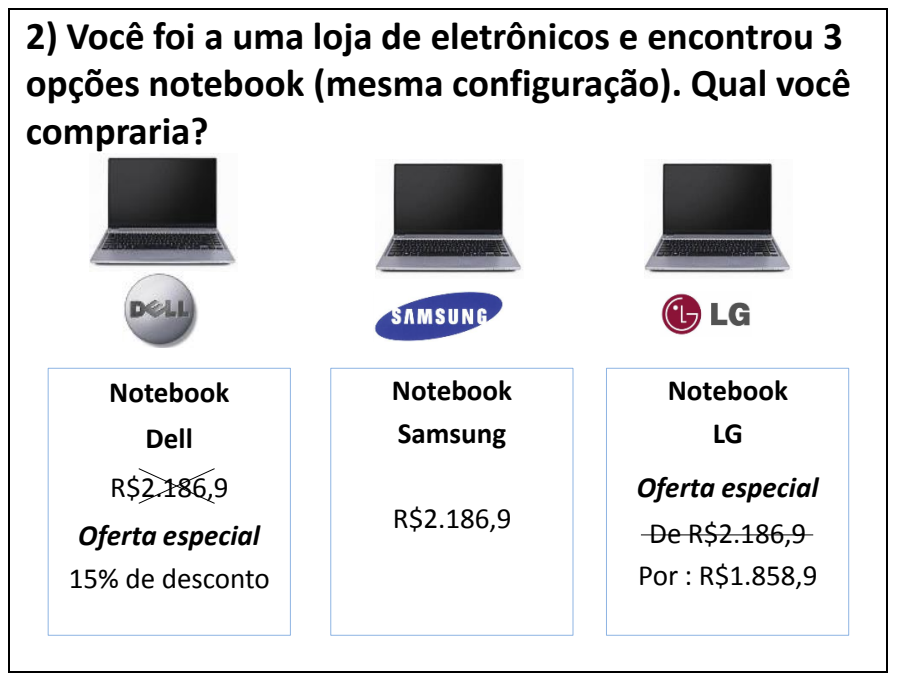

Ilustração 6 - Modelo de pergunta do questionário para produto de baixo valor

Cada uma das marcas escolhidas aparece duas vezes em cada situação ao longo do questionário (preço cheio, desconto em porcentagem e desconto em reais), totalizando seis situações para o produto de baixo valor e seis situações para o produto de alto valor. $\mathrm{O}$ respondente deveria indicar uma das três opções apresentadas em cada página. Ele foi informado que só havia três opções e que não poderia escolher nenhuma outra marca que não estivesse no questionário. 
O Quadro 4 revela a configuração do questionário, mostrando como cada marca é apresentada em cada item questionado. Procurou-se mesclar as perguntas de preferência por biscoito e notebooks com questões não relacionadas ao estudo (por exemplo, "qual é seu supermercado favorito") para que os entrevistados não ficassem 'viciados' em uma única resposta ao longo do questionário.

Quadro 4 - Estrutura do questionário aplicado junto aos consumidores

\begin{tabular}{|c|c|c|c|}
\hline Situs & \multicolumn{3}{|c|}{$\begin{array}{l}\text { Pergunta não relacionada: Você foi ao supermercado e encontrou } 3 \text { opções } \\
\text { chocolate. Qual você compraria? }\end{array}$} \\
\hline $\begin{array}{l}\text { Qual opção } \\
\text { compraria? }\end{array}$ & $\begin{array}{llll}\begin{array}{l}\text { Dell } \quad- \\
\text { desconto" }\end{array} & \text { "15\% } & \text { de }\end{array}$ & Samsung - Preço cheio & $\begin{array}{l}\text { LG - "De R } \$ 2.186,9 \text { por } \\
\text { R } \$ 1.858,9 "\end{array}$ \\
\hline $\begin{array}{l}\text { Qual opção } \\
\text { compraria? }\end{array}$ & $\begin{array}{l}\text { Bono - "De R } \$ 1,71 \text { por } \\
\text { R } \$ 1,54 "\end{array}$ & $\begin{array}{llll}\begin{array}{l}\text { Trakinas } \\
\text { desconto" }\end{array} & -10 \% & \mathrm{de} \\
\end{array}$ & Passatempo - Preço cheio \\
\hline Situação 4 & \multicolumn{3}{|c|}{ Pergunta não relacionada: Qual destes é seu supermercado preferido? } \\
\hline $\begin{array}{l}\text { Qual opção } \\
\text { compraria? }\end{array}$ & Bono - Preço cheio & $\begin{array}{l}\text { Passatempo - "De R } \$ 1,71 \\
\text { por } R \$ 1,54 "\end{array}$ & $\begin{array}{l}\text { Trakinas }-" 10 \% \text { de } \\
\text { desconto" }\end{array}$ \\
\hline $\begin{array}{l}\text { Qual opção } \\
\text { compraria? }\end{array}$ & LG - "15\% de desconto" & Dell - Preço cheio & $\begin{array}{l}\text { Samsung - "De R } \$ 2.186,9 \\
\text { por R } \$ 1.858,9 "\end{array}$ \\
\hline Situa & \multicolumn{3}{|c|}{$\begin{array}{l}\text { Pergunta não relacionada: O Extra lançou uma promoção na qual o prêmio é uma } \\
\text { viagem de carnaval com } 1 \text { acompanhante. Qual destes destinos você preferiria } \\
\text { conhecer? }\end{array}$} \\
\hline $\begin{array}{l}\text { Qual opção } \\
\text { compraria? }\end{array}$ & $\begin{array}{l}\text { Samsung }-“ 15 \% \text { de } \\
\text { desconto" }\end{array}$ & $\begin{array}{l}\text { Dell - "De R } \$ 2.186,9 \text { por } \\
\text { R } \$ 1.858,9 "\end{array}$ & LG - Preço cheio \\
\hline $\begin{array}{l}\text { Qual opção } \\
\text { compraria? }\end{array}$ & Passatempo - Preço cheio & Bono - "10\% de desconto" & $\begin{array}{l}\text { Trakinas - "De R\$1,71 por } \\
\text { R\$1,54" }\end{array}$ \\
\hline $\begin{array}{l}\text { Qual opção } \\
\text { compraria? }\end{array}$ & $\begin{array}{l}\text { Samsung } \\
\mathrm{R} \$ 2.186,9 \\
\mathrm{R} \$ 1.858,9\end{array}$ & LG - Preço cheio & Dell - "15\% de desconto" \\
\hline Situs & \multicolumn{3}{|c|}{$\begin{array}{l}\text { Pergunta não relacionada: Imagine que o Magazine Luiza queira contratar um } \\
\text { novo apresentador para estrelar os comerciais. Qual deles você preferiria ver nos } \\
\text { comerciais da marca? }\end{array}$} \\
\hline $\begin{array}{l}\text { Qual opção } \\
\text { compraria? }\end{array}$ & Trakinas - Preço cheio & $\begin{array}{l}\begin{array}{l}\text { Passatempo } \\
\text { desconto" }\end{array}\end{array}$ & $\begin{array}{l}\text { Bono - "De } \mathrm{R} \$ 1,71 \text { por } \\
\mathrm{R} \$ 1,54 "\end{array}$ \\
\hline Situação 13 & \multicolumn{3}{|c|}{$\begin{array}{l}\text { Pergunta não relacionada: Em quais destas lojas de eletrônicos você prefere fazer } \\
\text { compras? }\end{array}$} \\
\hline $\begin{array}{l}\text { Qual opção } \\
\text { compraria? }\end{array}$ & $\begin{array}{l}\text { LG - "De R\$2.186,9 por } \\
\text { R\$1.858,9" }\end{array}$ & Dell - Preço cheio & $\begin{array}{l}\text { Samsung } \\
\text { desconto" }\end{array}$ \\
\hline $\begin{array}{l}\text { Qual opção } \\
\text { compraria? }\end{array}$ & $\begin{array}{l}\text { Trakinas - "De } \mathrm{R} \$ 1,71 \\
\text { por } \mathrm{R} \$ 1,54 "\end{array}$ & Bono - Preço cheio & $\begin{array}{l}\text { Passatempo }-" 10 \% \text { de } \\
\text { desconto" }\end{array}$ \\
\hline Situação 16 & \multicolumn{3}{|c|}{$\begin{array}{l}\text { Pergunta não relacionada: Imagine que a Nestlé vai lançar uma linha de sorvetes } \\
\text { especiais de massa no ano que vem. Qual sabor você acha mais atraente? }\end{array}$} \\
\hline $\begin{array}{l}\text { Qual opção } \\
\text { compraria? }\end{array}$ & Samsung - Preço cheio & LG - " $15 \%$ de desconto" & $\begin{array}{l}\text { Dell - "De R\$2.186,9 por } \\
\text { R } \$ 1.858,9 "\end{array}$ \\
\hline $\begin{array}{l}\text { Qual opção } \\
\text { compraria? }\end{array}$ & $\begin{array}{l}\text { Passatempo - } \\
\mathrm{R} \$ 1,71 \text { por } \mathrm{R} \$ 1,54 "\end{array}$ & Bono - "10\% de desconto" & Trakinas - Preço cheio \\
\hline
\end{tabular}

Para chegar ao questionário final, foram aplicados dois pré-testes. O primeiro deles, realizado com 24 pessoas, não continha perguntas não relacionadas ao estudo. Também não intercalava os tipos de produto (primeiro era mostrada a sequência de situações de escolha com biscoitos, 
depois a sequência de notebooks). Isso levava algumas pessoas a responder de forma automática, optando sempre pela mesma marca, sem que houvesse uma reflexão maior no momento da escolha; além disso, outras pessoas estranhavam a sequência de perguntas sobre o mesmo produto e achavam se tratar de uma repetição da questão. O primeiro questionário continha a marca Positivo na seção de notebooks. Como esse item se mostrou bastante impopular entre os respondentes e prejudicou a análise dos dados.

Para a aplicação do segundo pré-teste, realizado com 54 pessoas, foi preciso fazer algumas mudanças, descritas a seguir:

- foram inseridas perguntas não relacionadas ao estudo para que os entrevistados não ficassem atrelados a um tipo de resposta e deixam de perceber o propósito do questionário;

- $\quad$ as páginas de biscoito e de notebook foram intercaladas;

- $\quad$ a marca Positivo foi substituída pela marca Dell.

O questionário levou cerca de 10 minutos para ser aplicado e as pessoas não mostraram dificuldade em entender como responder às perguntas das situações propostas. Além disso, pouquíssimos entrevistados notaram que o desconto em reais e o desconto em porcentagem são equivalentes, o que mostra que este formato mais variado de questionário tira o foco principal do respondente no quesito preço.

\subsection{Descrição}

O universo da pesquisa são consumidores de bens de consumo não duráveis (e.g. alimentos) e duráveis (e.g. eletrônicos) que efetuaram alguma compra de produto eletrônico ou alimento no último ano, residentes no município de São Paulo e maiores de 18 anos. O critério utilizado na pesquisa partiu da análise de nove variáveis que compõem o indicador sociodemográfico de cada um dos 96 distritos que integram o município de São Paulo, apresentados no Perfil Socioeconômico da População Paulistana.

Para formular a caracterização socioeconômica da população, foram consideradas as seguintes variáveis: distribuição territorial, perfil etário, nível de renda, escolaridade, condições de 
saúde, condições de habitação e segurança. Como os valores são de diferentes grandezas, optou-se por padronizar os dados para que pudesse haver comparação entre eles.

Após a padronização, foram estabelecidas relações entre os dados. Isso foi possível com a utilização da técnica estatística Análise Fatorial, que condensa informações por meio da transformação em fatores. De acordo com Hair et al. (op. cit.), a análise fatorial é um nome genérico dado uma classe de métodos estatísticos multivariados cujo propósito principal é definir a estrutura subjacente em uma matriz de dados. Ela aborda o problema de analisar a estrutura das inter-relações entre um número grande de variáveis, estabelecendo uma série de dimensões comuns, que podemos chamar de fatores. Portanto, o fator pode ser considerado como uma combinação linear das variáveis originais e que representam as dimensões que explicam um conjunto original de variáveis observadas.

Dentre todos os fatores criados, o Fator Principal é aquele que agrega as informações com correlação mais forte e que apresenta o maior número de informações correlacionadas. Os demais fatores apresentam correlações mais fracas com menor número de variáveis relacionadas, tendo menor importância na explicação da variável observada (HAIR et al.,Ibid.).

O Fator Principal de cada distrito proposto foi obtido pelo resultado dos pesos dos indicadores multiplicados pelos seus valores padronizados no respectivo distrito, gerando uma classificação segundo seu perfil socioeconômico em ordem crescente, do melhor padrão para o pior padrão.

A partir da Análise Fatorial para identificação de perfis distintos de consumo decorrentes das nove variáveis existentes, estratificou-se a cidade em cinco diferentes segmentos a partir do Fator Principal. Com a definição dos segmentos e o cálculo desse fator, foi possível identificar a amostra de consumidores.

Com esta metodologia, surgiu o mapa temático (Ilustração 7) do perfil socioeconômico da população paulistana; e isso permitiu definir cinco grupos com perfil demográfico semelhante por meio da criação do Fator Principal. O mapa serviu como referência para a coleta dos dados: 


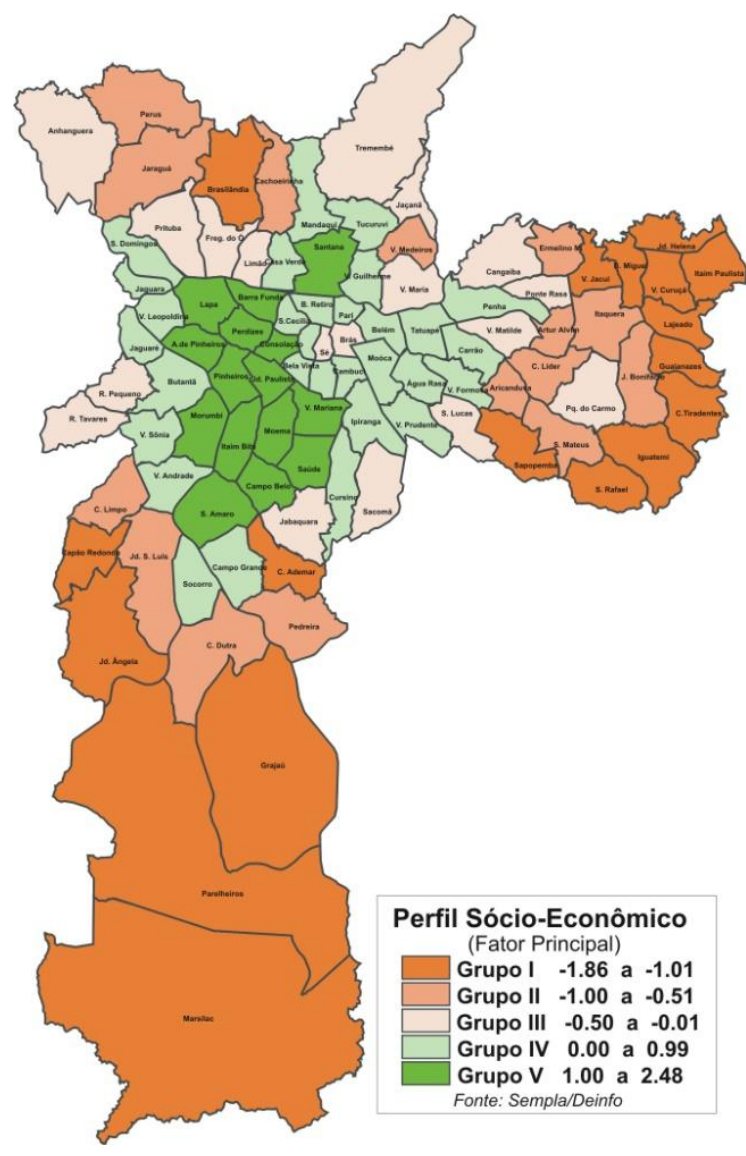

Ilustração 7 - Mapa temático do perfil da população paulistana FONTE: Sempla/Deinfo

\subsection{Dimensionamento da amostra}

Sabendo-se que uma pesquisa de caráter censitário requer um volume de recursos excessivamente elevado, optou-se pela seleção de uma amostra por cotas dimensionadas de acordo com os dados sociodemográficos da Prefeitura do Município de São Paulo. A amostragem por cotas não é rigorosamente probabilística, todavia estudos semelhantes de levantamento de opiniões, por meio de amostras dessa natureza, têm indicado bons resultados.

Como as perguntas são do tipo fechada, e não se conhece a dispersão da população a priori, preferiu-se trabalhar com um nível conservador de proporção, de 50\%. A fórmula (Ilustração 8) para determinar o tamanho da amostra é a seguinte (RAO,op. cit.):

$$
\boldsymbol{n}_{l}=\frac{Z^{2} * \boldsymbol{P} * \boldsymbol{Q}}{\boldsymbol{e}^{2}}
$$


Onde:

P é a estimativa da proporção populacional favorável a uma resposta, e neste caso igual a 0,5; $\mathrm{Q}=1-\mathrm{P}$, sendo a estimativa da proporção desfavorável, também igual a 0,5;

$\mathrm{Z}$ é a abscissa da distribuição normal padrão, fixado um determinado nível de confiança. No caso $\mathrm{Z}=2$, pois o nível de confiança foi de $95,5 \%$.

O tamanho da amostra encontrada reúne 400 entrevistas. Trata-se de uma amostragem muito menor do que a população e, em decorrência disso, não foi necessária a utilização de fator de correção para populações finitas.

Dividiu-se a coleta de dados em cinco pontos geográficos: Norte, Sul, Centro, Leste e Oeste. Em cada uma dessas localidades adotou-se o ponto onde se concentrava o maior fluxo de consumidores:

- $\quad$ Norte: Santana/Vila Guilherme/Carandiru

- $\quad$ Sul: Largo Treze/Brooklin/Grajaú

- $\quad$ Centro: Praça da República/Viaduto do Chá /Praça da Sé

- Leste: Tatuapé/Itaquera/São Miguel Paulista/Vila Prudente

- Oeste: Butantã/Rio Pequeno/Jaguaré/Pinheiros

Para garantir a representatividade da amostra, foram consideradas cinco grupos de distritos do município - grupo 1, grupo 2, grupo 3, grupo 4 e grupo 5 -, discriminados por meio da aplicação da técnica estatística de Análise Fatorial em nove variáveis de cada um dos 96 distritos. Essas variáveis estão relacionadas à renda familiar, quota residencial, nível de escolaridade, perfil etário, mortalidade infantil, crescimento populacional, índice de criminalidade, população favelada e densidade populacional.

A Tabela 2 mostra o perfil socioeconômico e demográfico em função do Fator Principal:

Tabela 2 - Perfil socieconômico e demográfico em função do Fator Principal

\begin{tabular}{|l|l|l|}
\hline $\begin{array}{l}\text { Perfil } \\
\text { sociodemográfico }\end{array}$ & Classificação & $\begin{array}{l}\text { Índice do Fator } \\
\text { Principal (IPF) }\end{array}$ \\
\hline Grupo 1 & Baixa & IPF $<-1,01$ \\
\hline Grupo 2 & Média Baixa & $-1,00<\mathrm{IPF}<-0,51$ \\
\hline Grupo 3 & Média & $-0,50<\mathrm{IPF}<-0,01$ \\
\hline Grupo 4 & Média Alta & $0,00<\mathrm{IPF}<0,99$ \\
\hline Grupo 5 & Alta & $1,00<\mathrm{IPF}<2,48$ \\
\hline
\end{tabular}




\section{RESULTADOS}

\subsection{Perfil da amostra}

Foram entrevistadas 400 pessoas, no município de São Paulo, durante o período de janeiro de fevereiro de 2013. A amostra foi composta por indivíduos de diferentes faixas de idade, escolaridade e classe social. A tabela abaixo mostra o perfil demográfico dos consumidores:

Tabela 3 - Perfil demográfico dos consumidores entrevistados

\begin{tabular}{|c|c|c|c|c|c|c|c|c|c|c|c|}
\hline \multicolumn{2}{|c|}{ Gênero } & \multicolumn{2}{|c|}{$\begin{array}{c}\text { Faixa etária } \\
\text { (anos) }\end{array}$} & \multicolumn{2}{|c|}{$\begin{array}{c}\text { Região de São } \\
\text { Paulo }\end{array}$} & \multicolumn{2}{|c|}{$\begin{array}{c}\text { Renda (R\$, } \\
\text { familiar) }\end{array}$} & \multicolumn{2}{|c|}{ Escolaridade } & \multicolumn{2}{|c|}{ Classe social } \\
\hline $\begin{array}{c}\text { Femi- } \\
\text { nino }\end{array}$ & $50 \%$ & $\begin{array}{l}\text { até } 25 \\
\text { anos }\end{array}$ & $29,8 \%$ & Norte & $16,8 \%$ & $\begin{array}{l}\text { Até } 1 \\
\text { s.m. }\end{array}$ & $1,3 \%$ & $\begin{array}{l}\text { Analfabeto } \\
\text { / Primário } \\
\text { incompleto }\end{array}$ & $0 \%$ & A1 & $0,5 \%$ \\
\hline $\begin{array}{l}\text { Mas- } \\
\text { culino }\end{array}$ & $50 \%$ & $\begin{array}{c}\text { de } 26 \\
\text { a } 35 \\
\text { anos }\end{array}$ & $26,3 \%$ & Sul & $21,3 \%$ & $\begin{array}{c}\text { de } 1,1 \\
\text { s.m. a } 2 \\
\text { s.m. }\end{array}$ & $\begin{array}{c}19,8 \\
\%\end{array}$ & $\begin{array}{c}\text { Primário } \\
\text { completo / } \\
\text { Ginasial } \\
\text { incompleto }\end{array}$ & $6 \%$ & $\mathrm{~A} 2$ & $6,5 \%$ \\
\hline & & $\begin{array}{c}\text { de } 36 \\
\text { a } 45 \\
\text { anos }\end{array}$ & $22,0 \%$ & Centro & $11,0 \%$ & $\begin{array}{c}\text { de } 2,1 \\
\text { s.m. a } 3 \\
\text { s.m. }\end{array}$ & $\begin{array}{c}27,8 \\
\%\end{array}$ & $\begin{array}{c}\text { Ginasial } \\
\text { completo / } \\
\text { Colegial } \\
\text { incompleto }\end{array}$ & $\begin{array}{l}14 \\
\%\end{array}$ & B1 & $21,0 \%$ \\
\hline & & $\begin{array}{c}\text { de } 46 \\
\text { a } 55 \\
\text { anos }\end{array}$ & $13,0 \%$ & Leste & $37,0 \%$ & $\begin{array}{c}\text { de } 3,1 \\
\text { s.m. a } 5 \\
\text { s.m. }\end{array}$ & $\begin{array}{c}23,0 \\
\%\end{array}$ & $\begin{array}{c}\text { Colegial } \\
\text { completo / } \\
\text { Superior } \\
\text { incompleto }\end{array}$ & $\begin{array}{l}56 \\
\%\end{array}$ & B2 & $31,0 \%$ \\
\hline & & $\begin{array}{c}\text { acima } \\
\text { de } 55 \\
\text { anos } \\
\end{array}$ & $9,0 \%$ & Oeste & $14,0 \%$ & $\begin{array}{c}\text { de } 5,1 \\
\text { s.m. a } 8 \\
\text { s.m. }\end{array}$ & $9,8 \%$ & $\begin{array}{l}\text { Superior } \\
\text { completo }\end{array}$ & $\begin{array}{l}21 \\
\%\end{array}$ & $\mathrm{C}$ & $27,5 \%$ \\
\hline & & & & & & $\begin{array}{c}\text { de } 8,1 \\
\text { sm a } 10 \\
\text { s.m. }\end{array}$ & $3,5 \%$ & $\begin{array}{c}\text { Pós- } \\
\text { Graduação }\end{array}$ & $3 \%$ & $\mathrm{D}$ & $11,3 \%$ \\
\hline & & & & & & $\begin{array}{c}\text { de } 10,1 \\
\text { s.m. a } \\
15 \text { s.m. }\end{array}$ & $3,8 \%$ & & & $E$ & $2,3 \%$ \\
\hline & & & & & & $\begin{array}{c}\text { de } 15,1 \\
\text { s.m. a } \\
20 \text { s.m. }\end{array}$ & $0,8 \%$ & & & & $100,0 \%$ \\
\hline & & & & & & $\begin{array}{c}\text { Acima } \\
\text { de } 20 \\
\text { s.m. }\end{array}$ & $0,8 \%$ & & & & \\
\hline & & & & & & $\begin{array}{c}\text { Não } \\
\text { respon- } \\
\text { deu }\end{array}$ & $9,8 \%$ & & & & \\
\hline
\end{tabular}


A maioria dos participantes tem idade entre 26 e 35 anos (26,3\%), residem na Zona Leste de São Paulo (37\%), tem renda mensal familiar entre $\mathrm{R} \$ 1.381$ a $\mathrm{R} \$ 2.070$, possui colegial completo/superior incompleto $(56 \%)$ e pertence à classe B2 (segundo o Critério de Classificação Econômica Brasil).

\subsection{Análise estatística dos dados}

\subsubsection{Preferências gerais por tipos de promoção}

\subsubsection{Produto de baixo valor - biscoito}

Para verificar a preferência dos respondentes em relação ao formato da promoção no caso do biscoito, serão efetuadas análises descritivas e testes de proporção estatísticos. A Tabela 4 mostra a porcentagem de escolhas feitas por tipo de apresentação da promoção. Nota-se que as opções apresentadas com desconto em reais obtiveram a maior parte das escolhas, com $35,4 \%$, seguido pelo desconto em porcentagem $(34,8 \%)$.

Tabela 4 - Número de escolhas* e intervalo de confiança por tipo de apresentação do produto para biscoito

\begin{tabular}{|l|l|l|}
\hline Forma apresentada & $\begin{array}{l}\text { Número de } \\
\text { escolhas }\end{array}$ & $\begin{array}{l}\text { Porcentagem } \\
\text { de escolhas }(\%)\end{array}$ \\
\hline Desconto em reais & 850 & 35,4 \\
\hline Desconto em porcentagem & 834 & 34,8 \\
\hline Preço cheio & 716 & 29,8 \\
\hline TOTAL & 2.400 & 100 \\
\hline
\end{tabular}

* Cada respondente faz seis escolhas para biscoito, uma para cada situação mostrada. O total de 400 respondentes gera um montante de 2.400 escolhas diferentes para biscoito.

Verificou-se que existe diferença estatística entre as proporções de escolhas de promoções em dinheiro $(35,4 \%)$ e produtos sem promoção $(29,8 \%)$ (intervalo de confiança: [2,4\%; 8,8\%]); e diferença entre a proporção de escolhas de produtos com promoção em porcentagem $(34,8 \%)$ e produtos sem promoção $(29,8 \%)$ (intervalo de confiança: $[1,7 \% ; 8,1 \%])$. 
No entanto, não podemos afirmar que exista diferença estatística entre a proporção de escolhas por promoções em porcentagem e proporção de escolhas por produtos mostrados com o desconto em reais, já que o intervalo de confiança é $[-2,7 \% ; 4,0 \%]$. Assim, nenhuma das formas de desconto se diferencia na preferência dos consumidores.

Ambos os tipos de promoção são preferíveis à opção sem desconto, mas não existe diferenciação entre o desconto em porcentagem e a redução de preço em reais. Isso não está de acordo com H1, que indica que para produtos de baixo valor, os consumidores percebem as promoções de preço apresentadas como desconto em porcentagem como mais vantajosas do que as mostradas em reais. No contexto brasileiro, para produtos de baixo valor, o consumidor é aparentemente indiferente para forma de promoção.

\subsubsection{Produto de alto valor - notebook}

No caso do produto de alto valor, a Tabela 5 mostra a porcentagem de escolhas por tipo de apresentação da promoção. Novamente, a maior parte das escolhas direcionou-se para o desconto em reais $(37,4 \%)$, seguido pelo desconto em porcentagem $(33,3 \%)$.

Tabela 5 - Número de escolhas* por tipo de apresentação do produto para notebook

\begin{tabular}{|l|l|l|}
\hline Forma apresentada & $\begin{array}{l}\text { Número de } \\
\text { escolhas }\end{array}$ & $\begin{array}{l}\text { Porcentagem de } \\
\text { escolhas }(\mathbf{\%})\end{array}$ \\
\hline Desconto em reais & 897 & 37,4 \\
\hline Desconto em porcentagem & 799 & 33,3 \\
\hline Preço cheio & 704 & 29,3 \\
\hline TOTAL & 2.400 & 100 \\
\hline
\end{tabular}

* Cada respondente faz seis escolhas para notebook, uma para cada situação mostrada. O total de 400 respondentes gera um montante de 2.400 escolhas diferentes para notebook.

Ao calcular o intervalo de confiança para diferença entre proporções amostrais, nota-se diferença variação estatística entre todas as opções: proporção de escolhas por produtos com desconto em porcentagem $(33,3 \%)$ e reais $(37,4 \%)$ (intervalo de confiança: $[0,7 \% ; 7,4 \%]$ ); proporção de escolhas por produtos com desconto em porcentagem $(33,3 \%)$ e sem desconto $(29,3 \%)$ (intervalo de confiança: $[0,8 \% ; 7,1 \%]$ ); e proporção de escolhas por produtos com desconto em reais $(37,4 \%)$ e sem desconto $(29,3 \%)$ (intervalo de confiança: [4,8\%; 11,3\%]). 
Neste caso, a promoção no formato "De $\mathrm{R} \$ \mathrm{x}$ por $\mathrm{R} \$ \mathrm{y}$ ” foi mais atrativa do que a promoção mostrada em porcentagem, que por sua vez foi melhor do que o produto mostrado com o preço cheio. Isto está de acordo com $\mathrm{H} 2$, que indica que nos produtos de alto valor, os consumidores perceberão as promoções de preço apresentadas em reais como mais vantajosas do que as mostradas em desconto.

\subsubsection{Impacto da promoção na preferência de marca}

A terceira hipótese refere-se ao impacto da promoção sobre a preferência de marca. Para comprová-la, serão realizadas algumas análises descritivas por marca, para o produto de baixo valor e para o produto de alto valor. Posteriormente, será feita uma análise de regressão logística multinomial visando verificar os efeitos causados.

\subsubsection{Produto de baixo valor - biscoito}

A marca Passatempo teve 212 escolhas pelo produto sem desconto. Com a promoção em porcentagem, este número saltou para 251, apresentando um crescimento de 18,4\%. Já com a promoção em porcentagem, o número de escolhas passa a ser 270 , representando um aumento de $27,4 \%$ sobre as escolhas feitas pelo produto sem desconto. Neste caso, o desconto apresentado em reais refletiu um aumento considerável em relação ao preço sem desconto. $\mathrm{O}$ Gráfico 1 mostra estes números:

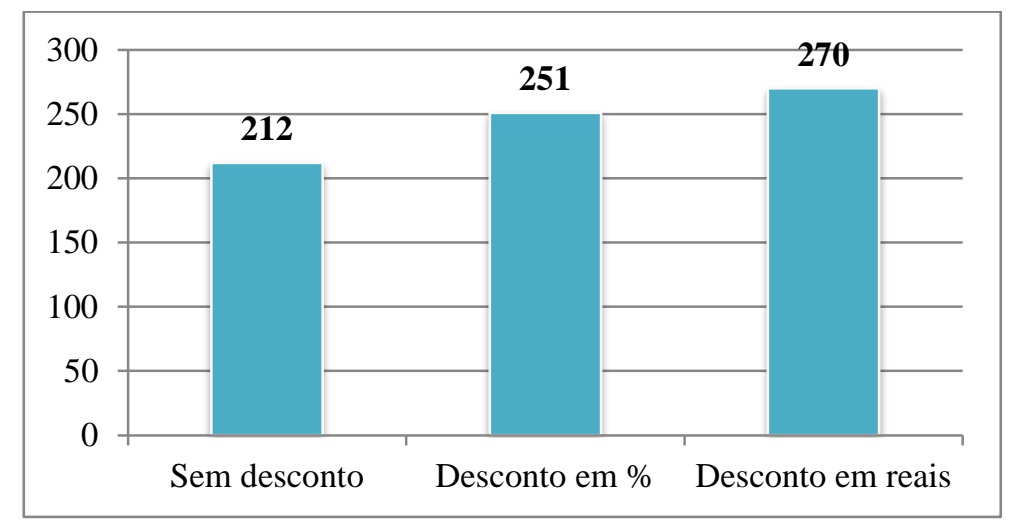

Gráfico 1 - Número de escolhas da marca Passatempo nas três situações apresentadas

No caso da marca Bono, o desconto em porcentagem teve impacto praticamente igual ao desconto em reais. O preço cheio obteve 241 escolhas; o valor com desconto em porcentagem 
teve 268 escolhas, um incremento de 11,2\%; e o preço com desconto em reais foi escolhido 266 vezes, um aumento de 10,4\% sobre as opções feitas pelo preço cheio. O Gráfico 2 ilustra estes dados:

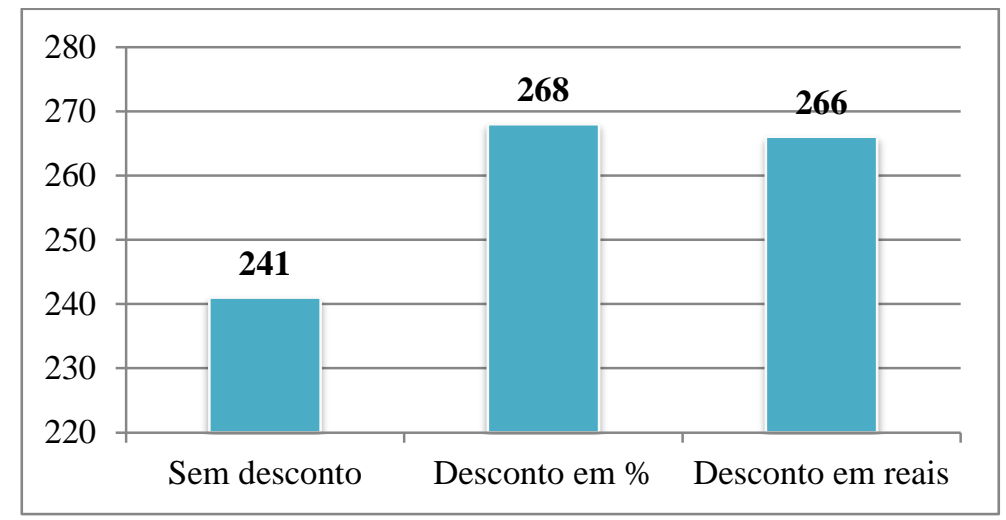

Gráfico 2 - Número de escolhas da marca Bono nas três situações apresentadas

Já a marca Trakinas teve 263 escolhas pelo produto sem desconto. O desconto em porcentagem aumentou estas preferências para 315, representando um incremento de 19,8\% sobre as opções feitas pelo preço cheio; e o desconto em reais provocou o aumento do número de seleções para 314, representando um incremento de 19,4\% sobre o preço cheio. O Gráfico 3 ilustra estas informações:

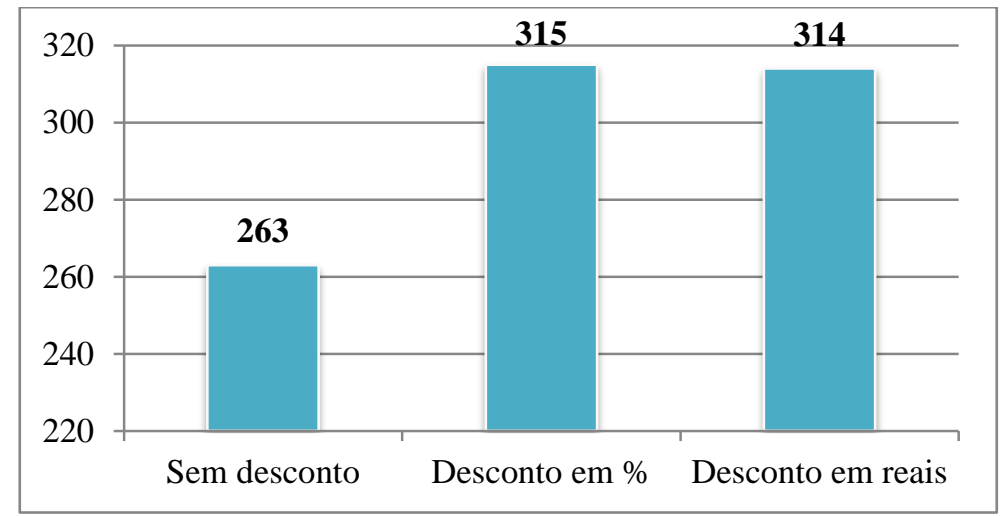

Gráfico 3 - Número de escolhas da marca Trakinas nas três situações apresentadas

Portanto, ao analisar as três marcas, percebemos que o desconto em reais e o desconto em porcentagem geram um impacto muito parecido nas escolhas dos consumidores, especialmente nos casos das marcas Bono e Trakinas.

Ao realizarmos uma análise agregada das promoções (número de opções feitas pela promoção mostrada em porcentagem ou reais em relação às realizadas pelo produto sem desconto), 
verifica-se que o desconto (tanto em porcentagem quanto em reais) na marca Passatempo gera um aumento de $146 \%$ das escolhas em relação às relacionadas ao preço cheio; na marca Bono, de 122\%; e na marca Trakinas, de 139\%. Deste modo, até o momento pode-se confirmar a hipótese 3 (H3), já que os descontos têm impactos diferentes nas marcas analisadas de biscoito.

\subsubsection{Produto de alto valor - notebook}

De acordo com o Gráfico 4, a marca Dell obteve 229 escolhas quando foi apresentada com o preço cheio, 252 preferências com desconto em porcentagem (aumento de 10\%) e 296 opções pelo desconto em reais (aumento de 29,3\%).

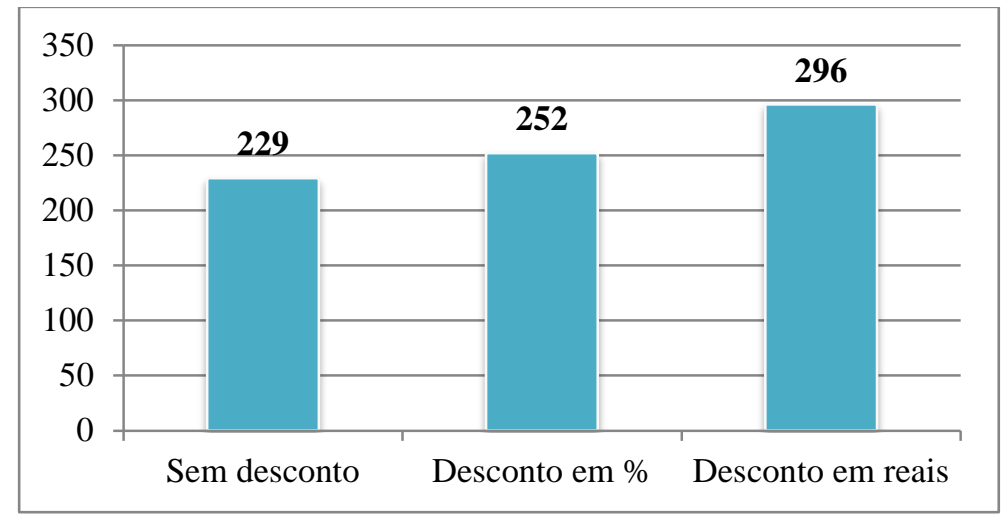

Gráfico 4 - Número de escolhas da marca Dell nas três situações apresentadas

A marca Samsung também foi mais escolhida quando apresentada com uma promoção em reais. Na opção da marca sem desconto algum ocorreu 298 escolhas; a com desconto em porcentagem, 331 (incremento de 11,1\%); e com desconto em reais, 368 (aumento de 23,5\%). O Gráfico 5 mostra as preferências por tipo de apresentação:

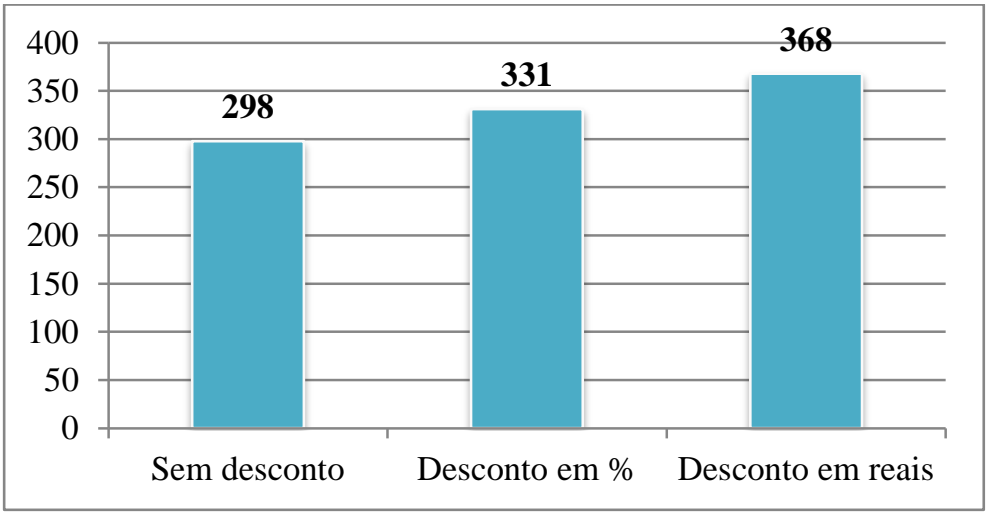

Gráfico 5 - Número de escolhas da marca Samsung nas três situações apresentadas 
A marca LG sofreu efeito semelhante às outras marcas. Os consumidores escolheram 177 vezes a opção sem desconto; 216 vezes a que oferecia desconto em porcentagem (aumento de $22 \%$ ); e 233 vezes a marca com desconto em reais (aumento de 31,6\%). O Gráfico 6 mostra as escolhas por tipo de apresentação:

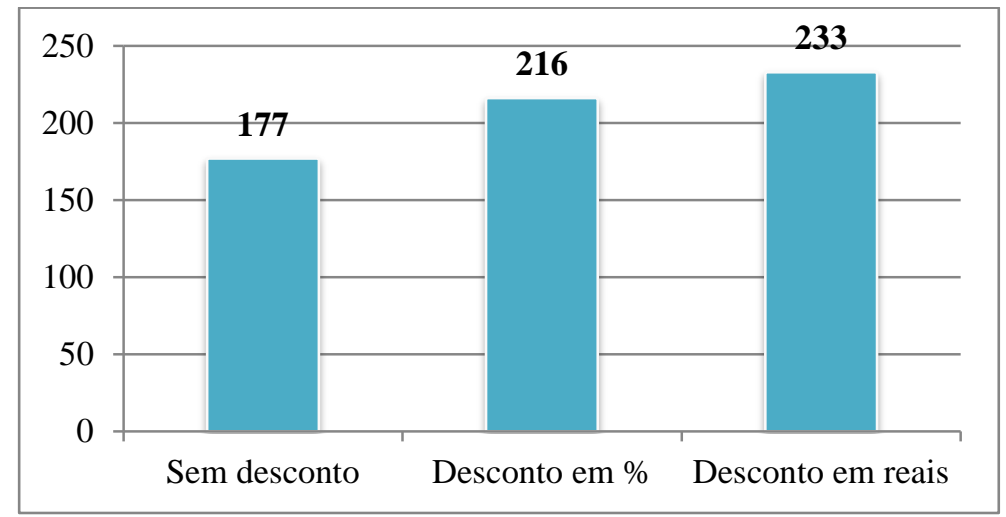

Gráfico 6- Número de escolhas da marca LG nas três situações apresentadas

Quando analisadas conjuntamente, as promoções geraram um aumento de $139 \%$ nas opções pela Dell com promoção (em reais ou em porcentagem) em relação às escolhas feitas pela marca sem desconto; um aumento de $135 \%$ na Samsung em relação à marca sem desconto; e um aumento de $154 \%$ em relação às escolhas feitas pela LG sem desconto. Aparentemente, as promoções tiveram efeito diferente entre marcas, porém no geral com maior magnitude do que nos produtos de baixo valor. Deste modo, pode-se confirmar a H3, já que os descontos têm impactos diferentes nas marcas analisadas de notebook.

A apresentação do produto com desconto também teve percepções distintas nas categorias avaliadas. O impacto dos descontos dados ao produto de baixo valor foi um pouco menor se comparados ao produto de alto valor, ou seja, o desconto neste produto tende a gerar mudanças um pouco maiores nas preferências dos consumidores. Este impacto também variou por marca de biscoito e notebook, o que nos permite aceitar $\mathrm{H} 3$.

\subsubsection{Preferências de acordo com a faixa de renda}

Para testar se a renda afeta o padrão de preferência de promoção, serão efetuadas as seguintes análises: teste de diferença de proporções dentro da amostra, teste de diferença de proporções entre populações diferentes; , análise de correspondência binária, e outras análises descritivas. A classificação de classes sociais se deu com base no critério do PNAD/IBGE, com alguns 
cortes adicionais (de 5,1 a 8 salários mínimos, de 10,1 a 15 e de 15,1 a 20). A Tabela 6 mostra as faixas de renda e o número de respondentes por classe social:

Tabela 6 - Número de respondentes por faixa de renda mensal familiar

\begin{tabular}{|c|c|c|}
\hline $\begin{array}{l}\text { Número de salários } \\
\text { mínimos (SM) }\end{array}$ & $\begin{array}{l}\text { Valor em reais } \\
\text { (base: salário mínimo de } \\
\text { R } 690 \text { de 2013) }\end{array}$ & $\begin{array}{ll}\begin{array}{l}\text { Número } \\
\text { respondentes }\end{array} & \text { de } \\
\text { amostra } & \text { na } \\
\end{array}$ \\
\hline Até $1 \mathrm{SM}$ & Até R\$ 690 & 5 \\
\hline De 1,1 a 2 SM & De $R \$ 691$ a $R \$ 1.380$ & 79 \\
\hline De 2,1 a 3 SM & De $R \$ 1.381$ a $R \$ 2.070$ & 111 \\
\hline De 3,1 a 5 SM & De $\mathrm{R} \$ 2.071$ a $\mathrm{R} \$ 3.450$ & 92 \\
\hline De 5,1 a 8 SM & De $R \$ 3.451$ a $R \$ 5.520$ & 39 \\
\hline De 8,1 a $10 \mathrm{SM}$ & De R\$ 5.521 a R\$ 6.900 & 14 \\
\hline De 10,1 a 15 SM & De R\$ 6.901 a R \$ 10.350 & 15 \\
\hline De 15,1 a $20 \mathrm{SM}$ & De $R \$ 10.351$ a $R \$ 13.800$ & 3 \\
\hline Acima de $20 \mathrm{SM}$ & Acima de $\mathrm{R} \$ 13.801$ & 3 \\
\hline Não respondeu & - & 39 \\
\hline
\end{tabular}

Para efetuar a análise optou-se por dividir os respondentes em dois grandes grupos, denominados 'baixa renda' e 'alta renda'. Não existe consenso na academia sobre o que constituiria a baixa renda. Prado (2008) faz uma revisão teórica de estudos que abordam este tema e analisa as diferentes definições para o termo "baixa renda". As diferentes classificações usam como critério a quantidade de salários mínimos recebidas; o instrumento de classificação econômica Critério Brasil; e a própria compreensão de cada autor acerca do que seria baixa renda. De acordo com estas definições, podem ser consideradas desde famílias sem renda mensal até famílias com renda de até dez salários mínimos por mês, o que constitui um grupo muito heterogêneo. A autora deste estudo então trabalha com a definição de que a baixa renda é composta por famílias com rendimentos mensais até cinco salários mínimos, em concordância com o governo brasileiro.

Portanto, foi utilizado o mesmo critério para separar os dois grupos. O grupo baixa renda inclui indivíduos com renda até cinco salários mínimos (renda mensal familiar de até R\$ 3.450 ), totalizando 287 pessoas; e o grupo alta renda inclui indivíduos com renda a partir de $\mathrm{R} \$ 3.451$ mensais, totalizando 74 respondentes. 


\subsubsection{Produto de baixo valor - biscoito}

Ao analisar a Tabela 7, nota-se que a alta renda fez um maior número de escolhas pelo produto com desconto $(72,3 \%)$, em oposição aos $69,8 \%$ de escolhas realizadas da baixa renda. O grupo de alta renda fez a maior parte de suas escolhas buscando o desconto em reais $(38,1 \%)$; e $34,2 \%$ das opções referentes ao desconto em porcentagem. Já o grupo de baixa renda preferiu o desconto em porcentagem $(35,2 \%)$, seguido pelo desconto em reais $(34,6 \%)$.

Tabela 7 - Contagem do número de escolhas* feitas por renda e tipo de desconto para biscoito

\begin{tabular}{|l|l|l|l|l|l|}
\hline & & $\begin{array}{l}\text { Baixa } \\
\text { renda }\end{array}$ & $\begin{array}{l}\text { Porcentagem } \\
\text { Baixa renda }\end{array}$ & $\begin{array}{l}\text { Alta } \\
\text { renda }\end{array}$ & $\begin{array}{l}\text { Porcentagem } \\
\text { Alta renda }\end{array}$ \\
\hline \multirow{3}{*}{ Apresentação } & Em reais & 596 & $34,6 \%$ & 169 & $38,1 \%$ \\
\cline { 2 - 6 } & $\begin{array}{l}\text { Em } \\
\text { porcentagem }\end{array}$ & 606 & $35,2 \%$ & 152 & $34,2 \%$ \\
\cline { 2 - 6 } & $\begin{array}{l}\text { Sem } \\
\text { promoção }\end{array}$ & 520 & $30,2 \%$ & 123 & $27,7 \%$ \\
\hline & TOTAL & 1.722 & & 444 & \\
\hline
\end{tabular}

* Cada respondente faz seis escolhas para biscoito, uma para cada situação mostrada. O total de 361 respondentes (excluindo os que não declararam faixa de renda) gera um montante de 2.166 escolhas diferentes para biscoito.

Para verificar se existe associação entre a forma como o produto é apresentado e a renda familiar, foi efetuado um teste qui-quadrado no software SPSS. Testou-se a independência das variáveis "apresentação do desconto" com "grupo de alta renda e baixa renda". As hipóteses do teste, para o produto de baixo valor, são as seguintes:

$\mathbf{H}_{\mathrm{A}}$ : A preferência pelo tipo de apresentação independe da faixa de renda.

$\mathbf{H}_{\mathrm{B}}$ : A preferência pelo tipo de apresentação depende da faixa de renda.

O valor-p (Pearson Chi-Square) encontrado foi de 0,364. Considerando uma significância de $5 \%$, não podemos rejeitar $\mathbf{H}_{\mathrm{A}}$ já que $\alpha<$ p-valor. Mesmo efetuando o teste qui-quadrado com todas as faixas de renda, o p-valor é igual a 0,998. Portanto, não se pode afirmar que haja relação entre a forma de apresentação do produto e a faixa de renda. Isso está de acordo com a H4, ao ressaltar que a renda não deveria afetar o padrão de escolhas.

Para entender se existe desigualdade entre as proporções de escolha, serão realizados dois tipos de testes: diferença de proporções dentro da mesma amostra, visando esclarecer se as formas de apresentação mudam entre si dentro dos grupos de alta e baixa renda, por meio de 
intervalos de confiança; e teste de hipóteses de diferença de proporções entre populações diferentes.

A Tabela 8, apresentada a seguir, mostra os intervalos de confiança de 95\% calculados para as diferenças na forma de apresentação dos produtos que fizeram parte da relação que integrou o questionário:

Tabela 8 - Intervalos de confiança calculados para as diferenças de proporção de escolhas pela forma de apresentação dentro da amostra para biscoito

\begin{tabular}{|l|l|l|}
\hline & $\begin{array}{l}\text { Baixa } \\
\text { renda }\end{array}$ & $\begin{array}{l}\text { Alta } \\
\text { renda }\end{array}$ \\
\hline Desconto em dinheiro e em porcentagem & & \\
\hline Diferença entre proporções & $-1 \%$ & $4 \%$ \\
\hline Intervalo de Confiança (+) $=$ & $3 \%$ & $12 \%$ \\
\hline Intervalo de Confiança (-) = & $-5 \%$ & $-4 \%$ \\
\hline & & \\
\hline Desconto em porcentagem e preço cheio & & \\
\hline Diferença entre proporções & $5 \%$ & $7 \%$ \\
\hline Intervalo de Confiança (+) $=$ & $9 \%$ & $14 \%$ \\
\hline Intervalo de Confiança (-) $=$ & $1 \%$ & $-1 \%$ \\
\hline & & \\
\hline Desconto em dinheiro e preço cheio & & \\
\hline Diferença entre proporções & $4 \%$ & $10 \%$ \\
\hline Intervalo de Confiança (+) $=$ & $8 \%$ & $18 \%$ \\
\hline Intervalo de Confiança (-) $=$ & $1 \%$ & $3 \%$ \\
\hline
\end{tabular}

Dentro do grupo de baixa renda existe diferença de proporção entre as escolhas pelo desconto em porcentagem e produto com preço cheio; e desconto em dinheiro e preço cheio. Ambas as formas de desconto se sobressaem sobre o produto sem desconto, porém não há distinção entre elas. Já dentro do grupo de alta renda, apenas o desconto em dinheiro se diferencia do produto sem promoção; o desconto em porcentagem não se distingue do produto sem desconto.

A próxima análise refere-se ao teste de hipóteses entre diferenças de proporções das amostras (no caso, consideraremos uma amostra de baixa renda e outra de alta renda). Serão testadas as variações de proporções de escolhas da forma de apresentação entre alta renda e baixa renda. Por exemplo, queremos saber se a preferência da alta renda de $38,1 \%$ pela promoção mostrada em reais é realmente maior do que os $34,6 \%$ da baixa renda. 
As hipóteses referentes a este teste são as seguintes:

$\mathbf{H}_{\mathrm{A}}: \mathrm{p}_{\text {alta renda }} \leq \mathrm{p}_{\text {baixa renda. }}$
$\mathbf{H}_{\mathrm{B}}: \mathrm{p}_{\text {alta renda }}>\mathrm{p}_{\text {baixa renda. }}$

Serão testadas as seguintes diferenças: proporção de escolhas pelo desconto em reais tanto na alta como na baixa renda; proporção de escolhas pelo desconto em porcentagem nas rendas alta e baixa, e proporção de escolhas pelo preço cheio das duas categorias de renda (alta e baixa).

A regra de decisão para os testes obedecerá ao seguinte critério: se o z calculado < z crítico, não rejeitaremos a $\mathrm{H}_{\mathrm{A}}$; caso contrário, abdicaremos da $\mathrm{H}_{\mathrm{A}}$. $\mathrm{O} \mathrm{Z}$ crítico adotado é 1,645 , com erro de $5 \%$.

Após efetuar os testes de hipóteses, não podemos rejeitar a hipótese A para a diferença de desconto em reais para alta e baixa renda, desconto em porcentagem para alta e baixa renda e produto sem promoção. Não podemos afirmar que, em termos populacionais, a alta renda tenha maior preferência por descontos (tanto em porcentagem quanto em reais) do que a baixa renda; ou que os $38,1 \%$ de preferência pelo desconto em reais da alta renda seja maior em relação aos $34,6 \%$ de preferência pelo desconto em reais da baixa renda.

Para completar a avaliação por marca, renda e forma de apresentação, tentou-se utilizar a análise de correspondência, técnica que permite analisar dados não métricos. No entanto, a análise o exame do qui-quadrado entre as opções de escolha (marca combinada com o desconto, por exemplo, Passatempo com desconto em porcentagem, Passatempo com desconto em reais e assim por diante, totalizando as nove opções) e as faixas de renda mostra que não existe relação entre as variáveis ( $\mathrm{p}$-valor de 0,684 ) não permitiu realizar a análise de correspondência.

\subsubsection{Produto de alto valor - notebook}

Ao analisar a Tabela 9, nota-se que os grupos tanto de alta renda quanto de baixa renda tiveram comportamento similar, preferindo os descontos apresentados pelas marcas sob a forma de reais. 
Tabela 9 - Contagem do número de escolhas* feitas por renda e tipo de desconto para notebook

\begin{tabular}{|l|l|l|l|l|l|}
\hline & & $\begin{array}{l}\text { Baixa } \\
\text { renda }\end{array}$ & $\begin{array}{l}\text { Porcentagem } \\
\text { Baixa renda }\end{array}$ & $\begin{array}{l}\text { Alta } \\
\text { renda }\end{array}$ & $\begin{array}{l}\text { Porcentagem } \\
\text { Alta renda }\end{array}$ \\
\hline \multirow{4}{*}{ Apresentação } & Em reais & 634 & $36,8 \%$ & 167 & $37,6 \%$ \\
\cline { 2 - 6 } & $\begin{array}{l}\text { Em } \\
\text { porcentagem }\end{array}$ & 570 & $33,1 \%$ & 157 & $35,4 \%$ \\
\cline { 2 - 6 } & $\begin{array}{l}\text { Sem } \\
\text { promoção }\end{array}$ & 518 & $30,1 \%$ & 120 & $27,0 \%$ \\
\cline { 2 - 6 } & TOTAL & 1.722 & $100 \%$ & 444 & $100 \%$ \\
\hline
\end{tabular}

* Cada respondente faz seis escolhas para o notebook, uma para cada situação mostrada. O total de 361 respondentes (excluindo os que não declararam faixa de renda) gera um montante de 2.166 escolhas diferentes para notebook.

O teste qui-quadrado confirma que não existe associação entre os grupos de renda e preferência pelo tipo de desconto (p-valor igual a 0,424). Efetuando o teste com todas as faixas de renda, o p-valor é igual a 0,866, ou seja, não existe relação entre as faixas de renda e a preferência pelo tipo de desconto. Isso está de acordo com a H4, que pontua que a renda não deveria afetar o padrão de escolhas.

Para compreender se há disparidade entre as proporções de escolha, serão realizados dois tipos de testes: diferença de proporções dentro da mesma amostra, para avaliar se as formas de apresentação diferenciam-se entre si dentro dos grupos de alta e baixa renda, por meio de intervalos de confiança; e teste de hipóteses de proporções entre populações diferentes, no caso, alta renda e baixa renda.

A Tabela 10 mostra os intervalos de confiança de $95 \%$ calculados para as diferenças na forma de apresentação: 
Tabela 10 - Intervalos de confiança calculados para as diferenças de proporção de escolhas pela forma de apresentação dentro da amostra para notebook

\begin{tabular}{|l|l|l|}
\hline & $\begin{array}{l}\text { Baixa } \\
\text { renda }\end{array}$ & $\begin{array}{l}\text { Alta } \\
\text { renda }\end{array}$ \\
\hline Desconto em dinheiro e em porcentagem & & \\
\hline Diferença entre proporções & $4 \%$ & $2 \%$ \\
\hline Intervalo de Confiança (+) $=$ & $8 \%$ & $10 \%$ \\
\hline Intervalo de Confiança (-) = & $-0,2 \%$ & $-6 \%$ \\
\hline & & \\
\hline Desconto em porcentagem e preço cheio & & \\
\hline Diferença entre proporções & $3 \%$ & $8 \%$ \\
\hline Intervalo de Confiança (+) $=$ & $7 \%$ & $16 \%$ \\
\hline Intervalo de Confiança (-) $=$ & $-1 \%$ & $1 \%$ \\
\hline & & \\
\hline Desconto em dinheiro e preço cheio & & \\
\hline Diferença entre proporções & $7 \%$ & $11 \%$ \\
\hline Intervalo de Confiança (+) $=$ & $11 \%$ & $18 \%$ \\
\hline Intervalo de Confiança (-) $=$ & $3 \%$ & $3 \%$ \\
\hline
\end{tabular}

Nota-se que, dentro da alta renda, existe diferença estatística entre a proporção de escolhas pela forma de apresentação do produto com desconto em porcentagem versus o produto sem desconto; e entre a proporção de escolhas pelo desconto em reais e o preço cheio. Já não se pode afirmar que exista diferença estatística entre a proporção de escolhas feitas pelo desconto em porcentagem e em reais. Porém, as opções com desconto claramente se destacam da opção do preço cheio.

A avaliação das proporções dentro da baixa renda mostrou que existe diferença estatística apenas entre a proporção de escolhas feitas pelo desconto em dinheiro e o preço cheio. $\mathrm{Ou}$ seja, a promoção em porcentagem não se diferencia da apresentação sem promoção.

Com relação à análise de teste de hipóteses das diferenças de proporções entre amostras (no caso, consideraremos uma amostra de baixa renda e outra de alta renda) não nos permite rejeitar a hipótese $\mathrm{A}$ ( $\mathrm{p}_{\text {alta renda }} \leq \mathrm{p}$ baixa renda). Não podemos, portanto, afirmar que em termos populacionais a alta renda tenha maior preferência por descontos (tanto em porcentagem quanto em reais) do que a baixa renda.

Para completar o exame de renda, marca e forma de apresentação, será efetuada uma análise de correspondência. Neste caso serão utilizadas as opções de escolha (marca combinada com 
o desconto, por exemplo: Dell com desconto em porcentagem, Dell com desconto em reais e assim por diante, até totalizar as nove opções), juntamente com a renda familiar. Como não é possível montar o mapa perceptual com a classificação de apenas duas faixas de renda (alta e baixa renda), optou-se por trabalhar com as sete faixas de renda. A ideia da análise é verificar se existe relação entre as opções de escolha e a classe social.

A análise do qui-quadrado realizada com as variáveis "renda familiar" e "opções de escolha" revela um p-valor baixo, de 0,000, o que nos permite afirmar que existe relação entre as duas variáveis e isso possibilita continuar com a análise de correspondência.

A Tabela 11 mostra que uma solução com duas dimensões explica 93,4\% da inércia, ou seja, é a quantidade de informação restituída pelos dois eixos. Optou-se por trabalhar com duas dimensões para simplificar a análise gráfica.

Tabela 11 - Teste Qui-quadrado para as variáveis "renda familiar" e "opções de escolha" e sumário da análise de correspondência

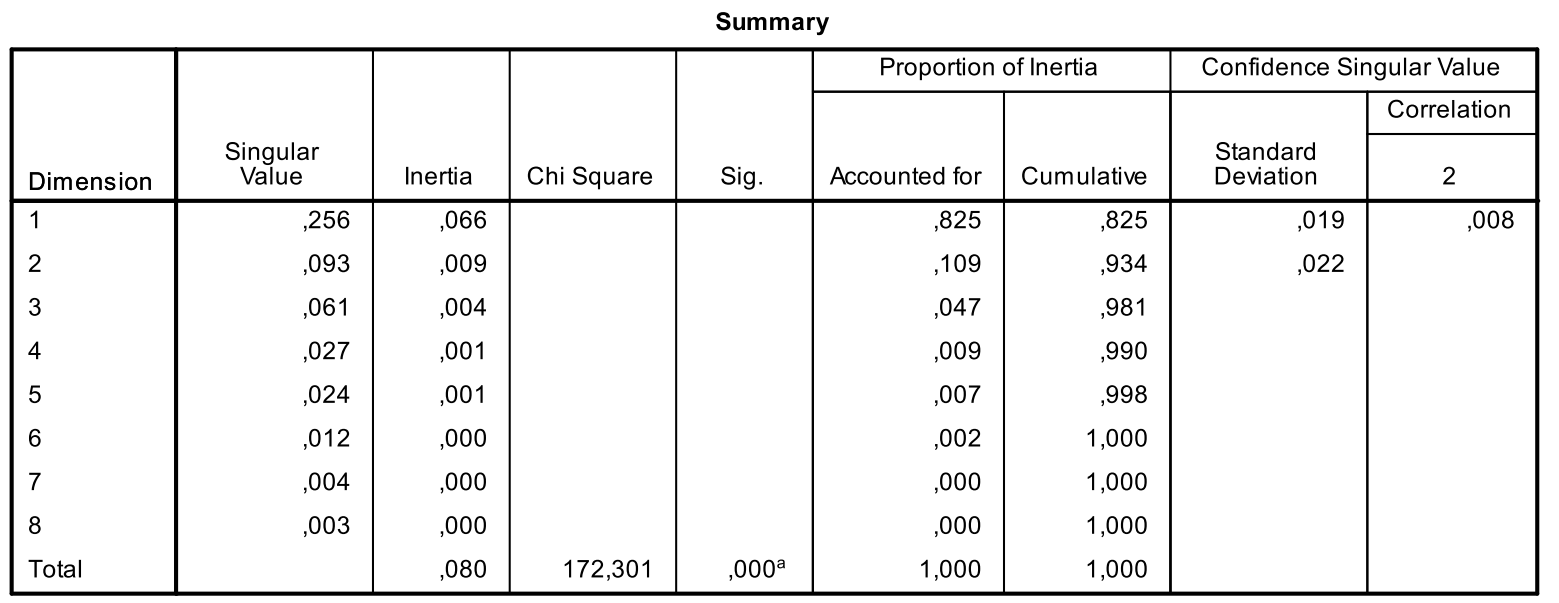

a. 64 degrees of freedom

De acordo com a Tabela 12, a análise das linhas indica que a Samsung mostrada com desconto em reais é a com maior frequência relativa (massa) no conjunto de dados estudado, seguido por Samsung com promoção em porcentagem. A análise das linhas também mostra que na dimensão 1, com base na contribuição relativa à inércia, a categoria que mais determina a identificação das dimensões da análise é a marca Dell apresentada com desconto em dinheiro; e na dimensão 2, a categoria preponderante é a marca LG sem desconto. 
Tabela 12 - Panorama dos pontos da linha

Overview Row Points ${ }^{a}$

\begin{tabular}{|c|c|c|c|c|c|c|c|c|c|}
\hline \multirow[b]{3}{*}{ Opção } & \multirow[b]{3}{*}{ Mass } & \multicolumn{2}{|c|}{ Score in Dimension } & \multirow[b]{3}{*}{ Inertia } & \multicolumn{5}{|c|}{ Contribution } \\
\hline & & & & & \multicolumn{2}{|c|}{ Of Point to Inertia of Dimension } & \multicolumn{3}{|c|}{ Of Dimension to Inertia of Point } \\
\hline & & 1 & 2 & & 1 & 2 & 1 & 2 & Total \\
\hline Dell\% & ,104 &,- 738 & 023 & 015 & ,221 & ,001 & ,962 & ,000 & 9,962 \\
\hline Dell\$ & , 120 &,- 707 &,- 019 &, 016 & ,234 &, 000 &, 967 &, 000 & ,967 \\
\hline DellPC & ,095 &,- 744 &,- 203 & 016 & ,205 &, 042 &, 866 &, 023 & 889 \\
\hline Sams \% & ,139 & ,236 & ,309 &, 003 & 030 & ,143 &, 603 & ,375 & ,978 \\
\hline Sams\$ & , 152 & , 199 & ,313 & ,003 &, 024 & , 161 &, 489 & ,438 & ,927 \\
\hline SamsPC & ,124 & ,393 & ,283 & ,007 & 074 & , 106 &, 715 & , 134 & 849 \\
\hline LG\% & ,092 & ,480 &,- 318 & ,007 & ,083 & , 101 & ,812 & , 130 & ,942 \\
\hline LG\$ & ,097 & ,443 &,- 265 & ,006 & 074 &, 074 &, 799 & , 104 & ,904 \\
\hline LCPC &, 076 & ,428 &,- 675 &, 007 & 054 & ,373 &, 515 & ,466 & ,981 \\
\hline Active Total & 1,000 & & & 080 & 1,000 & 1,000 & & & \\
\hline
\end{tabular}

a. Symmetrical normalization

Já a análise das colunas (Tabela 13) sinaliza que a faixa de renda 3 ( $R$ \$ 1.381 a $R$ \$ 2.070) tem maior massa. A faixa de renda $2(\mathrm{R} \$ 691$ a $\mathrm{R} \$ 1.380)$ mostra-se preponderante na dimensão 1 com base na contribuição relativa da inércia, e a faixa de renda 1 (até $R \$$ 690) é preponderante para a dimensão 2 .

Tabela 13 - Panorama dos pontos da coluna

Overview Column Points ${ }^{a}$

\begin{tabular}{|c|c|c|c|c|c|c|c|c|c|}
\hline \multirow[b]{3}{*}{ V31 } & \multirow[b]{3}{*}{ Mass } & \multicolumn{2}{|c|}{ Score in Dimension } & \multirow[b]{3}{*}{ Inertia } & \multicolumn{5}{|c|}{ Contribution } \\
\hline & & & & & \multicolumn{2}{|c|}{ Of Point to Inertia of Dimension } & \multicolumn{3}{|c|}{ Of Dimension to Inertia of Point } \\
\hline & & 1 & 2 & & 1 & 2 & 1 & 2 & Total \\
\hline 1 & ,014 & 1,485 & $-1,409$ & ,010 & 119 & ,296 & ,747 & ,244 & 991 \\
\hline 2 & ,219 & 677 & 218 & 027 & ,391 & 112 & ,957 & ,036 & ,993 \\
\hline 3 & ,307 & ,162 &,- 176 &, 003 & 031 & ,102 & ,649 & ,278 & ,928 \\
\hline 4 & ,255 &,- 446 &,- 008 & ,013 & 198 &, 000 & ,978 &, 000 & 978 \\
\hline 5 & 108 &,- 538 &,- 010 &, 009 & ,122 & ,000 & ,905 &, 000 & ,905 \\
\hline 6 & ,039 &,- 233 & ,704 &, 003 & ,008 & 207 & ,202 & ,671 & 873 \\
\hline 7 & ,042 &,- 789 & ,088 & ,008 & 101 & ,003 & ,815 &, 004 & 819 \\
\hline 8 & ,008 &,- 896 & $-1,365$ & ,004 & ,026 & 166 & ,426 & ,359 & ,786 \\
\hline 9 & ,008 & ,322 & 1,131 &, 002 &, 003 & 114 & ,102 & ,457 & ,559 \\
\hline Active Total & 1,000 & & & ,080 & 1,000 & 1,000 & & & \\
\hline
\end{tabular}

a. Symmetrical normalization

No mapa perceptual a seguir (Gráfico 7), nota-se grande associação entre as faixas de renda 4, 5 e 7 (respectivamente, de $R \$ 2.071$ a $R \$ 3.450$; de $R \$ 3.451$ a $R \$ 5.520$; e $R \$ 6.901$ a $R \$$ 10.350) com a marca Dell (principalmente as alternativas com desconto); da marca LG com 
desconto em reais e porcentagem e da marca Samsung com todas as formas de apresentação com as faixas 2 (de $R$ \$ 691 a $R \$ 1.390)$ e $3(R \$ 1.391$ a $R \$ 2.070)$.

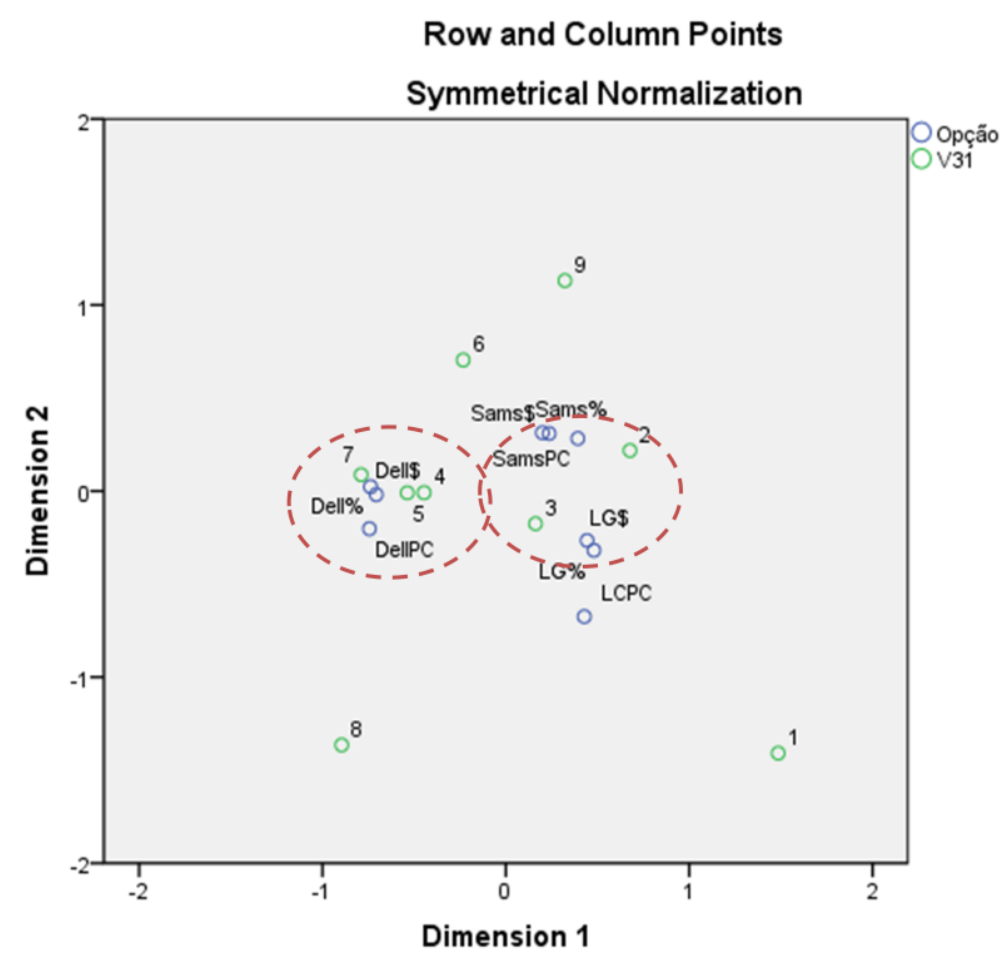

Gráfico 7 - Mapa perceptual para forma de apresentação do notebook e faixa de renda

\subsubsection{Conclusões - produto de baixo valor versus produto de alto valor}

Após efetuar as análises de diferença de proporções, podemos dizer que não existe muita variação entre o comportamento do grupo de alta renda e do grupo de baixa renda. $\mathrm{O}$ percentual de escolhas por opção foi bastante similar entre ambos os grupos.

Para o produto de baixo valor, no grupo de baixa renda houve uma ligeira preferência pelo desconto em porcentagem, e no grupo de maior renda pela dedução em reais. Apenas a redução em reais se diferencia da opção sem desconto no grupo de alta renda; e no grupo de baixa renda, os dois tipos de benefício se destacam do produto sem promoção. Em nenhum dos dois grupos há diferença entre o desconto em reais ou em porcentagem, o que também ocorre na amostra inteira.

No caso do produto de alto valor, ambos os grupos preferem a promoção em reais. Dentro do grupo de alta renda existe diferença entre os dois tipos de promoção e também no produto 
sem desconto; já no grupo de baixa renda, apenas o desconto em reais se diferencia do produto sem promoção. Em ambos os grupos, o desconto em reais não se distingue do desconto em porcentagem.

Embora o grupo de alta renda tenha feito mais opções por produtos com promoção $(72,3 \%$ de escolhas por produtos com promoção na alta renda $v s .69,8 \%$ de escolhas por produtos com promoção para o produto de baixo valor; e $73 \%$ de preferências por produtos com promoção no grupo de alta renda vs. $70 \%$ na baixa renda por produtos com promoção para o produto de alto valor), não podemos afirmar que exista diferença estatística entre estas proporções.

Portanto, não podemos rejeitar a H4, que supõe que a renda não deve afetar o padrão de escolhas. Embora tenha havido uma desigualdade na preferência pelo tipo de desconto no produto de baixo valor (alta renda preferiu o desconto em reais e a baixa renda o desconto em porcentagem), não houve variação estatística nas proporções de escolha entre os grupos. Isso não permite afirmar, por exemplo, que a preferência pelo tipo de promoção em reais do grupo de alta renda é maior do que a do grupo de baixa renda.

\subsubsection{Preferências de acordo com escolaridade}

Visando testar se a escolaridade afeta o padrão de preferência de promoção, serão efetuadas as seguintes análises: teste de diferença de proporções dentro da amostra e entre populações distintas, análise de correspondência binária e outras avaliações descritivas. A Tabela 14 mostra qual foi o número de respondentes por escolaridade:

Tabela 14 - Número de respondentes por faixa de renda mensal familiar

\begin{tabular}{|l|l|}
\hline Escolaridade & Número de respondentes \\
\hline Analfabeto/primário incompleto & 1 \\
\hline Primário completo /Ginasial incompleto & 23 \\
\hline Ginasial completo / Colegial incompleto & 56 \\
\hline Colegial completo / Superior incompleto & 224 \\
\hline Faculdade completo & 83 \\
\hline Pós-graduação & 13 \\
\hline
\end{tabular}

A avaliação deste quesito foi feita a partir da organização dos respondentes em dois grandes grupos, denominados "sem faculdade completa" (pessoas com até o colegial completo e/ou superior incompleto) e "com faculdade completa" (pessoas com faculdade completa e/ou pós- 
graduação). Figueiredo (2002) faz uma divisão similar em seu estudo, separando em grupos de pessoas com baixa escolaridade (até $2^{\circ}$ grau) e alta escolaridade (cursando a faculdade). No caso desta pesquisa, o grupo de baixa escolaridade conta com 304 pessoas e o de alta escolaridade, com 96 indivíduos.

\subsubsection{Produto de baixo valor - biscoito}

Ao analisar a Tabela 15, nota-se que ambos os grupos tiveram uma preferência muito parecida pelos dois tipos de incentivo promocional: a quantidade de escolhas pela promoção em porcentagem é muito próxima ao número de optantes pelo desconto em reais. A Tabela 15 mostra o número de escolhas feitas a partir da forma de apresentação organizadas por grupo de escolaridade:

Tabela 15 - Contagem do número de escolhas" nível de escolaridade e tipo de desconto para biscoito

\begin{tabular}{|l|l|l|l|l|l|}
\hline & & $\begin{array}{l}\text { Sem } \\
\text { faculdade } \\
\text { completa }\end{array}$ & $\begin{array}{l}\text { Porcentagem } \\
\text { sem faculdade } \\
\text { completa }\end{array}$ & $\begin{array}{l}\text { Com } \\
\text { faculdade } \\
\text { completa }\end{array}$ & $\begin{array}{l}\text { Porcentagem } \\
\text { com faculdade } \\
\text { completa }\end{array}$ \\
\hline \multirow{3}{*}{ Apresentação } & Em reais & 646 & $35,4 \%$ & 204 & $35,4 \%$ \\
\cline { 2 - 6 } & $\begin{array}{l}\text { Em } \\
\text { porcentagem }\end{array}$ & 628 & $34,4 \%$ & 206 & $35,8 \%$ \\
\cline { 2 - 6 } & Sem promoção & 550 & $30,2 \%$ & 166 & $28,8 \%$ \\
\cline { 2 - 6 } & TOTAL & 1.824 & $100 \%$ & 576 & $100 \%$ \\
\hline
\end{tabular}

* Cada respondente faz seis escolhas para o biscoito, uma para cada situação mostrada. $\mathrm{O}$ total de 400 respondentes gera um montante de 2.400 escolhas diferentes para biscoito.

De fato, o teste qui-quadrado confirma que não existe relação entre o grupo de escolaridade e a preferência pelo tipo de desconto oferecido pelo produto anunciado (p-valor igual a 0,785, maior do que 0,05$)$.

A verificação se existe ou não diferença entre as proporções de escolha baseou-se em dois tipos de testes: diferença de proporções dentro da mesma amostra por meio de intervalos de confiança para compreender se as formas de apresentação diferenciam-se entre si dentro dos grupos de alta e baixa escolaridade; e teste de hipóteses de diferença de proporções entre populações distintas, no caso, alta e baixa escolaridade. 
A Tabela 16 mostra os intervalos de confiança de 95\%, calculados para as diferenças de proporções de escolhas pela forma de apresentação, para os grupos sem faculdade completa e com faculdade completa:

Tabela 16 - Intervalos de confiança calculados para as diferenças de proporção de escolhas pela forma de apresentação dentro da amostra para biscoito

\begin{tabular}{|l|l|l|}
\hline & $\begin{array}{l}\text { Sem faculdade } \\
\text { completa }\end{array}$ & $\begin{array}{l}\text { Com faculdade } \\
\text { completa }\end{array}$ \\
\hline Desconto em dinheiro e em porcentagem & & \\
\hline Diferença entre proporções & $1 \%$ & $0 \%$ \\
\hline Intervalo de Confiança (+) = & $5 \%$ & $7 \%$ \\
\hline Intervalo de Confiança (-) & $-3 \%$ & $-7 \%$ \\
\hline & & \\
\hline Desconto em porcentagem e preço cheio & & $7 \%$ \\
\hline Diferença entre proporções & $4 \%$ & $13 \%$ \\
\hline Intervalo de Confiança (+) $=$ & $8 \%$ & $0,4 \%$ \\
\hline Intervalo de Confiança (-) & $1 \%$ & \\
\hline & & \\
\hline Desconto em dinheiro e preço cheio & & $7 \%$ \\
\hline Diferença entre proporções & $5 \%$ & $13 \%$ \\
\hline Intervalo de Confiança (+) = & $9 \%$ & $0,1 \%$ \\
\hline Intervalo de Confiança (-) $=$ & $2 \%$ & \\
\hline
\end{tabular}

Ambos os grupos tiveram o mesmo resultado no teste de diferença de proporções. Tanto o desconto em reais quanto o desconto em porcentagem se diferenciam do produto sem promoção, porém não há diferenciação entre os tipos de incentivo promocional.

O teste de hipóteses entre diferenças de proporções das amostras (no caso, consideraremos uma amostra que pertence ao grupo de 'sem faculdade completa' e outra 'com faculdade completa') apresenta as seguintes hipóteses:

$\mathbf{H}_{\mathrm{A}}: \mathrm{p}$ com faculdade completa $\leq \mathrm{p}_{\text {sem faculdade completa. }}$

$\mathbf{H}_{\mathbf{B}}: \mathrm{p}_{\text {com faculdade completa }}>\mathrm{p}_{\text {sem faculdade completa }}$

Foram testadas as seguintes diferenças: proporção de escolhas pelo desconto em reais tanto no grupo com faculdade completa quanto no grupo sem faculdade completa; proporção de escolhas pelo desconto em porcentagem nos grupos com e sem faculdade completa, e proporção de escolhas pelo preço cheio nos grupos com e sem faculdade completa. Por 
exemplo, queremos saber se a preferência do grupo de maior escolaridade de $35,8 \%$ pela promoção mostrada em porcentagem é realmente maior do que os $34,4 \%$ da baixa renda, em termos populacionais.

A regra de decisão para os testes obedeceu ao seguinte critério: se o z calculado $<\mathrm{z}$ crítico, não rejeitaremos a $\mathrm{H}_{\mathrm{A}}$; caso contrário, abdicaremos da $\mathrm{H}_{\mathrm{A}}$. $\mathrm{O} \mathrm{Z}$ crítico adotado é 1,645, com erro de $5 \%$.

O teste efetuado não nos permite rejeitar $\mathrm{H}_{\mathrm{A}}$, ou seja, não há diferença entre as proporções de escolha por alguma opção (desconto em reais, desconto em porcentagem e sem promoção) nos dois grupos.

Para efetuar a análise de correspondência, serão usadas as opções de escolha (marca combinada com o desconto, por exemplo, Trakinas com desconto em porcentagem, Trakinas com desconto em reais e assim por diante até totalizar as nove opções), juntamente com as faixas de escolaridade. Como não é possível montar o mapa perceptual com a classificação de apenas duas faixas de escolaridade, optou-se por trabalhar com as seis faixas de escolaridade. O propósito desta análise é verificar se existe relação entre as opções de escolha e o nível de escolaridade.

A avaliação do qui-quadrado realizada com as variáveis "escolaridade" e "opções de escolha" revela um p-valor baixo, de 0,000. Isso nos permite afirmar que existe relação entre as duas variáveis e possibilita prosseguir com a análise de correspondência.

A Tabela 17 mostra que uma solução com duas dimensões explica 97,1\% da inércia, ou seja, é a quantidade de informação restituída pelos dois eixos. Optou-se por trabalhar com duas dimensões para simplificar a análise gráfica. 
Tabela 17 - Teste Qui-quadrado para as variáveis "escolaridade" e "opções de escolha" e sumário da análise de correspondência

\begin{tabular}{|c|c|c|c|c|c|c|c|c|}
\hline \multirow[b]{4}{*}{ Dimension } & \multicolumn{8}{|c|}{ Summary } \\
\hline & \multirow[b]{3}{*}{$\begin{array}{c}\text { Singular } \\
\text { Value }\end{array}$} & \multirow[b]{3}{*}{ Inertia } & \multirow[b]{3}{*}{ Chi Square } & \multirow[b]{3}{*}{ Sig. } & \multicolumn{2}{|c|}{ Proportion of Inertia } & \multicolumn{2}{|c|}{ Confidence Singular Value } \\
\hline & & & & & \multirow[b]{2}{*}{ Accounted for } & \multirow[b]{2}{*}{ Cumulative } & \multirow[b]{2}{*}{$\begin{array}{l}\text { Standard } \\
\text { Deviation }\end{array}$} & Correlation \\
\hline & & & & & & & & 2 \\
\hline 1 & ,152 & ,023 & & & ,634 & ,634 & ,020 & ,031 \\
\hline 2 &, 111 & 012 & & & ,336 & ,971 &, 020 & \\
\hline 3 &, 023 &, 001 & & &, 014 & ,985 & & \\
\hline 4 &, 022 &, 000 & & &, 013 & ,998 & & \\
\hline 5 &, 009 &, 000 & & &, 002 & 1,000 & & \\
\hline Total & &, 036 & 87,418 &, $000^{a}$ & 1,000 & 1,000 & & \\
\hline
\end{tabular}

a. 40 degrees of freedom

De acordo com a Tabela 18, a análise das linhas indica que as opções com a marca Trakinas mostrada com desconto em reais e em porcentagem são aquelas com maior frequência relativa (massa) no conjunto de dados estudado. A análise das linhas também indica que na dimensão 1, com base na contribuição relativa à inércia, a categoria que mais determina a identificação das dimensões da análise é a marca Passatempo apresentada sem desconto; e na dimensão 2, a categoria preponderante é a marca Trakinas com preço cheio.

Tabela 18 - Panorama dos pontos da linha

\begin{tabular}{|c|c|c|c|c|c|c|c|c|c|}
\hline \multicolumn{10}{|c|}{ Overview Row Points ${ }^{a}$} \\
\hline \multirow[b]{3}{*}{ Opçao } & \multirow[b]{3}{*}{ Mass } & \multicolumn{2}{|c|}{ Score in Dimension } & \multirow[b]{3}{*}{ Inertia } & \multicolumn{5}{|c|}{ Contribution } \\
\hline & & & & & \multicolumn{2}{|c|}{ Of Point to Inertia of Dimension } & \multicolumn{3}{|c|}{ Of Dimension to Inertia of Point } \\
\hline & & 1 & 2 & & 1 & 2 & 1 & 2 & Total \\
\hline Pass $\%$ & ,105 &,- 535 & ,111 & ,005 & ,197 & ,012 & ,936 &, 029 & ,965 \\
\hline Pass\$ & ,113 &,- 532 & ,096 &, 005 & ,209 &, 009 & ,941 &, 022 & ,963 \\
\hline PassPC & ,088 &,- 675 & ,049 & ,006 & ,265 &, 002 & ,956 &, 004 & ,959 \\
\hline Bono $\%$ &, 112 & ,397 & ,317 & ,004 &, 116 & ,101 & 671 & ,310 & ,981 \\
\hline Bono\$ & ,111 & ,345 & ,371 &, 004 &, 087 & , 138 &, 530 & ,447 & ,978 \\
\hline BonoPC & ,100 & ,282 & ,426 & ,003 &, 052 & , 165 & ,363 & ,605 & ,968 \\
\hline Trak\% & ,131 & , 177 &,- 290 & ,002 &, 027 & , 100 & ,322 & ,633 & ,955 \\
\hline Trak\$ & ,131 & , 169 &,- 333 & ,002 &, 025 & ,131 & ,252 & ,708 & ,960 \\
\hline TrakPC & ,110 & , 175 &,- 588 & ,005 &, 022 & ,342 & ,109 & ,890 & ,998 \\
\hline Active Total & 1,000 & & & ,036 & 1,000 & 1,000 & & & \\
\hline
\end{tabular}

a. Symmetrical normalization

Já a análise das colunas (Tabela 19) revela que a faixa com colegial completo/faculdade incompleto tem maior massa, seguida pela faixa com faculdade completa. O grupo com primário completo/ginásio incompleto é o que mais contribui para determinar a identificação da dimensão 1, enquanto o grupo com faculdade completa colabora com a identificação da dimensão 2. 
Tabela 19 - Panorama dos pontos da coluna

Overview Column Points ${ }^{a}$

\begin{tabular}{|c|c|c|c|c|c|c|c|c|c|}
\hline \multirow[b]{3}{*}{ V32 } & \multirow[b]{3}{*}{ Mass } & \multicolumn{2}{|c|}{ Score in Dimension } & \multirow[b]{3}{*}{ Inertia } & \multicolumn{5}{|c|}{ Contribution } \\
\hline & & & & & \multicolumn{2}{|c|}{ Of Point to Inertia of Dimension } & \multicolumn{3}{|c|}{ Of Dimension to Inertia of Point } \\
\hline & & 1 & 2 & & 1 & 2 & 1 & 2 & Total \\
\hline analf/prim incomp &, 003 & $-3,820$ & ,772 & ,006 & 240 & 013 & 961 &, 029 & 990 \\
\hline $\begin{array}{l}\text { prim completo/ginasio } \\
\text { incomp }\end{array}$ & ,058 & $-1,197$ & ,184 & 013 &, 542 & ,018 & ,975 &, 017 & ,991 \\
\hline $\begin{array}{l}\text { ginasio complt/col } \\
\text { incomp }\end{array}$ & , 140 &,- 315 &,- 276 & ,004 & 091 & ,096 &, 583 & ,325 & 907 \\
\hline $\begin{array}{l}\text { col completo/facul } \\
\text { incomp }\end{array}$ &, 560 & ,141 &,- 187 &, 004 & 074 & ,178 & ,429 &, 549 & ,979 \\
\hline faculdade completo & ,208 & ,192 & ,487 &, 007 &, 050 & ,444 & 172 & ,807 & 979 \\
\hline Pós graduação & ,033 & ,111 & ,925 & ,003 &, 003 & ,251 &, 017 & ,885 & ,903 \\
\hline Active Total & 1,000 & & & ,036 & 1,000 & 1,000 & & & \\
\hline
\end{tabular}

a. Symmetrical normalization

O mapa perceptual abaixo (Gráfico 8) permite estabelecer relações entre as escolhas de produto e a escolaridade. A marca Trakinas está próxima do grupo ginásio completo/colegial incompleto e colegial completo/faculdade incompleto. A marca Bono, por sua vez, relacionase com os grupos de maior escolaridade (faculdade completa e pós-graduação). Por último, a marca Passatempo está mais relacionada ao grupo com primário completo/ginásio incompleto.

Row and Column Points

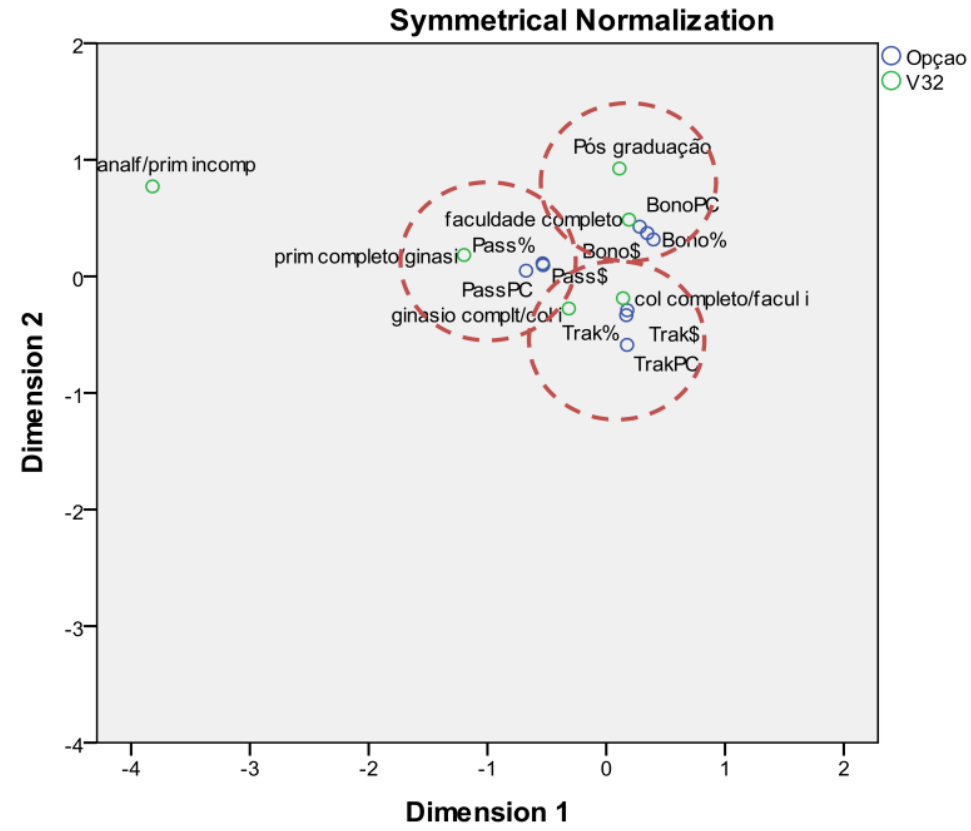

Gráfico 8 - Mapa perceptual para forma de apresentação do biscoito e nível de escolaridade 


\subsubsection{Produto de alto valor - notebook}

Ao analisar a Tabela 20, nota-se que os grupos tiveram preferências parecidas referentes ao tipo de promoção. Nos dois casos registra-se a preferência pelo desconto em dinheiro, seguido pelo desconto em porcentagem.

Ainda na Tabela 20 detalhes sobre o número de escolhas para o item notebook, classificadas pela forma de apresentação (dinheiro, porcentagem e preço cheio) agrupada de acordo com o nível de escolaridade dos respondentes em cada uma das opções:

Tabela 20 - Contagem do número de escolhas* nível de escolaridade e tipo de desconto para notebook

\begin{tabular}{|l|l|l|l|l|l|}
\hline & & $\begin{array}{l}\text { Sem } \\
\text { faculdade } \\
\text { completa }\end{array}$ & $\begin{array}{l}\text { Porcentagem } \\
\text { sem faculdade } \\
\text { completa }\end{array}$ & $\begin{array}{l}\text { Com faculdade } \\
\text { completa }\end{array}$ & $\begin{array}{l}\text { Porcentagem } \\
\text { com faculdade } \\
\text { completa }\end{array}$ \\
\hline \multirow{3}{*}{ Apresentação } & Em reais & 680 & $37,3 \%$ & 217 & $37,7 \%$ \\
\cline { 2 - 6 } & $\begin{array}{l}\text { Em } \\
\text { porcentagem }\end{array}$ & 603 & $33,1 \%$ & 196 & $34,0 \%$ \\
\cline { 2 - 6 } & Sem promoção & 541 & $29,7 \%$ & 163 & $28,3 \%$ \\
\cline { 2 - 6 } & TOTAL & 1.824 & $100 \%$ & 576 & $100 \%$ \\
\hline
\end{tabular}

*Cada respondente faz seis escolhas para o notebook, uma para cada situação mostrada. $\mathrm{O}$ total de 400 respondentes gera um montante de 2.400 escolhas diferentes para notebook.

De acordo com o que foi visto na tabela acima, não parece haver diferença na preferência pelo tipo de desconto para notebook. Ao fazer o teste qui-quadrado verificou-se que a preferência pelo tipo de desconto independe da escolaridade (p-valor igual a 0,619 , maior do que 0,05 ).

Para avaliar se existe diferença entre as proporções de escolha do referido produto, serão realizados dois tipos de testes: diferença de proporções dentro da mesma amostra visando identificar as formas de apresentação que se diferem entre si dentro dos grupos de alta e baixa escolaridade, por meio de intervalos de confiança; e teste de hipóteses de diferença de proporções entre populações díspares, no caso, alta e baixa escolaridade.

Ainda na amostra relacionada ao item notebook, a Tabela 21 traz intervalos de confiança de 95\% calculados para as diferenças na forma de apresentação, tanto para os grupos sem faculdade completa como aqueles com nível superior concluído: 
Tabela 21 - Intervalos de confiança calculados para as diferenças de proporção de escolhas pela forma de apresentação dentro da amostra para notebook

\begin{tabular}{|l|l|l|}
\hline & $\begin{array}{l}\text { Sem faculdade } \\
\text { completa }\end{array}$ & $\begin{array}{l}\text { Com faculdade } \\
\text { completa }\end{array}$ \\
\hline Desconto em dinheiro e em porcentagem & & \\
\hline Diferença entre proporções & $4 \%$ & $4 \%$ \\
\hline Intervalo de Confiança (+) $=$ & $8 \%$ & $11 \%$ \\
\hline Intervalo de Confiança (-) = & $0,4 \%$ & $-3 \%$ \\
\hline & & $6 \%$ \\
\hline Desconto em porcentagem e preço cheio & & $12 \%$ \\
\hline Diferença entre proporções & $3 \%$ & $-0,7 \%$ \\
\hline Intervalo de Confiança (+) $=$ & $7 \%$ & \\
\hline Intervalo de Confiança (-) $=$ & $-0,2 \%$ & $16 \%$ \\
\hline & & $3 \%$ \\
\hline Desconto em dinheiro e preço cheio & & \\
\hline Diferença entre proporções & $11 \%$ & $9 \%$ \\
\hline Intervalo de Confiança (+) $=$ & & \\
\hline Intervalo de Confiança (-) $=$ & & \\
\hline
\end{tabular}

Nota-se que dentro de grupo de maior escolaridade, apenas o desconto em reais se diferencia do preço cheio, não havendo distinção entre a proporção de escolhas pelo desconto em porcentagem ou em dinheiro. Também não há disparidade entre a proporção de escolhas de desconto em porcentagem ou preço cheio. Já no caso do grupo de menor escolaridade, nota-se que o desconto em reais se sobressai tanto do produto sem desconto quanto do produto com desconto em porcentagem.

O teste de hipóteses entre diferenças de proporções das amostras (no caso, consideraremos uma amostra que pertence ao grupo de 'sem faculdade completa' e outra 'com faculdade completa') apresenta as seguintes hipóteses:

$\mathbf{H}_{\mathrm{A}}: \mathrm{p}_{\text {com faculdade completa }} \leq \mathrm{p}$ sem faculdade completa.

$\mathbf{H}_{\mathbf{B}}: \mathrm{p}_{\text {com faculdade completa }}>\mathrm{p}_{\text {sem faculdade completa }}$

Foram testadas as seguintes diferenças: proporção de escolhas pelo desconto em reais tanto no grupo com faculdade completa quanto no grupo sem faculdade completa; proporção de 
escolhas pelo desconto em porcentagem nos grupos com e sem faculdade completa, e proporção de escolhas pelo preço cheio nos grupos com e sem faculdade completa.

A regra de decisão para os testes obedeceu ao seguinte critério: se o z calculado $<\mathrm{z}$ crítico, não rejeitaremos a $\mathrm{H}_{\mathrm{A}}$; caso contrário, abdicaremos da $\mathrm{H}_{\mathrm{A}}$. $\mathrm{O} \mathrm{Z}$ crítico adotado é 1,645 , com erro de $5 \%$.

O teste efetuado não nos permite rejeitar $\mathrm{H}_{\mathrm{A}}$, ou seja, não há diferença entre as proporções de escolha por alguma opção (desconto em reais, desconto em porcentagem e sem promoção) nos dois grupos.De fato percebeu-se que os percentuais de preferência entre os diferentes grupos são bastante parecidos.

A avaliação relacionada à análise de correspondência será feita com base nas opções por faixas de escolaridade em conjunto com as alternativas de escolha (marca combinada com o desconto, casos, por exemplo, da Dell com desconto em porcentagem, Dell com desconto em reais e assim por diante até totalizar as nove opções). Como não é possível montar um mapa perceptual com a classificação de apenas duas faixas de escolaridade, optou-se por trabalhar com as seis faixas de escolaridade presentes no questionário. A ideia da análise é verificar se existe relação entre as opções de escolha e o nível de escolaridade.

A análise do qui-quadrado realizada com as variáveis "escolaridade" e "opções de escolha" revela um p-valor baixo, de 0,000, o que possibilita afirmar que existe relação entre as duas variáveis e isso permite dar seguimento a análise de correspondência.

A Tabela 22, apresentada na sequência, mostra que uma solução com duas dimensões explica 97,6\% da inércia, ou seja, é a quantidade de informação restituída pelos dois eixos. Optou-se por trabalhar com duas dimensões para simplificar a análise gráfica. 
Tabela 22 - Teste Qui-quadrado para as variáveis "escolaridade" e “opções de escolha" e sumário da análise de correspondência

\begin{tabular}{|c|c|c|c|c|c|c|c|c|}
\hline \multirow[b]{4}{*}{ Dimension } & \multicolumn{8}{|c|}{ Summary } \\
\hline & \multirow[b]{3}{*}{$\begin{array}{c}\text { Singular } \\
\text { Value }\end{array}$} & \multirow[b]{3}{*}{ Inertia } & \multirow[b]{3}{*}{ Chi Square } & \multirow[b]{3}{*}{ Sig. } & \multicolumn{2}{|c|}{ Proportion of Inertia } & \multicolumn{2}{|c|}{ Confidence Singular Value } \\
\hline & & & & & \multirow[b]{2}{*}{ Accounted for } & \multirow[b]{2}{*}{ Cumulative } & \multirow[b]{2}{*}{$\begin{array}{l}\text { Standard } \\
\text { Deviation }\end{array}$} & Correlation \\
\hline & & & & & & & & 2 \\
\hline 1 & ,238 & ,056 & & & ,842 & ,842 & ,019 & ,272 \\
\hline 2 & ,095 &, 009 & & & ,134 & ,976 &, 018 & \\
\hline 3 & ,035 &, 001 & & & ,018 & ,994 & & \\
\hline 4 &, 016 &, 000 & & &, 004 & ,998 & & \\
\hline 5 &, 011 &, 000 & & &, 002 & 1,000 & & \\
\hline Total & &, 067 & 160,849 &, $000^{a}$ & 1,000 & 1,000 & & \\
\hline
\end{tabular}

a. 40 degrees of freedom

De acordo com a Tabela 23, a análise das linhas indica que a Samsung mostrada com desconto em reais, é o item com maior frequência relativa (massa) no conjunto de dados estudado. A análise das linhas também revela que na dimensão 1, com base na contribuição relativa à inércia, a categoria que mais determina a identificação das dimensões da análise é a marca LG apresentada sem desconto; e na dimensão 2, a categoria preponderante é a marca Samsung sem desconto.

Tabela 23 - Panorama dos pontos da linha

Overview Row Points ${ }^{a}$

\begin{tabular}{|c|c|c|c|c|c|c|c|c|c|}
\hline \multirow[b]{3}{*}{ Opção } & \multirow[b]{3}{*}{ Mass } & \multicolumn{2}{|c|}{ Score in Dimension } & \multirow[b]{3}{*}{ Inertia } & \multicolumn{5}{|c|}{ Contribution } \\
\hline & & & & & \multicolumn{2}{|c|}{ Of Point to Inertia of Dimension } & \multicolumn{3}{|c|}{ Of Dimension to Inertia of Point } \\
\hline & & 1 & 2 & & 1 & 2 & 1 & 2 & Total \\
\hline Dell\% & ,105 &,- 677 & ,286 & 012 & ,203 & ,091 & ,929 &, 066 & ,995 \\
\hline Dell\$ & ,123 &,- 569 & ,160 & 010 & ,168 & ,033 & ,965 &, 031 & ,996 \\
\hline DellPC & ,095 &,- 554 & ,224 & ,007 & ,123 & 050 & ,935 &, 061 & ,996 \\
\hline Sams $\%$ & ,138 & ,085 &,- 302 & 001 &, 004 & ,133 & ,161 &, 810 & ,971 \\
\hline Sams\$ & ,153 &,- 033 &,- 357 & ,002 & ,001 & 206 & ,017 &, 792 & 809 \\
\hline SamsPC & ,124 & , 172 &,- 410 & ,003 & ,015 & ,220 & ,267 & ,603 & 870 \\
\hline LG\% & ,090 & ,696 & ,310 & 011 & , 184 & ,091 & ,920 &, 073 & ,992 \\
\hline LG\$ & ,097 & ,403 & 166 & ,004 & ,066 & ,028 & ,862 & ,058 & ,921 \\
\hline LCPC & ,074 & ,871 & ,435 & ,015 & ,236 & 147 & ,903 &, 090 & ,993 \\
\hline Active Total & 1,000 & & & ,067 & 1,000 & 1,000 & & & \\
\hline
\end{tabular}

a. Symmetrical normalization

A análise das colunas (Tabela 24) permite concluir que a faixa de escolaridade 4 (colegial completo/superior incompleto) tem maior massa. Já a faixa de escolaridade pertencente ao primário completo/ginásio incompleto é a que mais contribui para determinar a identificação 
da dimensão 1. Enquanto, a faixa analfabeto/primário incompleto determina a identificação na dimensão 2.

Tabela 24 - Panorama dos pontos da coluna

\begin{tabular}{|c|c|c|c|c|c|c|c|c|c|}
\hline \multirow[b]{4}{*}{ V32 } & \multicolumn{8}{|c|}{ Overview Column Points ${ }^{a}$} & \\
\hline & \multirow[b]{3}{*}{ Mass } & \multicolumn{2}{|c|}{ Score in Dimension } & \multirow[b]{3}{*}{ Inertia } & \multicolumn{5}{|c|}{ Contribution } \\
\hline & & \multirow[b]{2}{*}{1} & \multirow[b]{2}{*}{2} & & \multicolumn{2}{|c|}{ Of Point to Inertia of Dimension } & \multicolumn{3}{|c|}{ Of Dimension to Inertia of Point } \\
\hline & & & & & 1 & 2 & 1 & 2 & Total \\
\hline analf/prim incomp & ,003 & ,314 & $-3,759$ & ,004 & 001 & ,373 & 016 & 940 & ,956 \\
\hline $\begin{array}{l}\text { prim completo/ginasio } \\
\text { incomp }\end{array}$ & 058 & 1,552 &, 513 & 034 &, 583 & 160 & ,958 & 042 & 999 \\
\hline $\begin{array}{l}\text { ginasio complt/col } \\
\text { incomp }\end{array}$ & 140 & ,457 &,- 142 & 008 & ,123 & 030 & ,915 & ,035 & ,950 \\
\hline $\begin{array}{l}\text { col completo/facul } \\
\text { incomp }\end{array}$ &, 560 &,- 057 &,- 146 & ,002 & ,008 & 126 & ,233 & ,620 & 854 \\
\hline faculdade completo & ,208 &,- 449 & ,374 & 013 & ,176 & ,307 & ,778 & ,216 & ,994 \\
\hline Pós graduação & 033 &,- 894 & 119 & ,007 & 109 &, 005 & 895 & ,006 & 901 \\
\hline Active Total & 1,000 & & & ,067 & 1,000 & 1,000 & & & \\
\hline
\end{tabular}

a. Symmetrical normalization

O Gráfico 9 mostra as associações entre faixas de escolaridade e produto escolhido pelos indivíduos entrevistados. Nota-se, porém, a existência de uma maior associação da marca Dell com as faixas de maior escolaridade.

\section{Row and Column Points}

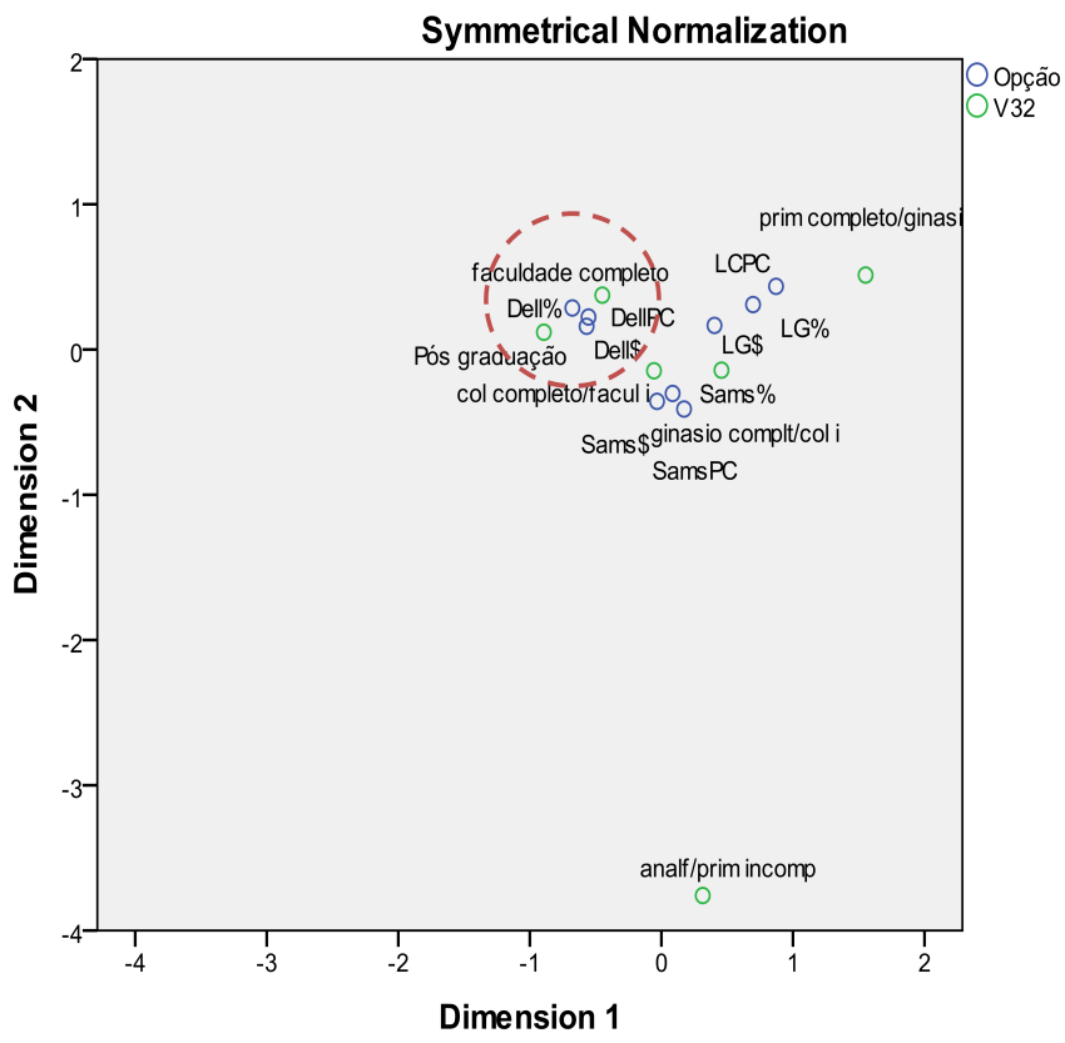

Gráfico 9 - Mapa perceptual para forma de apresentação do notebook e nível de escolaridade 


\subsubsection{Conclusões - produtos de baixo valor vs. produtos de alto valor}

Após as análises estatísticas, verifica-se que o comportamento dos grupos com maior e menor escolaridade são bastante parecidos; ambos tiveram um percentual muito similar de preferência pelos tipos de promoção.

No caso do produto de baixo valor, para os dois grupos o desconto em reais e o desconto em porcentagem se destacam do produto sem promoção. Porém, não existe diferença entre as proporções de escolha para a dedução em reais e a apresentação da redução do preço em termos percentuais.

No produto de alto valor, o grupo com menor escolaridade apresentou diferença na proporção de escolhas entre o item com desconto em porcentagem e aquele com desconto em reais. Vale ressaltar ainda que o desconto em reais se diferencia do produto sem promoção. No grupo com maior escolaridade, apenas a proporção de escolhas pelo produto com desconto em reais se destaca do produto sem promoção.

Portanto, podemos confirmar a H5, que pressupõe que a escolaridade não deve afetar o padrão de escolhas de promoção, ou seja, que as pessoas com alta escolaridade ou baixa escolaridade devem ser igualmente suscetíveis ao efeito do framing de promoções.

\subsubsection{Análise de regressão logística multinomial}

A adoção de uma regressão logística multinomial, método também empregado por Gendall et al. (op. cit.), ajudou a verificar quais fatores impactam na escolha dos consumidores. A regressão logística multinomial compara grupos múltiplos por meio da combinação de regressões logísticas binárias. No caso, queremos entender as diferentes escolhas de marcas pelos respondentes (Dell, Samsung e LG). O modelo é utilizado para computar a probabilidade de um indivíduo pertencer a cada um dos grupos (no caso daquele que tenha escolhido uma das marcas).

As variáveis independentes testadas incluem "sexo", "escolaridade", "faixa de renda", "tipo de desconto" (em reais, em porcentagem e sem desconto), "região", "estado civil", "classe social" e "faixa etária". Apenas as variáveis significativas foram incluídas nos modelos em análise. 
Tentou-se fazer um modelo de regressão logística multinomial com o produto de baixo valor, porém em nenhuma dos modelos testados a forma de desconto apareceu como significativa. Portanto, serão detalhados dois modelos que mostram o efeito dos descontos na escolha de marcas no produto de alto valor.

\subsubsection{Produto de alto valor - Modelo 1}

A elaboração da regressão logística multinomial permitiu diagnosticar se o modelo é adequado. De acordo com Hair et al. (op. cit.), a regressão múltipla emprega o método dos mínimos quadrados, que minimiza a soma dos quadrados dos erros (diferenças entre o valor real e o previsto da variável dependente). A natureza não linear da regressão logística requer outro procedimento, denominado máxima verossimilhança, usado em estimativas mais prováveis para os coeficientes.

Portanto, na regressão logística se utiliza o valor da verossimilhança ao invés da soma dos quadrados para calcular a medida de ajuste do modelo (que na realidade é - 2 vezes o log do valor da verossimilhança e é denominado $-2 \mathrm{LL}$ ou $-2 \log$ likelihood). $\mathrm{O}$ valor da verossimilhança pode ser comparado entre equações, com a diferença representando a mudança no ajuste preditivo de uma equação para outra. Se as variáveis independentes têm uma relação com a variável dependente, a capacidade de previsão desta última melhora, e a medida log likelihood irá diminuir (HAIR et al.,Ibid).

Na Tabela 25, o valor inicial do log likelihood $(2493,18)$ é a medida do modelo sem variáveis independentes, ou seja, somente com o intercepto. O valor final do log likelihood $(133,74)$ é a medida computada após todas as variáveis independentes serem inseridas na regressão logística. A diferença entre as duas medidas é o valor do modelo de qui-quadrado $(2359,45=$ 2493,18 - 133,74). O teste de significância do qui-quadrado é a evidência estatística da presença de uma relação entre a variável dependente e a combinação de variáveis independentes. Neste caso, a significância foi de 0,00 , o que permite concluir que existe uma relação significativa entre as variáveis dependentes e independentes. 
Tabela 25 - Adequação do modelo

Model Fitting Information

\begin{tabular}{|l|c|c|c|c|}
\hline \multirow{2}{*}{} & $\begin{array}{c}\text { Model } \\
\text { Fitting } \\
\text { Criteria }\end{array}$ & \multicolumn{3}{|c|}{ Likelihood Ratio Tests } \\
\cline { 2 - 5 } & $\begin{array}{c}\text {-2 Log } \\
\text { Likeliho } \\
\text { od }\end{array}$ & $\begin{array}{c}\text { Chi- } \\
\text { Square }\end{array}$ & df & Sig. \\
\hline $\begin{array}{l}\text { Intercept Only } \\
\text { Final }\end{array}$ & $\begin{array}{c}2493,18 \\
133,740\end{array}$ & 2359,45 & 10 &, 000 \\
\hline
\end{tabular}

De acordo com Hair et al. (Ibid.), existem medidas comparáveis ao $\mathrm{R}^{2}$ da regressão múltipla. A Tabela 26 mostra esses índices. O $\mathrm{R}^{2}$ de Cox e Snell opera da mesma forma; quanto maior o valor desta medida, melhor é o ajuste do modelo. Trata-se, porém, de uma avaliação limitada, pois não atinge o valor máximo de 1 . Para que o $\mathrm{R}^{2}$ varie entre 0 e 1 Nagelkerke propõe uma modificação, ou seja, que o valor do $\mathrm{R}^{2}$ seja 0,75 . Essa mudança indica uma boa associação entre as variáveis.

\section{Tabela 26 - Pseudo R-Square}

\section{Pseudo R-Square}

\begin{tabular}{|l|r|}
\hline Cox and Snell &, 664 \\
Nagelkerke &, 750 \\
McFadden &, 504 \\
\hline
\end{tabular}

No entanto, os $\mathrm{R}^{2}$ encontrados na regressão logística não são os mesmos presentes na regressão linear. Essas variedades de pseudo $\mathrm{R}^{2}$ podem gerar conclusões contraditórias e não significam o mesmo que na regressão linear (a proporção da variância da variável dependente explicada pelas variáveis preditoras). Portanto, alguns autores propõem que estas medidas sejam usadas com cautela (UCLA, 2012).

Uma maneira de medir a eficácia da regressão logística multinomial ocorre por meio da precisão de classificação. Ela compara a classificação prevista pela regressão logística com a classificação real do grupo, que é o valor da variável dependente (UNIVERSITY OF TEXAS, 2012a). Se os grupos previsto e real são os mesmos, isso denota que a previsão está correta para aquele caso. Se os grupos forem diferentes, então o modelo falha para o caso em questão. 
A referência usada para verificar a utilidade de um modelo de regressão logística multinomial apresenta melhora de $25 \%$ sobre a taxa de precisão alcançada por acaso. A porcentagem geral de projeções corretas do modelo gerado pelo SPSS é de 83,6\% de acordo com a Tabela 27.

Tabela 27 - Precisão da Classificação

\section{Classification}

\begin{tabular}{|l|r|r|r|r|}
\hline \multirow{2}{*}{ Observed } & \multicolumn{4}{|c|}{ Predicted } \\
\cline { 2 - 5 } & \multicolumn{1}{|c|}{ Dell } & Samsung & \multicolumn{1}{c|}{ LG } & $\begin{array}{c}\text { Percent } \\
\text { Correct }\end{array}$ \\
\hline Dell & 578 & 72 & 40 & $83,8 \%$ \\
Samsung & 54 & 777 & 69 & $86,3 \%$ \\
LG & 58 & 63 & 455 & $79,0 \%$ \\
Overall Percentage & $31,9 \%$ & $42,1 \%$ & $26,0 \%$ & $83,6 \%$ \\
\hline
\end{tabular}

Para calcular a taxa de precisão alcançada por acaso, será utilizado um valor de precisão proporcional e ocasional, computado pela soma dos quadrados das porcentagens dos casos em cada grupo. A Tabela 28 mostra a porcentagem de escolhas por marca. A taxa de precisão é de $34,5 \%\left(0,319^{2}+0,416^{2}+0,266^{2}\right)$ e há um aumento de $25 \%$ sobre esta taxa gerando um valor de $43,1 \%$.

Tabela 28 - Porcentagem marginal de escolhas de marca

\begin{tabular}{|ll|r|r|r|r|}
\multicolumn{7}{|c|}{ V04 - Marca } \\
\hline & & Frequency & Percent & Valid Percent & $\begin{array}{c}\text { Cumulative } \\
\text { Percent }\end{array}$ \\
\hline Valid & Dell & 690 & 31,9 & 31,9 & 31,9 \\
& Samsung & 900 & 41,6 & 41,6 & 73,4 \\
& LG & 576 & 26,6 & 26,6 & 100,0 \\
& Total & 2166 & 100,0 & 100,0 & \\
\hline
\end{tabular}

A taxa de precisão de classificação gerada pelo modelo foi de 83,6\%; um valor maior do que a taxa proporcional de precisão por acaso, equivalente a 43,1\%. Portanto, o critério de precisão para a classificação está satisfeito pelo modelo de regressão.

A seguir, será feita uma análise individual das variáveis independentes, iniciando-se pelo teste de likelihood ratio, que avalia a relação geral entre a variável independente e a variável dependente. 
A Tabela 29 mostra que, em um nível de 10\%, as variáveis independentes de desconto em porcentagem, de preferência pela marca e de faixa de renda têm uma relação significativa com a variável independente (escolha da marca).

Tabela 29 - Testes de Likelihood ratio

Likelihood Ratio Tests

\begin{tabular}{|l|r|r|r|r|}
\hline & $\begin{array}{c}\text { Model } \\
\text { Fitting } \\
\text { Criteria }\end{array}$ & \multicolumn{3}{|c|}{ Likelihood Ratio Tests } \\
\cline { 2 - 5 } & $\begin{array}{c}\text {-2 Log } \\
\text { Likeliho } \\
\text { od of } \\
\text { Reduce } \\
\text { d Model }\end{array}$ & $\begin{array}{c}\text { Chi- } \\
\text { Square }\end{array}$ & df & \multicolumn{1}{|c|}{ Sig. } \\
\hline Intercept & $133,74^{\mathrm{a}}$ &, 00 & 0 &. \\
Pref_marca & 2456,01 & 2322,27 & 6 &, 00 \\
DescPorc & 139,58 & 5,84 & 2 &, 05 \\
Baixo5sm & 151,85 & 18,11 & 2 &, 00 \\
\hline
\end{tabular}

The chi-square statistic is the difference in -2 log-

likelihoods between the final model and a reduced

model. The reduced model is formed by omitting an

effect from the final model. The null hypothesis is that all parameters of that effect are 0 .

a. This reduced model is equivalent to the final model because omitting the effect does not increase the degrees of freedom.

Se uma variável independente tem relação geral com a variável dependente, esta pode ser ou não estatisticamente significante ao diferenciar entre pares de grupos definidos pela variável dependente (UNIVERSITY OF TEXAS, 2012a). O teste Wald avalia se a variável independente é estatisticamente significante para diferenciar entre os dois grupos em cada uma das comparações logísticas binárias. Neste caso, o grupo de referência é a marca Dell, então se trata de um modelo estimado da marca Samsung em relação a Dell, e da LG em relação a Dell.

As estimativas dos parâmetros compõem a Tabela 30. As duas equações desta Tabela são classificadas pelo grupo que contrastam em relação ao grupo de referência (Dell). A primeira equação é denominada "Samsung" e a segunda "LG". Os coeficientes de cada equação estão na coluna denominada B. A hipótese de que o coeficiente é diferente de zero (ou seja, muda a probabilidade de ocorrência de evento da variável dependente) foi testada pela estatística de Wald (UNIVERSITY OF TEXAS, 2012b). 
Tabela 30 - Estimativas dos Parâmetros

\begin{tabular}{|c|c|c|c|c|c|c|c|c|c|}
\hline \multirow{2}{*}{\multicolumn{2}{|c|}{ V04 - Marca ${ }^{a}$}} & \multirow{3}{*}{$\frac{B}{-, 919}$} & \multirow{2}{*}{$\begin{array}{l}\text { Desvio } \\
\text { Padrão } \\
\end{array}$} & \multirow{2}{*}{ Wald } & \multirow{2}{*}{ df } & \multirow[b]{2}{*}{ Sig. } & \multirow[b]{2}{*}{$\operatorname{Exp}(B)$} & \multicolumn{2}{|c|}{ 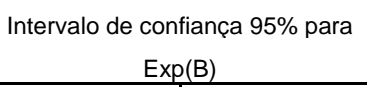 } \\
\hline & & & & & & & & Limite inferior & Limite superior \\
\hline \multirow[t]{9}{*}{ Samsung } & Intercept & & ,302 & 9,267 & 1 & ,002 & & & \\
\hline & Com desc \% & 217 & 174 & 1,566 & 1 & 211 & 1,242 & ,884 & 1,746 \\
\hline & Sem desc $\%$ & $0^{b}$ & & & 0 & & & & \\
\hline & Acima $5 \mathrm{sm}$ & ,383 & 205 & 3,512 & 1 & 061 & 1,467 & ,983 & 2,191 \\
\hline & Abaixo $5 \mathrm{sm}$ & $0^{\mathrm{b}}$ & & & 0 & & & & . \\
\hline & Prefere LG & 1,303 & ,356 & 13,424 & 1 &, 000 & 3,679 & 1,833 & 7,384 \\
\hline & Prefere Samsung & 3,177 & ,319 & 99,085 & 1 &, 000 & 23,968 & 12,823 & 44,799 \\
\hline & Prefere Dell & $-1,980$ & ,342 & 33,470 & 1 &, 000 & ,138 &, 071 & ,270 \\
\hline & Sem preferência & $0^{\mathrm{b}}$ & & & 0 & & & & \\
\hline \multirow[t]{9}{*}{ LG } & Intercept &,- 517 & 272 & 3,609 & 1 & ,057 & & & \\
\hline & Com desc $\%$ & ,445 & , 185 & 5,772 & 1 & ,016 & 1,561 & 1,085 & 2,244 \\
\hline & Sem desc \% & $0^{\mathrm{b}}$ & & & 0 & & & & \\
\hline & Acima $5 \mathrm{sm}$ &,- 502 & ,224 & 5,021 & 1 &, 025 & ,605 & ,390 & ,939 \\
\hline & Abaixo $5 \mathrm{sm}$ & $0^{\mathrm{b}}$ & & & 0 & & & & \\
\hline & Prefere LG & 2,918 & ,312 & 87,292 & 1 &, 000 & 18,500 & 10,031 & 34,120 \\
\hline & Prefere Samsung & ,280 & ,315 & ,787 & 1 & ,375 & 1,323 &, 713 & 2,454 \\
\hline & Prefere Dell & $-2,290$ & 319 & 51,607 & 1 &, 000 & 101 &, 054 & 189 \\
\hline & Sem preferência & $0^{\mathrm{b}}$ & & & 0 & & & & \\
\hline
\end{tabular}

a. A categoria de referência é: Dell.

b. Este parâmetro é zero porque é redundante

De acordo com Hair et al. (1998), os coeficientes estimados (B1, B2, B3, etc.) são na realidade medidas das mudanças na relação de probabilidades (odds ratio). Como estão expressos na forma de logaritmo, precisam ser transformados para que o efeito relativo das probabilidades seja acessado mais facilmente. O logaritmo modificado aparece na coluna $\operatorname{Exp}(B)$. Um coeficiente B positivo aumenta a probabilidade de o evento ocorrer; um negativo, diminui essa possibilidade (caso a escolha da marca aconteça). Se B for positivo, a transformação (anti log) será maior que 1 e a probabilidade (odds ratio) deve aumentar. Esta ampliação se dá quando a probabilidade prevista da ocorrência do evento sobe e a perspectiva de não ocorrência diminui. Já quando o sinal de B for negativo, o anti log é menor que 1 e a probabilidade também reduz.

Uma análise dos valores dos desvios-padrão revela que o modelo não apresenta nenhum problema numérico (multicolinearidade, observações sem número, etc.), uma vez que nenhum desvio padrão excede o valor de 2 . Além disso, anomalias podem gerar coeficientes B muito altos, o que não ocorreu neste caso. 
Ainda de acordo com a Tabela 30 e considerando um erro de 10\%, a estatística Wald evidencia as variáveis independentes que distinguem as escolhas entre Samsung e Dell (avaliadas na primeira regressão logística): pertencer ao grupo com renda acima de cinco salários mínimos e ter preferências pelas marcas LG, Samsung e Dell. Portanto, a preferência por Samsung aumenta em $2.296 \%$ a probabilidade de pertencer no grupo que escolhe a esta marca em relação a Dell; a preferência pela marca LG aumenta em $268 \%$ a probabilidade de escolher Samsung em relação a Dell e a preferência por Dell reduz em 86,2\% a chance de escolher Samsung. Ter renda acima de cinco salários mínimos aumenta em 46,7\% a probabilidade de escolher a marca Samsung. Neste último caso, o desconto não foi significativo para aumentar a probabilidade de escolha da marca.

O intercepto também foi estatisticamente significativo. Pode ser interpretado como o log de preferência pela marca Samsung quando todas as outras variáveis independentes são iguais a zero. Assim, quando o produto é apresentado sem desconto, o respondente tem renda abaixo de cinco salários mínimos e não tem preferência por nenhuma marca, o log de preferência por Samsung em relação a Dell é -0,919.

Na segunda regressão logística, considerando um erro de 10\%, as variáveis independentes que distinguem as escolhas de LG em relação a Dell são: desconto em porcentagem, renda acima de cinco salários mínimos e preferência por LG e Dell. O desconto em porcentagem aumenta em 56,1\% a probabilidade de o respondente escolher LG em relação a Dell, ter renda maior do que cinco salários mínimos reduz em 39,5\% a possibilidade de escolher LG, ter preferência pela marca LG aumenta a probabilidade em $1.750 \%$ e ter preferência por Dell reduz a probabilidade em $89,9 \%$.

O intercepto, calculado em -0,517, também foi estatisticamente significativo. Ele pode ser interpretado como o log de preferência pela marca LG quando todas as outras variáveis independentes representam zero.

Portanto, a análise da regressão logística multinomial permite concluir que renda, preferência pela marca e desconto em porcentagem influenciam na escolha da marca. Embora o quesito preferência pela marca tenha um peso forte na escolha do consumidor, é interessante notar que o desconto em porcentagem tornou uma das opções mais atrativa em relação à outra. 


\subsubsection{Produto de alto valor - Modelo 2}

Encontrou-se um segundo modelo que ajuda a explicar o papel das promoções na escolha do consumidor. $\mathrm{O}$ teste de significância do qui-quadrado resultou em um valor de 0,000. Isso permite concluir que existe uma relação significativa entre a variável dependente e as variáveis independentes.

O valor do $\mathrm{R}^{2}$ de Nagelkerke é de 0,746 , indicando boa associação entre variáveis. Utilizando o critério de precisão da classificação, verificou-se que a porcentagem geral de previsões corretas do modelo gerada pelo SPSS equivale a $83,6 \%$, e que a taxa de precisão alcançada por acaso é de $34,5 \%$ - o aumento de $25 \%$ sobre esta taxa resulta em um valor de $43,1 \%$. Como a taxa de precisão de classificação gerada pelo modelo de regressão foi maior do que a taxa proporcional de precisão por acaso, conclui-se que o critério de precisão para a classificação está satisfeito pelo modelo.

O teste de likelihood ratio, usado para avaliar a relação geral entre a variável independente e a variável dependente, mostra que em um nível de $10 \%$ de erro, as variáveis independentes (preferência pela marca e desconto em reais) são significativas para explicar a variável dependente (escolha da marca).

Uma análise dos valores dos desvios padrão revela que o modelo não apresenta nenhum problema numérico (multicolinearidade, observações sem número, etc.), uma vez que não há desvio padrão excedendo o valor de 2 . Além disso, anomalias podem gerar coeficientes B muito altos, o que não ocorreu neste caso. 
Tabela 31 - Estimativas dos Parâmetros

\begin{tabular}{|c|c|c|c|c|c|c|c|c|c|}
\hline \multicolumn{10}{|c|}{ Parameter Estimates } \\
\hline \multirow[b]{2}{*}{$\mathrm{Marca}^{\mathrm{a}}$} & & \multirow[b]{2}{*}{ B } & \multirow{2}{*}{$\begin{array}{l}\text { Desvio } \\
\text { Padrão }\end{array}$} & \multirow[b]{2}{*}{ Wald } & \multirow[b]{2}{*}{ df } & \multirow[b]{2}{*}{ Sig. } & \multirow[b]{2}{*}{$\operatorname{Exp}(B)$} & \multicolumn{2}{|c|}{$\begin{array}{l}\text { Intervalo de confiança95\% para } \\
\operatorname{Exp}(B)\end{array}$} \\
\hline & & & & & & & & Limite inferior & \\
\hline \multirow[t]{7}{*}{ Dell } & Intercepto & ,294 & 271 & 1,177 & 1 & 278 & & & \\
\hline & Prefere LG & $-2,888$ & 311 & 86,197 & 1 &, 000 &, 056 &, 030 & ,102 \\
\hline & Prefere Samsung &,- 302 & ,315 & ,919 & 1 & ,338 & ,740 & ,399 & 1,370 \\
\hline & Prefere Dell & 2,352 & ,317 & 54,966 & 1 & ,000 & 10,502 & 5,640 & 19,554 \\
\hline & Sem preferência & $0^{\mathrm{b}}$ & & & 0 & & & & \\
\hline & Com descem $\mathrm{R} \$$ & ,381 & 180 & 4,473 & 1 & ,034 & 1,464 & 1,028 & 2,083 \\
\hline & Sem desc em $\mathrm{R} \$$ & $0^{\mathrm{b}}$ & & & 0 & & & & \\
\hline \multirow[t]{7}{*}{ Samsung } & Intercepto &,- 400 & ,322 & 1,545 & 1 & 214 & & & \\
\hline & Prefere LG & $-1,551$ & ,343 & 20,490 & 1 & ,000 & ,212 & 108 & 415 \\
\hline & Prefere Samsung & 2,856 & ,343 & 69,288 & 1 &, 000 & 17,395 & 8,879 & 34,080 \\
\hline & Prefere Dell & ,437 & ,396 & 1,213 & 1 & 271 & 1,547 &, 712 & 3,365 \\
\hline & Sem preferência & $0^{\mathrm{b}}$ & & & 0 & & & & \\
\hline & Com descem $R \$$ & ,163 & ,164 & ,988 & 1 & 320 & 1,177 & ,854 & 1,623 \\
\hline & Sem desc em $R \$$ & $0^{b}$ & & & 0 & & & & \\
\hline
\end{tabular}

a. A categoria de referência é LG

b. Este parâmetroé zero porqueé redundante

A Tabela 31 traz duas equações. Na primeira equação (Dell) conclui-se que: o desconto em reais aumentou em 46,4\% a probabilidade de o respondente escolher Dell em relação à LG, ter preferência pela marca LG reduz em $94,4 \%$ a probabilidade de escolher Dell; e a preferência por Dell aumenta em 950,2\% a probabilidade de escolher a própria marca.

Na segunda regressão logística, a estatística Wald mostra que, considerando um nível de erro de $10 \%$, as variáveis independentes que distinguem as escolhas de Samsung das escolhas de LG foram as preferências por estas marcas. A preferência pela marca LG reduz em 78,8\% a probabilidade de escolher a marca Samsung e a preferência pela marca Samsung aumenta em $1.639,5 \%$ essa mesma probabilidade.

As regressões explicitadas acima ajudam a comprovar a $\mathrm{H} 3$, que pressupõe que os descontos têm impactos diferentes nas marcas. No caso, foi possível verificar o impacto dos descontos nas marcas LG e Dell. A LG ficou mais atrativa em relação à Dell com o desconto em porcentagem. Já a Dell tornou-se mais atraente se comparada à LG com o desconto em reais. Isso revela que mesmo que a preferência geral dos consumidores seja pelo desconto em reais, 
em alguns casos específicos o desconto em porcentagem pode gerar mais efeito positivo na preferência de uma marca em detrimento de outra.

\subsubsection{Análise de outros fatores}

\subsubsection{Produto de baixo valor - biscoito}

A verificação de outros fatores relevantes para explicar a preferência por promoções para produtos de baixo valor foi realizada a partir de um teste qui-quadrado entre as variáveis "desconto" e as variáveis "sexo", "região", "faixa etária”, “estado civil” e "classe social". Como as variáveis "renda" e "escolaridade" foram estudadas anteriormente, elas não estão incluídas nesta análise. Assim, elaborou-se as seguintes hipóteses para testar a independência das variáveis:

$\mathbf{H}_{\mathbf{A}}$ : A preferência pelo tipo de apresentação independe do sexo/região/faixa etária/estado civil/classe social.

$\mathbf{H}_{\mathrm{B}}$ : A preferência pelo tipo de apresentação depende do sexo/região/faixa etária/estado civil/classe social.

A Tabela 32 apresenta o valor-p (Pearson Chi-Square) para as associações testadas:

Tabela 32 - Valor-p para o teste qui-quadrado do produto de baixo valor

\begin{tabular}{|l|l|}
\hline Teste qui-quadrado da variável desconto com: & Valor-p \\
\hline Classe social & 0,989 \\
\hline Região & 0,995 \\
\hline Sexo & 0,943 \\
\hline Faixa etária & 0,905 \\
\hline Estado civil & 0,952 \\
\hline
\end{tabular}

O valor-p (Pearson Chi-Square) encontrado foi acima de 5\% em todos os casos. Considerando uma significância de 5\%, não é possível rejeitar a $\mathrm{H}_{\mathrm{A}}$ já que $\alpha<$ p-valor. Com base nisso, não se pode afirmar que exista relação entre a forma de apresentação do produto e as variáveis "sexo", "região", "faixa etária", "estado civil", "classe social". Portanto, nenhuma das variáveis testadas revela relação com a forma de apresentação preferida dos consumidores (sem promoção, desconto em porcentagem, desconto em reais). 


\subsubsection{Produto de alto valor - notebook}

Um teste qui-quadrado entre as variáveis "desconto" e as variáveis "sexo", "região", "faixa etária", "estado civil" e "classe social" foi realizado para verificar se existem outros fatores relevantes que expliquem a preferência por promoções de produtos de alto valor. As variáveis "renda" e "escolaridade" já foram estudadas anteriormente, por isso elas não integraram essa análise. Para tanto, foram elaboradas duas hipóteses com objetivo de testar a independência das variáveis:

$\mathbf{H}_{\mathrm{A}}$ : A preferência pelo tipo de apresentação independe do sexo/região/faixa etária/estado civil/classe social.

$\mathbf{H}_{\mathbf{B}}$ : A preferência pelo tipo de apresentação depende do sexo/região/faixa etária/estado civil/classe social.

A Tabela 33, apresentada a seguir, apresenta o valor-p (Pearson Chi-Square) para as associações testadas:

Tabela 33 - Valor-p para o teste qui-quadrado de produto de alto valor

\begin{tabular}{|l|l|}
\hline Teste qui-quadrado da variável desconto com: & Valor-p \\
\hline Classe social & 0,934 \\
\hline Região & 0,827 \\
\hline Sexo & 0,523 \\
\hline Faixa etária & 0,639 \\
\hline Estado civil & 0,913 \\
\hline
\end{tabular}

O valor-p (Pearson Chi-Square) encontrado foi acima de 5\% em todos os casos. Considerando uma significância de $5 \%$, não podemos rejeitar a $\mathrm{H}_{\mathrm{A}}$ já que $\alpha<\mathrm{p}$-valor. Portanto, não é possível afirmar que haja relação entre a forma de apresentação do produto e as variáveis "sexo", "região", "faixa etária", "estado civil", "classe social". Nenhuma das variáveis testadas têm relação com a forma de apresentação preferida dos consumidores (sem promoção, desconto em porcentagem, desconto em reais). 


\section{CONCLUSÕES, LIMITAÇÕES E POSSÍVEIS EXTENSÕES}

O objetivo deste trabalho foi verificar se os consumidores são suscetíveis aos efeitos do framing de promoções de preço, ou seja, se as diferentes formas de desconto - "De R $\$$ x por R\$ y" ou em porcentagem (" $10 \%$ de desconto", por exemplo) - têm atratividades diferentes junto às pessoas. Os objetivos específicos procuraram identificar qual tipo de promoção é mais atraente para o consumidor, para produtos de alto e baixo valor; se indivíduos pertencentes a diferentes grupos de renda ou escolaridade têm preferências distintas pelo tipo de promoção; se o efeito das promoções varia por marca e categoria, e se existe alguma outra variável que possa influenciar na preferência pelo tipo de desconto.

O método escolhido para a coleta de dados compreendeu uma pesquisa com abordagem quantitativa, a partir de um experimento com hipóteses, aplicado em uma amostra formada por consumidores da cidade de São Paulo entre janeiro e fevereiro de 2013.

A importância deste trabalho pode ser aferida à medida que busca entender os efeitos da apresentação dos preços entre os consumidores. Como já explicitado por Smith e Nagle (op. cit.), a determinação do preço não deve envolver apenas o nível de preço, mas também como este preço é mostrado ao consumidor. Diversos estudos foram realizados nos Estados Unidos e Europa, porém este tema ainda é pouco explorado dentro do contexto brasileiro.

Devido à racionalidade limitada, as pessoas são suscetíveis ao efeito framing e avaliam promoções equivalentes (no caso, em porcentagem e em reais) de maneiras diferentes. De acordo com as análises estatísticas realizadas, a promoção mostrada em reais demonstrou ser mais atrativa do que a promoção em porcentagem para o produto de alto valor. Existem algumas explicações possíveis para tal comportamento, entre elas, a pouca propensão dos consumidores para processar descontos baixos e a maior complexidade para calcular desconto em porcentagem.

Grewal et al. (1996, apud HARDESTY; BEARDEN 2003, p. 18) sugeriram que os consumidores processam informações de acordo com uma curva $U$ invertida de reação a promoções de preço. Isso quer dizer que quando o desconto de preço é baixo, as pessoas são pouco propensas a avaliar a informação de forma exaustiva, já que a promoção de preço tem 
baixo valor monetário. De forma similar, quando o desconto é alto, elas também tendem a processar menos a informação, pois há menos incerteza quanto às vantagens de efetuar o negócio. Porém, nas situações em que são apresentados níveis moderados de desconto, existe grande incerteza em relação ao negócio, logo os consumidores têm maior propensão para processar a informação de forma mais elaborada e cuidadosa. Como o estudo trabalhou com um nível de desconto baixo (10\% e 15\%), é possível que os indivíduos não tenham recebido estímulo suficiente para processar esta informação e tenham preferido o desconto em reais já que este apresentava o preço final do produto.

Outra explicação plausível refere-se ao fato de o desconto em porcentagem exigir um processamento mais complexo do que o desconto no formato cents-off (que é similar ao formato de desconto em reais utilizado neste estudo, “de R\$ x por R \$ y"). De acordo com Delvecchio et al. (2007), quando os consumidores são expostos a uma promoção, a probabilidade de que irão calcular um novo preço depende da facilidade deste cálculo.

Para identificar o novo preço resultante de uma promoção no formato cents-off, o consumidor precisa saber o preço normal e a partir dele subtrair o desconto oferecido. A subtração é um cálculo relativamente fácil de ser feito, e que resulta em grande precisão. Já o desconto mostrado no formato de percentage-off (equivalente aos "10\% de desconto" neste estudo) requer um procedimento adicional de processamento: a porcentagem tem de ser multiplicada pelo preço base para encontrar o valor do desconto. Além disso, o processo de multiplicação é relativamente difícil, o que torna o desconto em porcentagem mais difícil de ser calculado se comparado ao desconto em termos monetários. Esta dificuldade pode fazer com que os indivíduos sejam menos propensos a guardar o preço revisado.

Desta forma, os consumidores podem ficar inseguros em relação ao preço resultante porque não fazem o esforço necessário na aritmética mental para transformar a forma de porcentagem para uma métrica de preço. Ademais, mesmo se o preço revisado for calculado, a maior dificuldade para avaliar a promoção em porcentagem pode resultar em menor confiança no preço calculado. O desconto em reais já mostra o preço final do produto, o que elimina esta incerteza no cálculo da promoção em porcentagem.

No caso do produto de baixo valor, não houve diferenciação entre o desconto em reais e o desconto em porcentagem, que tiveram percentuais de escolha muito parecidos, com uma 
diferença de apenas $0,7 \%$ das preferências. Uma possível explicação é que por ser um produto de baixo valor e o desconto ser relativamente pequeno (apenas $\mathrm{R} \$ 0,17$ ), a preferência pela marca foi determinante na escolha e o desconto teve pouco efeito. De fato, foram elaborados alguns modelos de regressão logística para o produto de baixo valor. Em todos eles a preferência pela marca aparecia como significativo, porém a forma de desconto, não.

Estas conclusões estão de acordo com o estudo de Gendal et al. (op. cit.), que afirma que para produtos de baixo valor, a forma de promoção é praticamente indiferente; e que, para produtos de alto valor, a forma com maior preferência seria pelo desconto em dinheiro.

Em relação às variações nas preferências pelo tipo de desconto de diferentes grupos de renda e escolaridade, não existem diferenças significativas de preferência por tipo de desconto entre os vários grupos de renda e escolaridade.

Mesmo que as disparidades nas preferências não sejam muito significativas, é interessante notar que pode haver alguma mudança no comportamento para os diferentes grupos de renda. No caso do biscoito, o grupo de alta renda tende a preferir o desconto em reais, ao passo que o grupo de baixa renda é indiferente ao tipo de promoção. Já para o produto de alto valor, ambos os grupos preferem a promoção em reais, porém no grupo de alta renda os dois tipos de desconto se diferenciam do produto sem promoção, e no grupo de baixa renda apenas a opção com desconto em reais se distingue.

Outro aspecto interessante do trabalho aponta que a efetividade do desconto em reais e do desconto em porcentagem será distinta para marcas diferentes, em categorias diferentes. Esta hipótese foi comprovada por uma comparação entre o número de escolhas de produtos sem promoção e com promoção, assim como pela regressão logística multinomial para o produto de alto valor. No caso do biscoito, a marca Passatempo com desconto tornou-se mais atraente do que as outras, tendo um aumento de 18,4\% quando foi mostrada com o desconto em porcentagem, e 27,4\% de aumento de escolhas quando apresentada com o desconto em reais.

No caso do notebook, a marca LG teve o maior acréscimo no número de escolhas: $22 \%$ de aumento em relação à apresentação sem promoção quando foi oferecida com desconto em porcentagem, e 31,6\% para desconto em reais. De acordo com as regressões logísticas efetuadas, tanto a marca Dell como a LG tornaram-se mais atrativas quando oferecidas com 
descontos. A marca LG tornou-se mais atraente em relação à Dell com o desconto em porcentagem (coeficiente B de 0,445); já a marca Dell mostrou-se mais interessante que a LG com o desconto em reais (coeficiente $\mathrm{B}$ de 0,381 ). Portanto, efetividade do desconto em reais e do desconto em porcentagem é diferente para marcas distintas.

O Quadro 5 relaciona as cinco hipóteses do estudo, a justificativa teórica por trás de cada uma delas, os resultados obtidos após a análise dos dados da pesquisa direcionada aos consumidores e as conclusões obtidas a partir das avaliações individuais de cada hipótese presente neste estudo.

\section{Quadro 5 - Hipóteses do estudo, justificativa e conclusões}

\begin{tabular}{|c|c|c|c|}
\hline Hipóteses & Justificativa teórica & Resultados & Conclusões \\
\hline $\begin{array}{l}\text { H1: Para produtos } \\
\text { de baixo valor, os } \\
\text { consumidores } \\
\text { percebem as } \\
\text { promoções de } \\
\text { preço } \\
\text { apresentadas } \\
\text { como desconto } \\
\text { em porcentagem } \\
\text { como mais } \\
\text { vantajosas do que } \\
\text { as mostradas em } \\
\text { reais. }\end{array}$ & $\begin{array}{l}\text { Chen et al. (1998) e Gendall et al. (2006) } \\
\text { trabalham com a hipótese de que é mais } \\
\text { efetivo mostrar um desconto em } \\
\text { porcentagem para itens de baixo valor do } \\
\text { que mostrar este mesmo desconto em } \\
\text { dinheiro. O trabalho de Chen et al. } \\
\text { (1998) comprova totalmente esta } \\
\text { hipótese; já para Gendall et al. (2006), o } \\
\text { framing do desconto em porcentagem } \\
\text { tem pouco ou nenhum efeito sobre a } \\
\text { escolha do consumidor. }\end{array}$ & $\begin{array}{l}\text { A análise dos dados da } \\
\text { pesquisa revelou que } \\
\text { ambos os tipos de } \\
\text { promoção são preferíveis } \\
\text { à opção sem desconto, } \\
\text { mas não há diferença } \\
\text { entre o desconto em } \\
\text { porcentagem ( } 34,8 \% \text { das } \\
\text { escolhas) e o desconto } \\
\text { em reais ( } 35,4 \% \text { das } \\
\text { escolhas). }\end{array}$ & $\begin{array}{l}\text { H1 não pode ser } \\
\text { confirmada. No } \\
\text { contexto } \\
\text { brasileiro, para } \\
\text { produtos de } \\
\text { baixo valor, } \\
\text { aparentemente é } \\
\text { indiferente a } \\
\text { forma de } \\
\text { promoção. }\end{array}$ \\
\hline $\begin{array}{l}\text { H2: Para produtos } \\
\text { de alto valor, os } \\
\text { consumidores } \\
\text { percebem as } \\
\text { promoções de } \\
\text { preço } \\
\text { apresentadas } \\
\text { reais como mais } \\
\text { vantajosas } \\
\text { comparadas } \\
\text { aquelas } \\
\text { mostradas } \\
\text { formato em } \\
\text { porcentagem. }\end{array}$ & $\begin{array}{l}\text { Chen et al. (1998) e Gendall et al. (2006) } \\
\text { trabalham com a hipótese de que é mais } \\
\text { efetivo mostrar um desconto em dólares } \\
\text { para itens de alto valor do que mostrar } \\
\text { este mesmo desconto em porcentagem. } \\
\text { Ambos os trabalhos comprovam } \\
\text { totalmente esta hipótese. }\end{array}$ & $\begin{array}{l}\text { Os resultados revelam } \\
\text { que o desconto mostrado } \\
\text { em reais para o produto } \\
\text { de alto valor foi mais } \\
\text { atrativo para os } \\
\text { consumidores do que } \\
\text { aquele em porcentagem. } \\
\text { O desconto apresentado } \\
\text { no formato "De R\$ x por } \\
\mathrm{R} \$ \text { y" obteve } 37,4 \% \text { das } \\
\text { escolhas, enquanto o } \\
\text { desconto divulgado em } \\
\text { porcentagem obteve } \\
33,3 \% \text { das escolhas. }\end{array}$ & \begin{tabular}{lr}
$\mathrm{H} 2$ & se \\
confirmou, uma \\
vez que para o \\
item de alto \\
valor \\
desconto em \\
reais mostrou- \\
\multicolumn{3}{c}{ se mais atrativo. }
\end{tabular} \\
\hline $\begin{array}{l}\text { H3: A efetividade } \\
\text { do desconto em } \\
\text { reais e do } \\
\text { desconto em } \\
\text { porcentagem } \\
\text { diferente par } \\
\text { marcas } \\
\text { diferenciadas, } \\
\text { encontradas em } \\
\text { categorias } \\
\text { diferentes. }\end{array}$ & $\begin{array}{l}\text { A terceira hipótese tem como base o } \\
\text { trabalho de Gendall et al. (2006). No } \\
\text { mundo real, os consumidores encontram } \\
\text { várias marcas dentro de uma categoria, } \\
\text { que podem apresentar algum desconto ou } \\
\text { não. É possível que a reação dos } \\
\text { indivíduos a um desconto dependa de } \\
\text { uma série de fatores, como, por exemplo, } \\
\text { a importância da marca dentro da } \\
\text { categoria de produto. Portanto, o } \\
\text { desconto pode gerar efeitos diferentes em } \\
\text { marcas e categorias díspares. }\end{array}$ & $\begin{array}{l}\text { A análise dos dados } \\
\text { mostrou que algumas } \\
\text { marcas tornam-se mais } \\
\text { atrativas do que outras } \\
\text { quando mostradas com } \\
\text { determinada forma de } \\
\text { desconto. Na média, as } \\
\text { marcas de notebook } \\
\text { tornaram-se mais } \\
\text { atraentes com o desconto } \\
\text { do que as marcas de } \\
\text { biscoito. }\end{array}$ & $\begin{array}{lr}\text { H3 } & \text { se } \\
\text { confirmou, } & \\
\text { visto que } & \text { os } \\
\text { efeitos } & \text { dos } \\
\text { descontos } & \\
\text { variaram } & \text { de } \\
\text { acordo com a } \\
\text { marca e r a } \\
\text { categoria } \\
\text { produto. }\end{array}$ \\
\hline
\end{tabular}




\begin{tabular}{|c|c|c|c|}
\hline $\begin{array}{lr}\text { H4: A renda não } \\
\text { deve afetar } \quad \text { o } \\
\text { padrão } & \text { de } \\
\text { escolhas } & \text { de } \\
\text { promoção, ou } & \text { ou } \\
\text { seja, pessoas de } \\
\text { alta renda e baixa } \\
\text { renda devem ser } \\
\text { igualmente } \\
\text { suscetíveis ao } \\
\text { efeito do framing } \\
\text { de promoções. }\end{array}$ & $\begin{array}{l}\text { Queiroz (2007) revela que as variáveis } \\
\text { socioeconômicas e demográficas não } \\
\text { explicam a preferência dos consumidores } \\
\text { pelo parcelamento de compras. Existem } \\
\text { evidências que o efeito de apresentação } \\
\text { do parcelamento (efeito framing) sobre a } \\
\text { exposição do valor à vista ocorre em } \\
\text { quase todos os grupos da amostra. Há, } \\
\text { ainda, um efeito da apresentação sobre a } \\
\text { forma de pagamento na preferência dos } \\
\text { consumidores, independente do perfil } \\
\text { socioeconômico. }\end{array}$ & $\begin{array}{l}\text { Os resultados apontam } \\
\text { que o padrão de } \\
\text { preferências por tipo de } \\
\text { desconto não se altera } \\
\text { com a renda do } \\
\text { indivíduo. Embora para o } \\
\text { biscoito o grupo de alta } \\
\text { renda tenha preferido o } \\
\text { desconto em reais, e o } \\
\text { grupo de baixa renda } \\
\text { tenha sido indiferente ao } \\
\text { tipo de desconto, não se } \\
\text { pode afirmar que os } 38 \% \\
\text { de preferência da alta } \\
\text { renda pelo desconto em } \\
\text { reais seja } \\
\text { estatisticamente maior do } \\
\text { que os } 34 \% \\
\text { preferência da baixa } \\
\text { renda. }\end{array}$ & 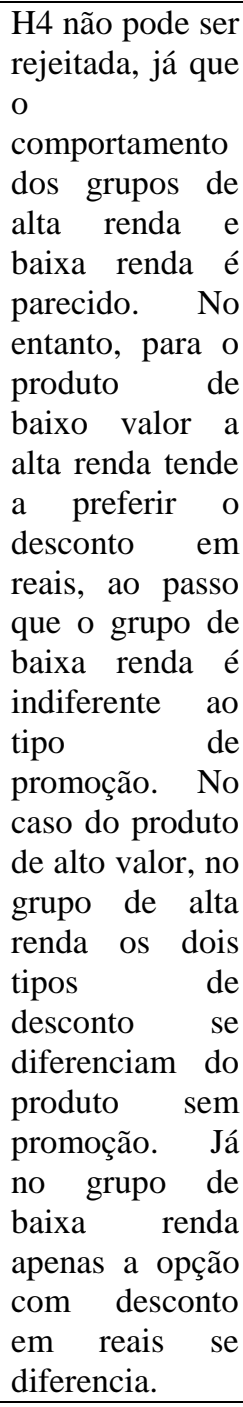 \\
\hline $\begin{array}{lr}\text { H5: } & \text { A } \\
\text { escolaridade } & \text { não } \\
\text { deve afetar } & \text { o } \\
\text { padrão } & \text { de } \\
\text { escolhas } & \text { de } \\
\text { promoção, } & \text { ou } \\
\text { seja, pessoas com } \\
\text { alta escolaridade } \\
\text { e } \\
\text { escolaridade baixa } \\
\text { devem } \\
\text { igualmente } \\
\text { suscetíveis } \\
\text { efeito do framing } \\
\text { de promoções. }\end{array}$ & $\begin{array}{l}\text { De acordo com diversos autores, } \\
\text { percebe-se que a necessidade por } \\
\text { cognição ou experiência/formação em } \\
\text { algum ramo (que poderia ser uma proxy } \\
\text { para escolaridade) não evitam o efeito } \\
\text { framing nas preferências dos indivíduos } \\
\text { (LEBOEUF; SHAFIR, 2003; MCNEIL } \\
\text { et al., 1982 apud KAHNEMAN, 2003a, } \\
\text { p.702; ROSZKOWSKI; SNELBECKER, } \\
\text { 1990). }\end{array}$ & $\begin{array}{l}\text { O grupo com maior } \\
\text { escolaridade tem um } \\
\text { comportamento muito } \\
\text { similar ao grupo com } \\
\text { menor escolaridade. }\end{array}$ & $\begin{array}{ll}\text { H5 pode ser } & \text { sen } \\
\text { confirmada, } & \\
\text { pois não } & \\
\text { existem } & \\
\text { diferenças } & \text { de } \\
\text { preferências } & \\
\text { entre ambos os } \\
\text { grupos. }\end{array}$ \\
\hline
\end{tabular}

O método escolhido possui algumas limitações. Embora tente simular a realidade, a pesquisa não replica uma situação real de compra. Na prática, as marcas com desconto podem ter uma sinalização diferente para atrair a atenção do consumidor para a redução de preço, e as pessoas podem reagir de forma desigual a tais estímulos. 
Além disso, optou-se por um número limitado de produtos, marcas e formas de promoção. $\mathrm{O}$ ambiente de compras real oferece uma variedade muito maior do que o retratada na pesquisa. Também deve ser levado em consideração que diversos fatores não abordados na pesquisa (formas de pagamento, varejista, atendimento, etc.) podem alterar as preferências dos consumidores no momento da compra. Por fim, só foram entrevistadas pessoas residentes no município de São Paulo. Isso também limita a generalização das conclusões originadas neste estudo.

Como já explicitado, esta pesquisa traz algumas contribuições ao entendimento do efeito do framing de promoções nos consumidores. Pesquisas futuras são necessárias para um melhor entendimento deste tema, ainda pouco explorado pelo meio acadêmico no Brasil. Esses estudos poderão examinar os efeitos das promoções em outros tipos de produtos, como, por exemplo, comparar produtos que podem ser estocados por um período grande de tempo (e.g. mercearia doce) com produtos perecíveis; ou então examinar diferentes tipos de promoções, como as promoções de volume ("leve 3 pague 2" ou "500 ml a mais") ou promoções com brindes. Outras possibilidades incluem variar a intensidade do desconto, utilizando valores maiores do que a faixa entre $10 \%$ e $15 \%$. 


\section{REFERÊNCIAS}

ALLAIS, Maurice. Le comportement de l'homme rationnel devant le risque: critique des postulats et axiomes de l'école américaine. Econometrica, [S.I.], v. 21, n. 4, p. 503-546, oct. 1953.

ANDERSON, David R. et al. Estatística Aplicada à Administração e Economia. 2. ed. São Paulo: Cengage Learning. 2007

ANGNER, Erik; LOEWENSTEIN, George. Behavioral Economics. In: Handbook of the philosophy of science: philosophy of economic. Amsterdam: Elsevier, jan. 2007.

ARIELY, Dan. Previsivelmente Irracional: como as situações do dia-a-dia influenciam nossas decisões. Rio de Janeiro: Elsevier, 2008.

BARON, Jonathan. Normative models of judgment and decision making. In: KOEHLER, D. J.; HARVEY, N. (Org.). Blackwell Handbook of Judgment and Decision Making. London: Blackwell, 2004.

BAZERMAN, Max H. Judgment in Managerial Decision Making. 2nd ed. New Jersey: Wiley, 1996.

BAZERMAN, Max H. Processo decisório: para cursos de administração e economia. 5. ed. Rio de Janeiro: Elsevier, 2004.

BERNOULLI, Daniel. Exposition of a New Theory on the Measurement of Risk. Econometrica, [S.I.], v. 22, n. 1, p. 22-36, jan 1954.

BETTMAN, James R. et al. Consumer decision making. In: ROBERTSON, T. S. e KASSARJIAN H. H (Org.). Handbook of consumer behavior. Englewood Cliffs: PrenticeHall, 1991.

BlattBerg, R. C.; NESLIN, S. A. Sales Promotion: concepts, methods, and strategies. Englewood Cliffs, New Jersey: Prentice Hall, 1990 apud NESLIN, Scott A. Sales Promotion. In: WEITZ, Barton; WENSLEY, Robin. (Org.). Handbook of Marketing. London: Sage, 2002.

CAMERER, Colin F.; LOEWENSTEIN, George. Behavioral Economics: past, present, future. In: CAMERER, Colin F. et al. (Org.). Advances in Behavioral Economics. New Jersey: Princeton University Press, 2003.

CHANDON, Pierre et al. A Benefit Congruency Framework of Sales Promotion Effectiveness. Journal of Marketing, v. 64, n. 4, p. 65-81, oct 2000. 
CHEN, Shih-Fen S. et al. The Effects of Framing Price Promotion Messages on Consumers' Perceptions and Purchase Intentions. Journal of Retailing, New York, v. 74, n. 785, p. 353372, 1998.

CLEMEN, Robert T. Making Hard Decisions: an introduction to decision analysis. 2nd ed. Belmont, CA: Duxbury Press, 1996.

COBRA, Marcos. Administração de Marketing no Brasil. 2. ed. São Paulo: Cobra Editora, 2005.

CONNOLLY, Terry; ORDÓÑEZ, Lisa. Judgment and Decision Making. Handbook of Psychology, [S.I.],p. 493-517, 2003.

DARKE, Peter R.; CHUNG, Cindy M. Y. Effects of pricing and promotion on consumer perceptions: it depends on how you frame it. Journal of Retailing, New York, v. 81, n. 1, p. 35-47, 2005.

DARKE, Peter R.; DAHL, Darren W. Fairness and discounts: the subjective value of a bargain. Journal of Consumer Psychology, [S.I.], v. 13, n. 3, p. 328-338, 2003.

DELVECCHIO, Devon et al. The effect of sales promotion on post-promotion brand preference: a meta-analysis. Journal of Retailing, New York, v. 82, n. 3, p. 203-213, 2006.

DELVECCHIO, Devon et al. Cents or Percent? The Effects of Promotion Framing on Price. Journal of Marketing, [S.I.], v. 71, p. 158-170, jul 2007.

DIAMOND, William D.; CAMPBELL, Leland. The framing of sales promotions: effects on reference price change. Advances in Consumer Research, [S.I.],v. 16, p. 241-247, 1989.

DIAMOND, William D.; JOHNSON, Robert R. The framing of sales promotions: an approach to classification. Advances in Consumer Research, [S.I.], v. 17, p. 494-500, 1990.

DIAMOND, William D.; SANYAL, Abhijit. The effect of framing on the choice of supermarket coupons. Advances in Consumer Research, [S.I.], v. 17, p. 488-493, 1990.

DODSON, Joe A. et al. Impact of deals and deal retraction on brand switching. Journal of Marketing Research, [S.I.], v. 15, p. 72-81, 1978.

FIGUEIREDO, Rachael Botelho. Estruturação de descontos na percepção de consumidores de diferentes níveis de escolaridade: um teste experimental. Rio de Janeiro, 2002. Dissertação (Mestrado em Administração) - Instituto Coppead de Administração, Universidade Federal do Rio de Janeiro. 
FOLHA DE S. PAUlO. Pesquisa Folha Top of Mind. São Paulo, 2011. Disponível em: <http://www1.folha.uol.com.br/especial/2011/topofmind/>. Acesso em 01/03/2012.

GEDENK, Karen; NESLIN, Scott A. The role of retail promotion in determining future brand loyalty: its effect on purchase event feedback. Journal of Retailing, New York, v. 75, n. 4, p. 433-459, 1999.

GENDALL, Philip et al. Message framing effects on price discounting. Journal of Product \& Brand Management, [S.I.], v. 15, n. 7, p. 458-465, 2006.

GIL, A.C. Métodos e Técnicas de Pesquisa Social. 5. ed. São Paulo: Editora Atlas, 1999.

GREWAL, Dhruv et al. Communicating price information through semantic cues: The moderating effects of situation and discount size. Journal of Consumer Research, v. 23, p. 148-155, sep 1996 apud HARDESTY, David M.; BEARDEN, William O. Consumer evaluations of different promotion types and price presentations: the moderating role of promotional benefit level. Journal of Retailing, New York, v. 79, n. 1, p. 17-25, 2003.

GREWAL, Dhruv; MARMORSTEIN, Howard. Market price variation, perceived price variation, and consumers' price search decisions for durable goods. Journal of Consumer Research, v. 21, n.3, p. 453-460, 1994 apud CHEN, Shih-Fen S. et al. The Effects of Framing Price Promotion Messages on Consumers' Perceptions and Purchase Intentions. Journal of Retailing, New York, v. 74, n. 785, p. 353-372, 1998.

HAIR, Joseph F. et al. Multivariate Data Analysis. 5th ed. New Jersey, Pearson Prentice Hall, 1998.

HAIR, Joseph F. et al. Multivariate Data Analysis. 7nd ed. New Jersey, Pearson Prentice Hall, 2010.

HARDESTY, David M.; BEARDEN, William O. Consumer evaluations of different promotion types and price presentations: the moderating role of promotional benefit level. Journal of Retailing, New York, v. 79, n. 1, p. 17-25, 2003.

HASTIE, Reid. Problems for judgment and decision making. Annual Review of Psychology, [S.I.], v. 52, p. 653-683, 2001.

HEATH, Timothy B. et al. Mental Accounting and Changes in Price: the frame dependence of reference dependence. Journal of Consumer Research, v. 22, n. 1, p. 90-97, 1995 apud CHEN, Shih-Fen S. et al. The Effects of Framing Price Promotion Messages on Consumers' Perceptions and Purchase Intentions. Journal of Retailing, New York, v. 74, n. 785, p. 353372, 1998.

INSTITUTO BRASILEIRO DE GEOGRAFIA E ESTATÍSTICA - IBGE. Censo Demográfico. 2010 
KAHNEMAN, Daniel. A Perspective on judgment and choice: mapping bounded rationality. American Psychologist, [S.I.], v. 58, n. 9, p. 697-720, 2003 a.

KAHNEMAN, Daniel. Maps of Bounded Rationality: psychology for behavioral economics. The American Economic Review, [S.I.], v. 93, n. 5, p. 1449-1475, dec 2003b.

KAHNEMAN, Daniel; TVERSKY, Amos. Prospect Theory: an analysis of decision under risk. Econometrica, [S.I.], v. 47, n. 2, p. 263-292, mar 1979.

KREPS, David. M. Microeconomics for Managers. New York: Norton, p. 266, 2004.

KRISHNA, Aradhna et al. A meta-analysis of the impact of price presentation on perceived savings. Journal of Retailing, New York, v. 78, n. 2, 2002.

LAL, Rajiv; RAO, Ram. Supermarket Competition: the case of every day low pricing. Marketing Science, [S.I.], v. 19, n. 1, p. 60-80, 1997.

LEBOEUF, Robyn A.; SHAFIR, Eldar. Deep thoughts and shallow frames: on the susceptibility to framing effects. Journal of Behavioral Decision Making, [S.I.], v. 16, p. 77-92, 2003.

LECLERC, France. Special session summary monetary promotions vs. non-monetary promotions, which is more effective? Advances in Consumer Research, [S.I.], v. 24, p. 220221, 1997.

LEVIN, Irwin P.; GAETH, Gary J. How Consumers are Affected by the Framing of Attribute Information Before and After Consuming the Product. Journal of Consumer Research, [S.I.], v. 15, n. 3, p. 374-378, dec 1988.

LUPPE, Marcos Roberto. A heurística da ancoragem e seus efeitos no julgamento: decisões de consumo. São Paulo, 2006. Dissertação (Mestrado em Administração) Faculdade de Economia, Administração e Contabilidade, Universidade de São Paulo.

MARCH, James G. Bounded rationality, ambiguity and the engineering of choice. In: BELL, David E. et al. (Org.). Decision Making: descriptive, normative e prescriptive interactions. Cambridge: Cambridge University Press, 1977.

MCNEIL, Barbara J. et al. On the elicitation of preferences for alternative therapies. New England Journal of Medicine, v. 306, p. 1259-1262, 1982 apud KAHNEMAN, Daniel. A Perspective on judgment and choice: mapping bounded rationality. American Psychologist, [S.I.], v. 58, n. 9, p. 697-720, 2003a.

MELA, Carl F. et al. The Impact of Promotions on Consumer Stockpiling Behavior. Journal of Marketing Research, [S.I.], v. 35, p. 250-262, 1998. 
MONGIN, Philippe. Expected utility theory. In: DAVIS, John B. et al. (Org.). Handbook of Economic Methodology. London, 1997.

MONROE, K.B. Pricing: making profitable decisions. New York: McGraw-Hill Book Co, 1990 apud CHEN, Shih-Fen S. et al. The Effects of Framing Price Promotion Messages on Consumers' Perceptions and Purchase Intentions. Journal of Retailing, New York, v. 74, n. 785, p. 353-372, 1998.

MONROE, Kent B.; CHAPMAN, Joseph D. Framing effects on buyers' subjective product evaluations. Advances in Consumer Research, [S.I.], v. 14, p. 193-197, 1987.

NESLIN, Scott A. Sales Promotion. In: WEITZ, Barton; WENSLEY, Robin. (Org.). Handbook of Marketing. London: Sage, 2002.

OLSHAVSKY, Richard W.; GRANBOIS, Donald H. Consumer decision making: fact or fiction? Journal of Consumer Research, [S.I.], v. 6, p. 93-100, sep 1979.

PALAZON, Mariola; DELGADO-BALLESTER, Elena. Effectiveness of price discounts and premium promotions. Psychology \& Marketing, [S.I.], v. 26, n. 12, p. 1108-1129, dec 2009.

Perfil Socioeconômico da População Paulistana. Disponível em: <.http://atlasambiental.prefeitura.sp.gov.br/pagina.php?id=23>. Acesso em: 22/11/2012.

POPESCU, Ioana; WU, Yaozhong. Dynamic pricing strategies with reference effects. Operations Research, [S.I.], v. 55, n. 3, 413-429, 2007.

PRADO, Karen Perrotta Lopes de Almeida. A preferência da marca no processo de decisão de compra: um estudo exploratório no segmento de baixa renda. São Paulo, 2008. Tese (Doutorado em Administração) - Faculdade de Economia, Administração e Contabilidade, Universidade de São Paulo.

PROMOTION MARKETING ASSOCIATION OF AMERICA INC. Winning with Promotion Power: The Reggie Awards Winners. Ravenswood, IL: Dartnell Corporation, 1994 apud CHANDON, Pierre et al. A Benefit Congruency Framework of Sales Promotion Effectiveness. Journal of Marketing, [S.I.], v. 64, n. 4, p. 65-81, oct 2000.

QUEIROZ, Renata Steffanoni Bernardes de. Processo de tomada de decisão na aquisição de crédito e preferências entre alternativas de financiamento no varejo. São Paulo, 2007. Dissertação (Mestrado em Administração) - Faculdade de Economia, Administração e Contabilidade, Universidade de São Paulo.

RAO, Poduri S.R.S. Sampling Methodologies with Applications. Florida: Chapman \& Hall/CRC, 2000. 
ROSZKOWSKI, Michael J.; SNELBECKER, Glenn E. Effects of "Framing" on measures of risk tolerance: financial planners are not immune. Journal of Behavioral Economics, [S.I.], v. 19, n. 3, p. 237-246, 1990.

SHAFIR, E. (Ed.). Preferences, beliefs and similarity: selected writings. Massachusetts: The MIT Press, 2004. Disponível em: <http://books.google.com.br/books?hl=pt$\mathrm{BR} \& \mathrm{lr}=\& \mathrm{id}=\mathrm{OCXAgA3}$ sigIC\&oi=fnd\&pg=PA3\&dq=shafir $+2004+$ preferences + beliefs\&ots $=P 8 t v i 2 v N p h \& s i g=N f o R 9 t z K N R w \_I \_P b F g f y y v n a \_p I \# v=$ snippet\&q=tversky\&f=false $>$. Acesso em: 08/04/2012.

SIMON, Herbert A. A Behavioral Model of Rational Choice. The Quarterly Journal of Economics, [S.I.], vol. 69, n. 1, p. 99-118, feb 1955.

SIMON, Herbert A. Administrative behavior: a study of decision-making processes in Administrative Organization. 1st ed. New York: The Macmillan Company, 1947.

SIMON, Herbert A. An Empirically Based Microeconomics. Cambridge, UK: Cambridge University Press, 1997.

SIMON, Herbert A. Rational choice and the structure of the environment. Psychological Review, [S.I.], v. 63, n. 2, p. 129-38, 1956.

SINHA, Indrajit; SMITH, Michael F. Consumers' perceptions of promotional framing of price. Psychology \& Marketing, [S.I.], v. 17, n. 3, p. 257-275, mar 2000.

SLOVIC, Paul; LICHTENSTEIN; Sarah. Preference reversals: a broader perspective. American Economic Review, [S.I.], v. 73, p. 596-605, 1983.

SMITH, Gerald E.; NAGLE, Thomas T. Frames of reference and buyers' perception of price and value. California Management Review, [S.I.], v. 38, n. 1, p. 98-116, 1995.

STANOVICH, K. E.; WEST, R. F. Individual differences in reasoning: Implications for the rationality debate. Behavioral and Brain Sciences, [S.I.], v. 23, p. 645-665, 2000.

SUPERMERCADO MODERNO. Guia Prático de Sortimento. Ano 41, n. 5. São Paulo: Grupo Lund, mai 2010. Disponível em: <http://www.sm.com.br/Publique/cgi/cgilua.exe/sys/start.htm?infoid=9764\&sid=23\&tpl=section_tpl13>. Acesso em: 01/03/2012.

TERENCE, Ana Cláudia Fernandes; ESCRIVÃO FILHO; Edmundo. Abordagem quantitativa, qualitativa e a utilização da pesquisa-ação nos estudos organizacionais. In: ENCONTRO NACIONAL DE ENGENHARIA DE PRODUÇÃO, 26, 2006, Anais... Fortaleza: ENEGEP, 2006.

THALER, Richard H. Toward a positive theory of consumer choice. Journal of Economic Behavior and Organization, [S.I.], v. 1, n. 1, p. 39-60, mar 1980. 
THALER, Richard H. Mental Accounting and Consumer Choice. Marketing Science, [S.I.], v. 4, n. 3, p. 199-214, 1985.

THALER, Richard H.; JOHNSON, Eric J., Gambling with the House Money and Trying to Break Even: the effects of prior outcomes on risky choice (1990). Management Science, [S.I.], vol. 36, n. 6, p. 643-660, 1990.

THALER, Richard H; SUNSTEIN, Cass R. Nugde: O empurrão para a escolha certa: aprimore suas decisões sobre saúde, riqueza e felicidade. Rio de Janeiro: Elsevier, 2009.

TVERSKY, Amos. Intransitivity of Preferences. Psychological Review, [S.I.], v. 76, p. 3148, 1969.

TVERSKY, Amos; KAHNEMAN, Daniel. Judgment under uncertainty: heuristics and biases. Science, [S.I.], v. 185, p. 1124-1131, 1974.

TVERSKY, Amos; KAHNEMAN, Daniel. The framing of decisions and the psychology of choice. Science, New Series, [S.I.], v. 211, n. 4481, p. 453-458, 1981.

TVERSKY, Amos; KAHNEMAN, Daniel. Rational Choice and the Framing of Decisions. The Journal of Business, Part 2: The Behavioral Foundations of Economic Theory, [S.I.], v. 59, n. 4, p. 251-278, oct 1986.

UNIVERSITY OF CALIFORNIA, LOS ANGELES - UCLA. Annotated SPSS Output Multinomial Logistic Regression, 2012. Disponível em: <http://www.ats.ucla.edu/stat/spss/output/mlogit.htm>. Acesso em: 14/03/2012.

UNIVERSITY OF TEXAS. Multinomial logistic regression basic relationships. 2012a. Disponível em: <www.utexas.edu/courses/schwab/sw388r7/SolvingProblems/MultinomialLogisticRegression_BasicRelationships.ppt>. Acesso em: 14/03/2012.

UNIVERSITY OF TEXAS. The SPSS sample problem. 2012b. Disponível em: < www.utexas.edu/courses/schwab/sw388r7/ClassMaterials/SPSSMulitNomialLogisticRegressi onProblem.ppt>. Acesso em: 14/03/2012.

URBANY, Joel E. et al. The effect of plausible and exaggerated reference prices on consumer perceptions and price search. Journal of Consumer Research, [S.I.], v. 15, n. 1, p. $95-110,1988$.

VON NEUMANN, John; MORGENSTERN, Oskar. Theory of games and economic Behavior. 2nd ed. Princeton, New Jersey: Princeton University Press, 1947. 


\section{APÊNDICES}

APÊNDICE 1 - Questionário preenchido pelo entrevistador

APÊNDICE 2 - Situações do questionário mostradas aos consumidores 


\section{APÊNDICE 1 - Questionário preenchido pelo entrevistador}

UNIVERSIDADE DE SÃO PAULO
FACULDADE DEECONOMIA EADMINISTRAÇÃO-FEA-USP
MESTRADO EM ADMINISTRAÇÃO DE EMPRESAS-PPGA

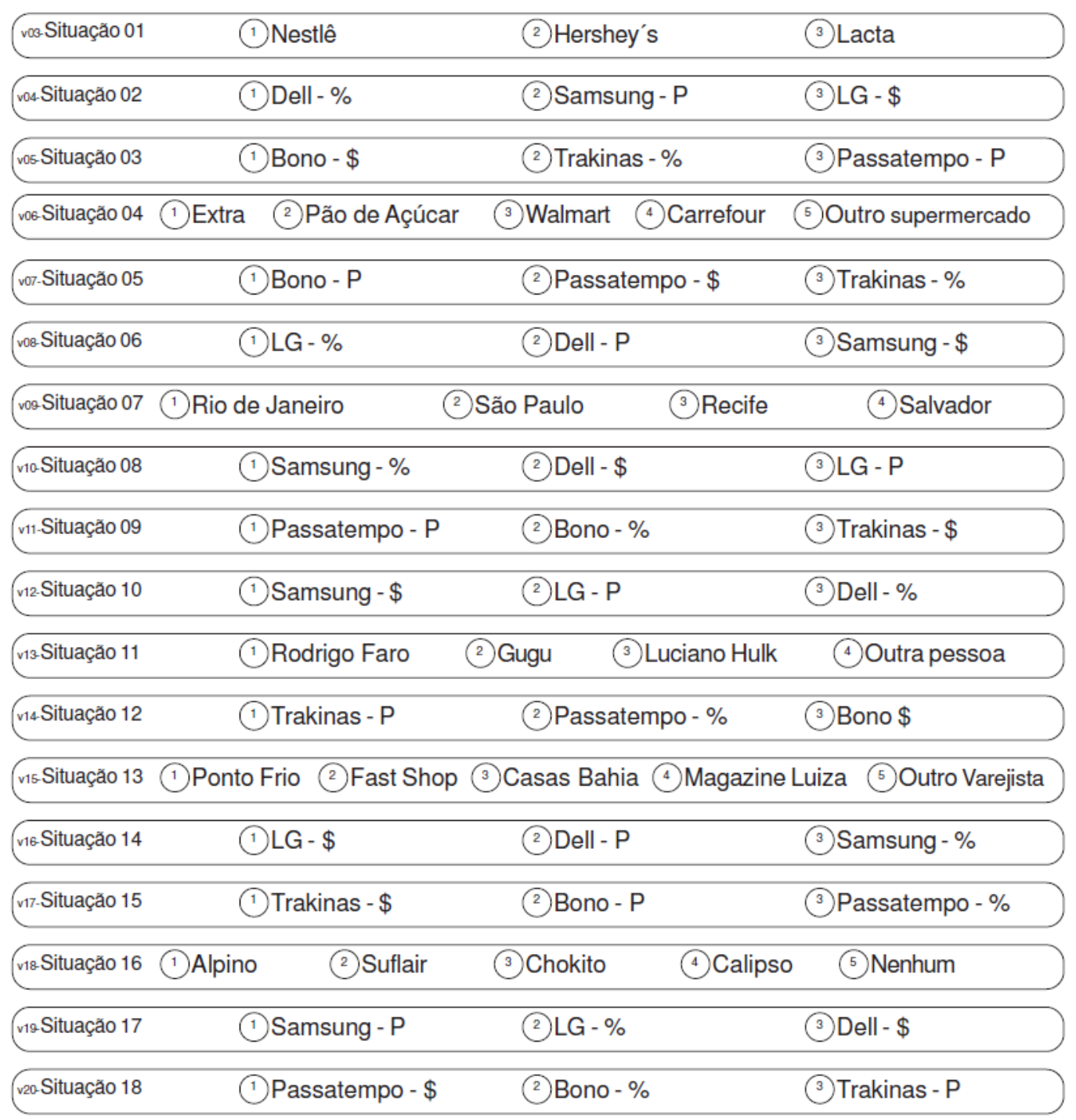


v21-01-Quais destas marcas de bolacha você conhece? - Respostas múltiplas
(1) Passatempo
(2) Trakinas
(3) Bono

v22-02-Você conhece quais destas marcas de notebook? - Respostas múltiplas
(1) LG
(2) Samsung
(3) Dell

v23-04-Qual destas marcas de biscoitos é a sua preferida?
(1) Passatempo
(2) Trakinas
(3) Bono

(4) Não tenho preferência por nenhuma destas marcas

${ }_{24}$.05-Qual destas marcas de notebook é a sua preferida?
(1) LG
(2) Samsung
(3) Dell
(4) Não tenho preferência por nenhuma destas marcas

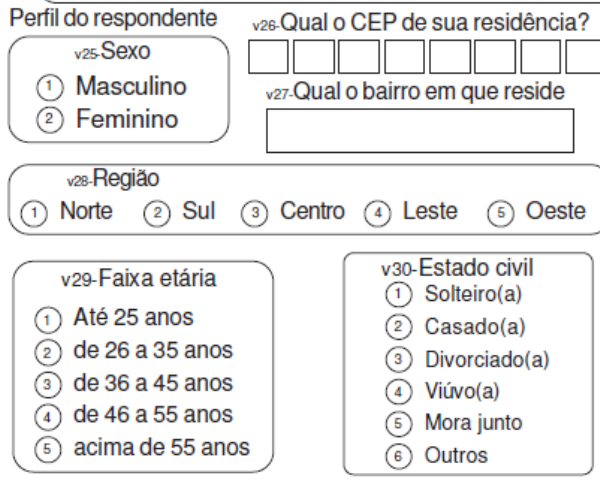

v32-Escolaridade do entrevistado

(1) Analfabeto/ Primário incompleto

(2) Primário completo / Ginasial incompleto

(3) Ginasial completo/ Colegial incompleto

(4) Colegial completo/Superior incompleto

(5) Superior completo

(6) Pós-Graduaçăo

\begin{tabular}{|l|c|}
\hline \multicolumn{2}{|l|}{ v33-Grau de instrução do chefe da família } \\
\hline \hline Analfabeto/ Primário incompleto & 0 \\
\hline Primário completo/Ginasial incompleto & 1 \\
\hline Ginasial completo / Colegial incompleto & 2 \\
\hline Colegial completo / Superior incompleto & 4 \\
\hline Superior completo & 8 \\
\hline
\end{tabular}

\begin{tabular}{|l|c|c|c|c|c|}
\hline $\begin{array}{c}\text { Itens de Classificação } \\
\text { Sócio Econômica }\end{array}$ & NT & $\mathbf{1}$ & $\mathbf{2}$ & $\mathbf{3}$ & $\mathbf{4 +}$ \\
\hline v34 Televisăo em cores & 0 & 1 & 2 & 3 & 4 \\
\hline \hline v35-Rádio & 0 & 1 & 2 & 3 & 4 \\
\hline \hline v66-Banheiro & 0 & 4 & 5 & 6 & 7 \\
\hline \hline v37-Automóvel & 0 & 4 & 7 & 9 & 9 \\
\hline \hline v38-Empregada mensalista & 0 & 3 & 4 & 4 & 4 \\
\hline v39-Aspirador de pó & 0 & 2 & 2 & 2 & 2 \\
\hline \hline v40-Máquina de lavar & 0 & 2 & 2 & 2 & 2 \\
\hline \hline v41-Vídeo-cassete e/ou DVD & 0 & 2 & 2 & 2 & 2 \\
\hline \hline v42-Geladeira & 0 & 4 & 4 & 4 & 4 \\
\hline \hline v43-Freezer $\begin{array}{c}\text { (aparethoindependenteou } \\
\text { parteda Geladeira duplax) }\end{array}$ & 0 & 2 & 2 & 2 & 2 \\
\hline
\end{tabular}

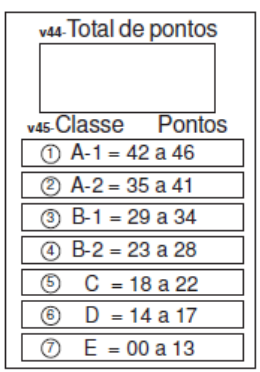

\begin{tabular}{|c|c|c|c|c|c|}
\hline $\begin{array}{l}\text { Itens de Classificação } \\
\text { Sócio Econômica }\end{array}$ & NT & 1 & 2 & 3 & $4+$ \\
\hline v34 Televisăo em cores & 0 & 1 & 2 & 3 & 4 \\
\hline v35-Rádio & 0 & 1 & 2 & 3 & 4 \\
\hline ⿶66-Banheiro & 0 & 4 & 5 & 6 & 7 \\
\hline v37-Automóvel & 0 & 4 & 7 & 9 & 9 \\
\hline v38 Empregada mensalista & 0 & 3 & 4 & 4 & 4 \\
\hline v39-Aspirador de pó & 0 & 2 & 2 & 2 & 2 \\
\hline v40-Máquina de lavar & 0 & 2 & 2 & 2 & 2 \\
\hline v41-Vídeo-cassete e/ou DVD & 0 & 2 & 2 & 2 & 2 \\
\hline v42-Geladeira & 0 & 4 & 4 & 4 & 4 \\
\hline \begin{tabular}{|ll} 
v43-Freezer & (aparelho independente ou \\
pate da Geladeira duplax)
\end{tabular} & 0 & 2 & 2 & 2 & 2 \\
\hline
\end{tabular}

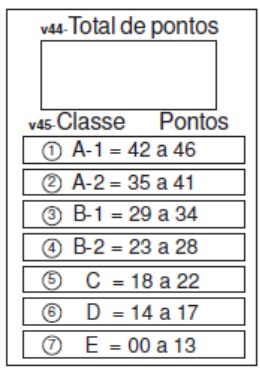

Salários mínimo em $\quad$ em $\$$ (Reais)

(1) Até $1 \mathrm{s.m}$. Até $\mathrm{R} \$ 690,00$

(2) de 1,1 s.m. a 2 s.m. de $\mathrm{R} \$ 691,00$ a $\mathrm{R} \$ 1.380,00$

(3) de 2,1 s.m. a 3 s.m. de $\mathrm{R} \$ 1.381,00$ a $2.070,00$

(4) de 3,1 s.m. a 5 s.m. de $\mathrm{R} \$ 2.071,00$ a $3.450,00$

(5) de 5,1 s.m. a 8 s.m. de $\mathrm{R} \$ 3.451,00$ a $5,520,00$

(6) de 8,1 s.m. a 10 s.m. de R\$ $5.521,00$ a $6.900,00$

(7) de 10,1 s.m. a 15 s.m. de $\mathrm{R} \$ 6.901,00$ a $10.350,00$

(8) de 15,1 s.m. a 20 s.m. de $\mathrm{R} \$ 10.351,00$ a $13.800,00$

(9) Acima de 20 s.m.

de $\mathrm{R} \$ 13.801,00$

(10) Nâo respondeu 
APÊNDICE 2 - Situações do questionário mostradas aos consumidores

1) Você foi ao supermercado e encontrou 3 opções chocolate. Qual você compraria?
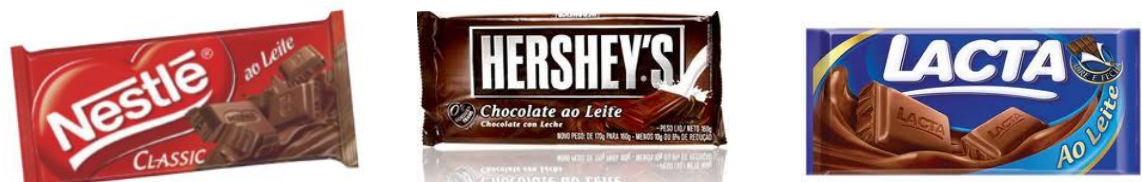

Chocolate ao leite Nestlé Classic $180 \mathrm{~g}$

Chocolate ao leite Hershey's

Chocolate ao leite $180 \mathrm{~g}$ Lacta $180 \mathrm{~g}$

$\mathrm{R} \$ 4,99$

$R \$ 3,99$

$\mathrm{R} \$ 4,79$

2) Você foi a uma loja de eletrônicos e encontrou 3 opções notebook (mesma configuração). Qual você compraria?

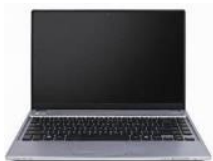

DeI

Notebook

Dell

$R \$ 2.186,9$

Oferta especial

$15 \%$ de desconto

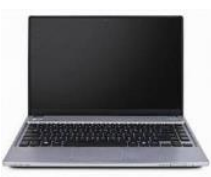

SnMSUNA

Notebook

Samsung

$\mathrm{R} \$ 2.186,9$

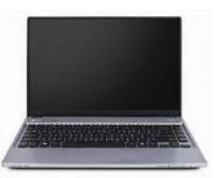

(6) LG

Notebook

LG

Oferta especial

De $R \$ 2.186,9$

Por : $\mathrm{R} \$ 1.858,9$ 


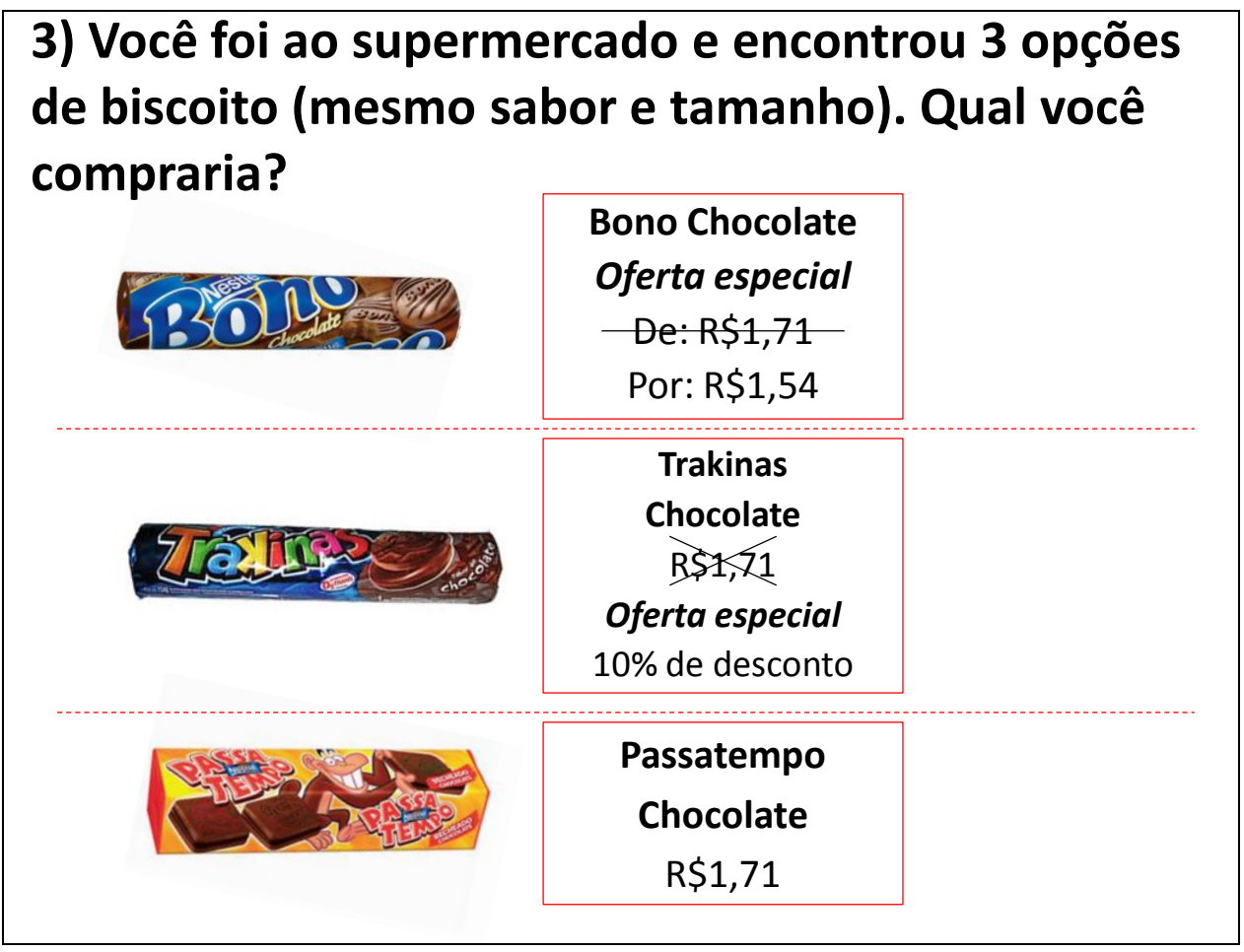

\section{4) Qual destes é seu supermercado} preferido?

1

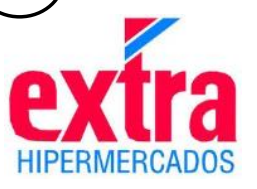

2

PãodeAçúcar

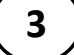

Walmart

4

(5) Outro supermercado

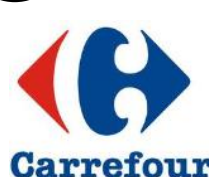


5) Você foi ao supermercado e encontrou 3 opções de biscoito (mesmo sabor e tamanho). Qual você compraria?

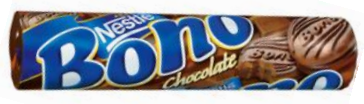

Bono

Chocolate

$\mathrm{R} \$ 1,71$

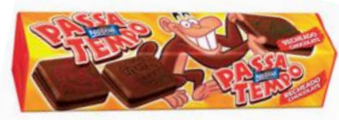

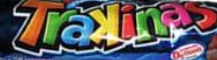

Trakinas

Chocolate

B $\$ 1,71$

Oferta especial

Passatempo

$10 \%$ de desconto

Chocolate

Oferta especial

De: $\mathrm{R} \$ 1,71$

Por: $\mathrm{R} \$ 1,54$

6) Você foi a uma loja de eletrônicos e encontrou 3 opções notebook (mesma configuração). você compraria?

Notebook
LG
R\$2.186,9
Oferta especial

\begin{tabular}{|c|}
\hline $\begin{array}{c}\text { Notebook } \\
\text { Dell }\end{array}$ \\
$\mathrm{R} \$ 2.186,9$ \\
\hline
\end{tabular}

Notebook
Samsung

Oferta especial

De $R \$ 2.186,9$

Por : $\mathrm{R} \$ 1.858,9$

(6) LG

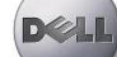

ShMSUN
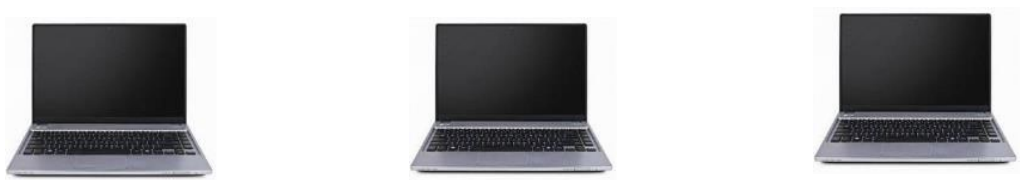
7) O Extra lançou uma promoção na qual o prêmio é uma viagem de carnaval com 1 acompanhante. Qual destes destinos você preferiria conhecer?

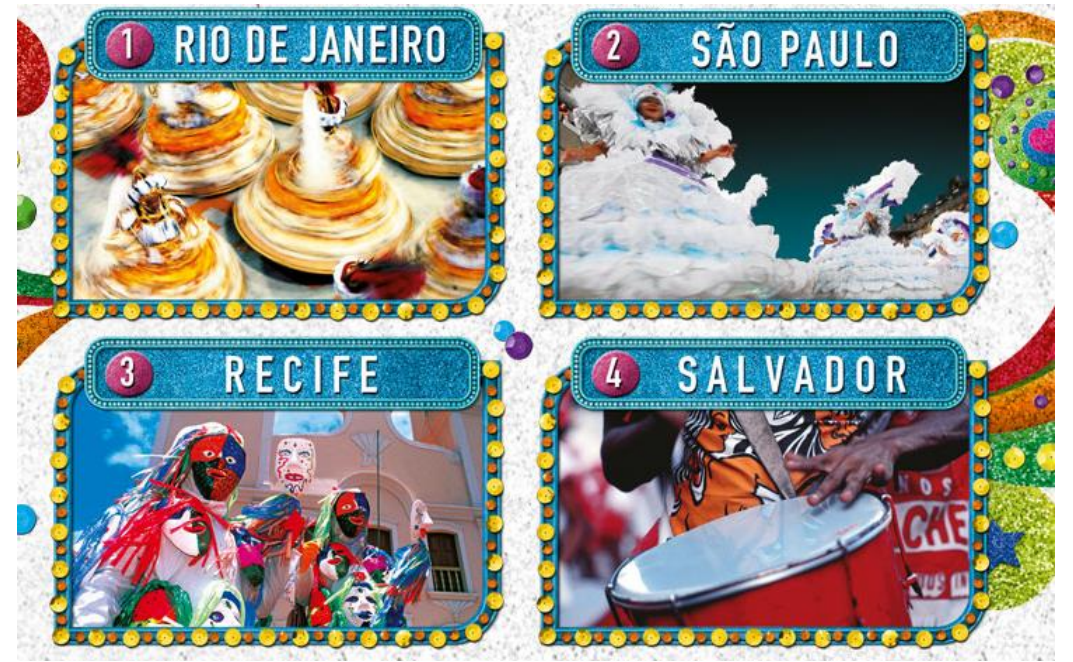

8) Você foi a uma loja de eletrônicos e encontrou 3 opções notebook (mesma configuração). Qual você compraria?

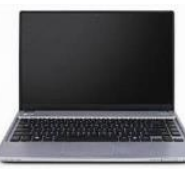

(b) LG

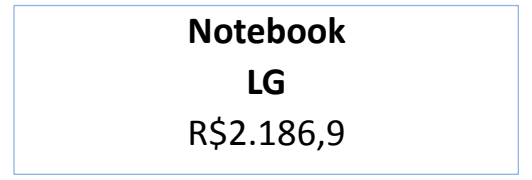
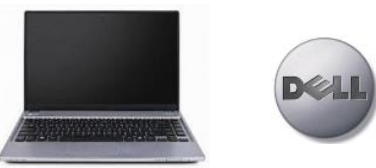

Notebook Dell

Oferta especial

De R\$2.186,9

Por : $\mathrm{R} \$ 1.858,9$

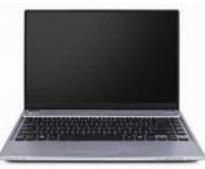

Notebook Samsung

$\mathrm{R}$ S2.186,9

Oferta especial

$15 \%$ de desconto 
9) Você foi ao supermercado e encontrou 3 opções de biscoito (mesmo sabor e tamanho). Qual você compraria?

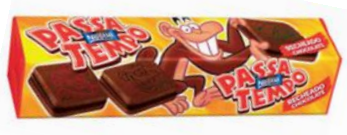

Passatempo

Chocolate

$\mathrm{R} \$ 1,71$
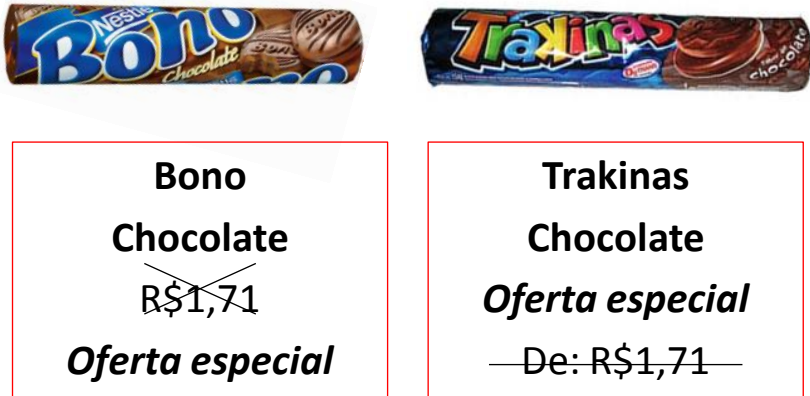

$10 \%$ de desconto
Trakinas

Chocolate

Oferta especial

De: $\mathrm{R} \$ 1,71$

Por: $\mathrm{R} \$ 1,54$

\section{0) Você foi a uma loja de eletrônicos e encontrou} 3 opções notebook (mesma configuração). Qual você compraria?

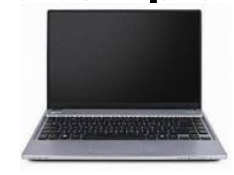

STMSUNP

Notebook

Samsung

Oferta especial

De R\$2.186,9

Por : $\mathrm{R} \$ 1.858,9$

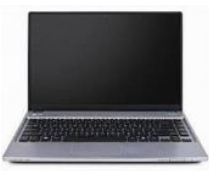

(ㄴ) LC

Notebook

LG

$\mathrm{R} \$ 2.186,9$
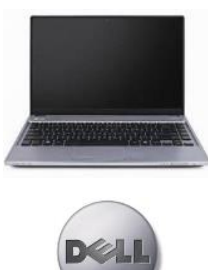

Notebook

Dell

$R \$ 2.186,9$

Oferta especial

$15 \%$ de desconto 
11) Imagine que o Magazine Luiza queira contratar um novo apresentador para estrelar os comerciais. Qual deles você preferiria ver nos comerciais da marca?

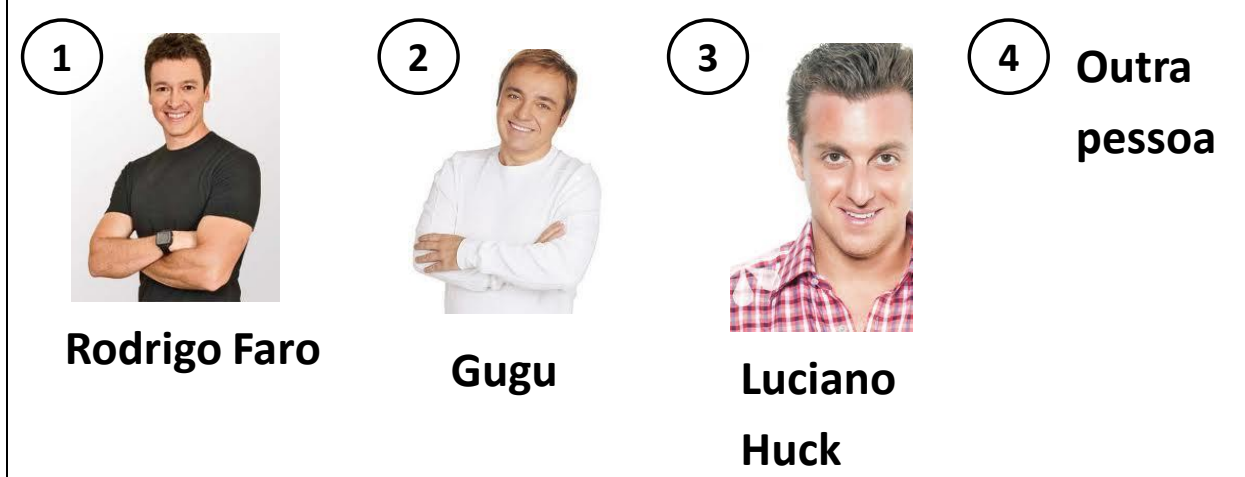

12) Você foi ao supermercado e encontrou 3 opções de biscoito (mesmo sabor e tamanho). Qual você compraria?
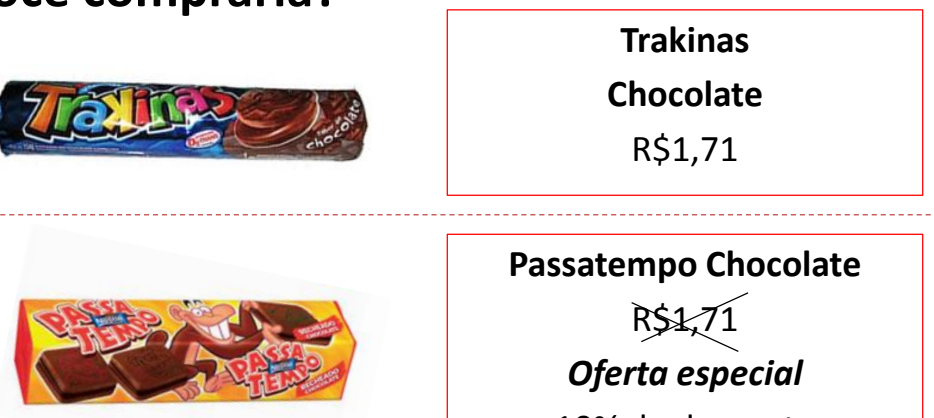

Passatempo Chocolate RSI, T1

Oferta especial

$10 \%$ de desconto

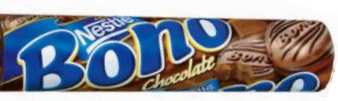

Bono Chocolate

oferta especial

De: R\$1,71

Por: $\mathrm{R} \$ 1,54$ 
13) Em quais destas lojas de eletrônicos você prefere fazer compras?

(1)

\section{PONTO FRIO}

3

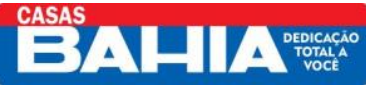

(2)

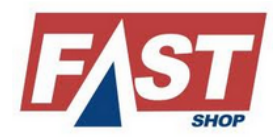

(4)

magazineluiza

(5) Outro varejista

14) Você foi a uma loja de eletrônicos e encontrou 3 opções notebook (mesma configuração). Qual você compraria?

(1) LG

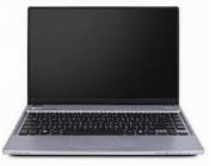

Notebook

LG

Oferta especial

De R\$2.186,9

Por : $\mathrm{R} \$ 1.858,9$
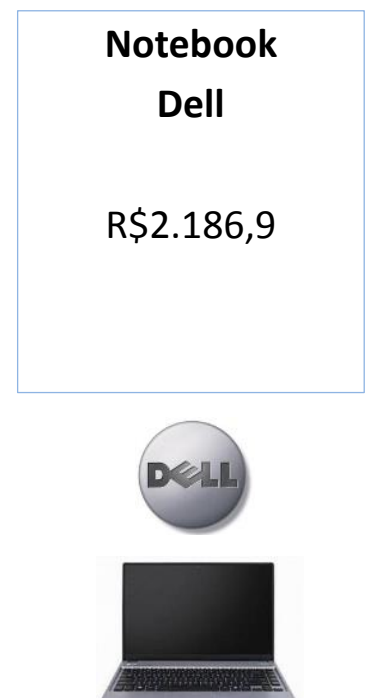

STMSUN

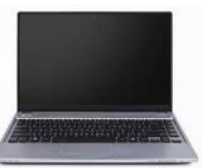

Notebook

Samsung

$R \$ 2.186,9$

Oferta especial

$15 \%$ de desconto 
15) Você foi ao supermercado e encontrou 3 opções de biscoito (mesmo sabor e tamanho). Qual você compraria?
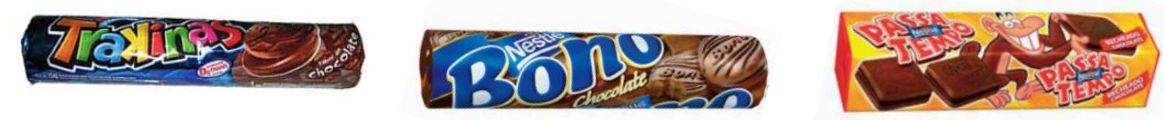

Trakinas

Chocolate

Oferta especial

De: $\mathrm{R} \$ 1,71$

Por: $\mathrm{R} \$ 1,54$

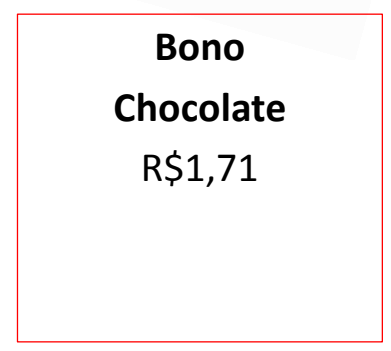

\section{Passatempo Chocolate $B \$ 1,71$ \\ Oferta especial \\ $10 \%$ de desconto}

16) Imagine que a Nestlé vai lançar uma linha de sorvetes especiais de massa no ano que vem. Qual sabor você acha mais atraente?

(1)

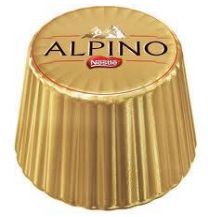

3

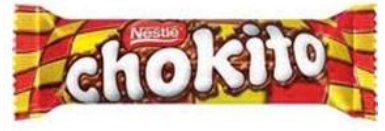

2

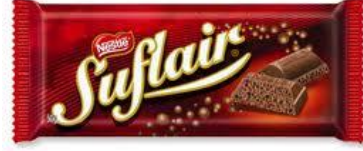

(4)

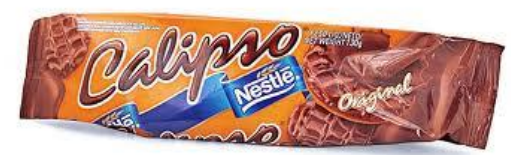

(5) Nenhum 
17) Você foi a uma loja de eletrônicos e encontrou 3 opções notebook (mesma configuração). Qual você compraria?

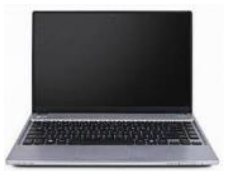

SAMSUNR

Notebook

Samsung

$\mathrm{R} \$ 2.186,9$

Notebook LG

$\mathrm{R} \$ 2.186,9$

Oferta especial

$15 \%$ de desconto

Notebook Dell

Oferta especial

De $R \$ 2.186,9$

Por : $\mathrm{R} \$ 1.858,9$

18) Você foi ao supermercado e encontrou 3 opções de biscoito (mesmo sabor e tamanho). Qual você compraria?

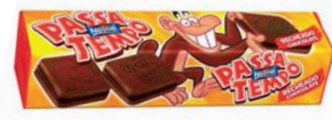

Passatempo

Chocolate

Oferta especial

De: $\mathbf{R} \$ 1,71$

Por: $\mathrm{R} \$ 1,54$

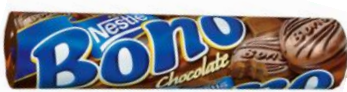

Bono

Chocolate

RSI, T1

Oferta especial

$10 \%$ de desconto

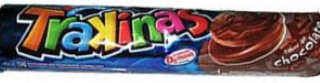

Trakinas

Chocolate

$\mathrm{R} \$ 1,71$ 